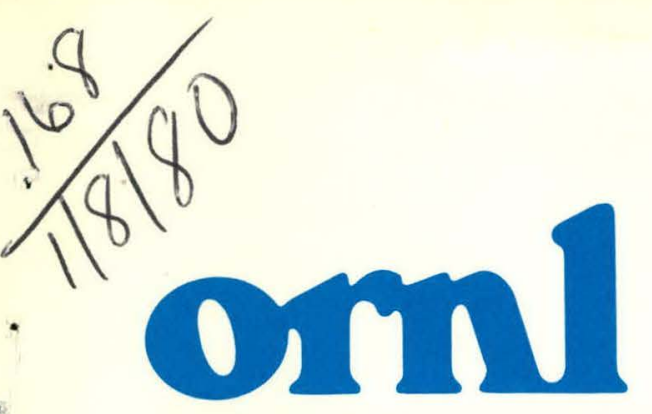

OAK

RIDGE

NATIONAL

LABORATORY

UNION

CARBIDE

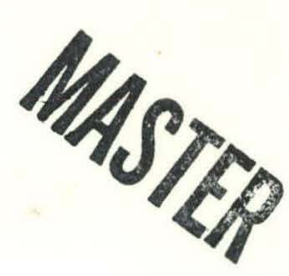

ORNL/TM-6892

\section{HTGR Experiment HRB-15b: Particle Loadings and Irradiation in the High Flux Isotope Reactor}

\author{
W. E. Thomas \\ E. L. Long, Jr. \\ J. A. Conlin \\ B. P. Johnsen
}

OPERATED BY

UNION CARBIDE CORPORATION FOR THE UNITED STATES DEPARTMENT OF ENERGY 


\section{DISCLAIMER}

This report was prepared as an account of work sponsored by an agency of the United States Government. Neither the United States Government nor any agency Thereof, nor any of their employees, makes any warranty, express or implied, or assumes any legal liability or responsibility for the accuracy, completeness, or usefulness of any information, apparatus, product, or process disclosed, or represents that its use would not infringe privately owned rights. Reference herein to any specific commercial product, process, or service by trade name, trademark, manufacturer, or otherwise does not necessarily constitute or imply its endorsement, recommendation, or favoring by the United States Government or any agency thereof. The views and opinions of authors expressed herein do not necessarily state or reflect those of the United States Government or any agency thereof. 


\section{DISCLAIMER}

Portions of this document may be illegible in electronic image products. Images are produced from the best available original document. 


\section{Printed in the United States of America. Available from}

National Technical Information Service

U.S. Department of Commerce

5285 Port Royal Road, Springfield, Virginia 22161

NTIS price codes-Printed Copy: A05; Microfiche A01

This report was prepared as an account of work sponsored by an agency of the United States Government. Neither the United States nor any agency thereof, nor any of their employees, makes any warranty, expressed or implied, or assumes any legal liability or responsibility for any third party's use or the results of such use of any information, apparatus, product or process disclosed in this report, or represents that its use by such third party would not infringe privately owned rights. 
ORNL/TM-6892

Dist. Category UC-77

Contract No. W-7405-eng-26

Metals and Ceramics Division Engineering Technology Division

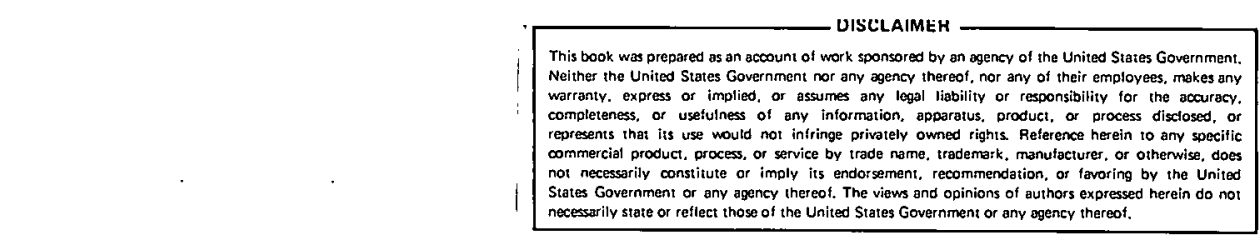

HTGR BASE TECHNOLOGY PROGRAM

FUELED GRAPHITE DEVELO PMENT PROGRAM

\section{HTGR EXPER IMENT HRB-15b: PARTICLE LOADINGS AND IRRADIATION IN THE HIGH FLUX ISOTOPE REACTOR}
W. E. Thomas
E. L. Long, Jr.
J. A. Conlin
B. P. Johnsen

Date Published - December 1979

NOTICE: This document contains information of a preliminary nature. It is subject to revision or correction and thereforc dooe not roprosent a final repnrt.

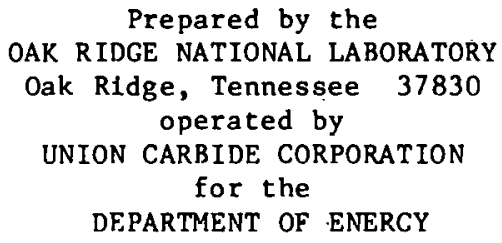




\section{THIS PAGE}

\section{WAS INTENTIONALLY \\ LEFT BLANK}


ABSTRACT $\quad \ldots \ldots \ldots \ldots \ldots \ldots \ldots \ldots \ldots \ldots \ldots \ldots \ldots \ldots \ldots \ldots \ldots \ldots \ldots \ldots \ldots \ldots \ldots . \ldots \ldots$

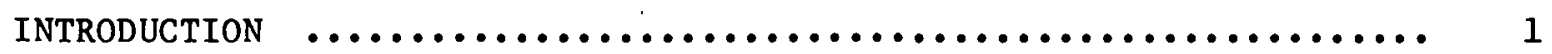

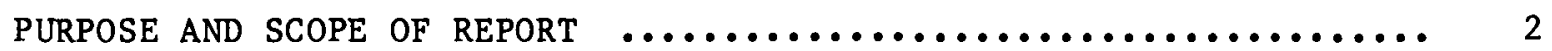

DESCRIPTION OF EXPERIMENT $\ldots \ldots \ldots \ldots \ldots \ldots \ldots \ldots \ldots \ldots \ldots \ldots \ldots \ldots \ldots \ldots \ldots$

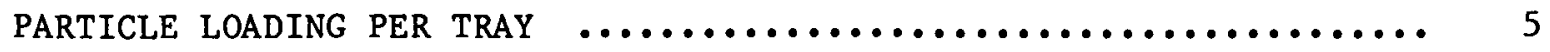

MODEL FOR COMPUTING REGIONAL TEMPERATURES $\ldots \ldots \ldots \ldots \ldots \ldots \ldots \ldots \ldots \ldots . \ldots$

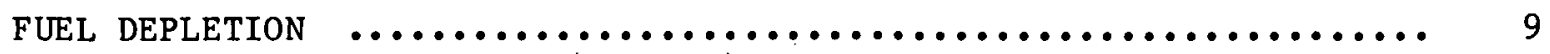

PROCEDURE FOR COMPUTING PARTICLE LOADINGS $\ldots \ldots \ldots \ldots \ldots \ldots \ldots \ldots \ldots \ldots . \ldots 14$

MODELS FOR COMPUTING PARTICLE SURFACE TEMPERATURES $\ldots \ldots \ldots \ldots \ldots \ldots \ldots$

TEMPERATURES, FUEL BURNUP, AND FAST NEUTRON FLUENCE $\ldots \ldots \ldots \ldots \ldots \ldots . . .22$

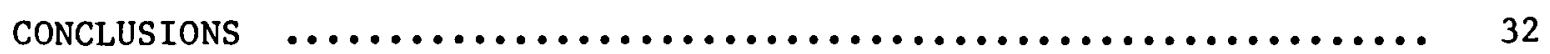

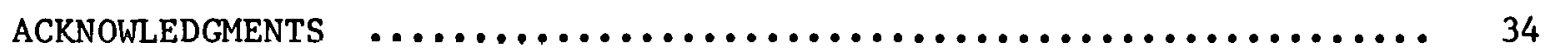

APPENDIX A. DATA AND CALCULATIONAL PROCEDURES $\ldots \ldots \ldots \ldots \ldots \ldots \ldots \ldots . . \ldots$

A. 1 Thermal Analysis Program ........................ 35

A. 2 Properties ................................... 40

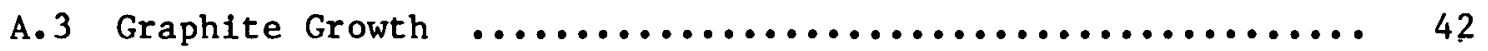

A. 4 Nuclear Heating in Graphite and Stainless Steel ......... 46

A.5 Neutron Fluxes $. \ldots \ldots \ldots \ldots \ldots \ldots \ldots \ldots \ldots \ldots \ldots \ldots \ldots \ldots \ldots . \ldots . \ldots$

A.6 Thermocouple Temperatures $\ldots \ldots \ldots \ldots \ldots \ldots \ldots \ldots \ldots \ldots \ldots \ldots$

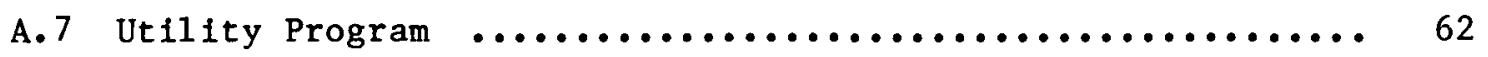

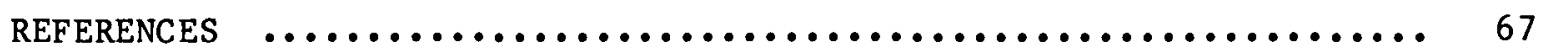




\title{
HTGR EXPERIMENT HRB-15b: PARTICLE LOADINGS AND IRRADIATION IN THE HIGH FLUX ISOTOPE REACTOR
}

\author{
W. E. Thomas \\ J. A. Conlin \\ E. L. Long, Jr.* \\ B. P. Johnsen ${ }^{\dagger}$
}

\begin{abstract}
Candidate high-temperature gas-cooled reactor fissile and fertile particles were irradiated in the High Flux Isotope Reactor removable beryllium reflector facility (RB-5) for eight reactor cycles. The experiment contained 18 different "types" of fissile particles and five different "types" of fertile particles. All uranium was $20 \%$ enriched in $235 \mathrm{U}$. The loose particles were loaded into "trays" that resemble flat graphite washers, each having 116 drilled holes in one face. One hundred eighty-four trays were stacked in columns in an alternate fertile particle-fissile particle sequence. The particles were irradiated for 169.4 full power days. Peak fuel burnup in percent fissions per initial heavy metal atom (FIMA) was as follows: $20.5 \%$ for mixed-oxide fissile particles, $33.5 \%$ for the other fissile particles, and $\sim 7 \%$ for fertile particles. Maximum fast neutron fluence ( $E>183 \mathrm{KeV}$ ) at the end of the test was $\sim 7 \times 10^{25}$ neutrons $/ \mathrm{m}^{2}$. The report discusses methods used to specify particle loadings and contains thermal and neutronics results applicable to the irradiation test period.
\end{abstract}

\section{INTRODUC TION}

In high-temperature gas-cooled reactors (HTGRs), all fissile and fertile materials are contained in tiny microspheres called coated particles. The kernel of the coated particle contains the initial (preirradiation) fissile material, ${ }^{235} \mathrm{U}$, and/or the initial fertile material, $232 \mathrm{Th}$. Kernel diameters may range from about 300 to $\sim 500 \mu \mathrm{m}$. Deposited on the kernel may be several layers of carbon and carbide material (e.g., SiC). A coated particle is usually defined as consisting of the kernel and the various coatings and may be further classified as BISO or TRISO, depending on the number and type of coatings deposited on the kernel. A conventional BISO particle has two coatings deposited over the kernel; innermost is the buffer, which is a low-density pyrocarbon (PyC) whose

\footnotetext{
* Meta1.s and Ceramics Division.

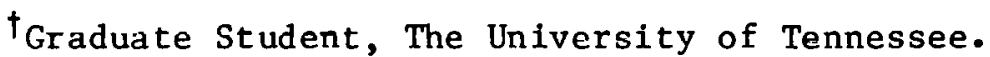


purpose is to (1) provide a volume for storing gaseous fission products, (2) accommodate fuel swelling, and (3) attenuate fission recoil. The outer isotropic PyC coating acts as a pressure vessel to contain the fission products. A conventional TRISO particle has four coatings: a buffer, which serves the same purpose as for the BISO particle; an inner isotropic PyC coating to provide mechanical support for the particle and to protect the next layer from detrimental reactions with fuel and fission products; a coating of SiC to provide containment for the gaseous and solid fission products; and an outer isotropic PyC coating to prevent evaporation of the SiC layer and to protert the particle from damagc during handling. The purpose of coated particles in HTGRs, therefore, is to contain the fission products and to prevent their escape into other regions of the reactor, such as the graphite moderator and the helium coolant.

Experiment $H R B-15 b$ tested some conventional TRISO and BISO particles. However, many of the particles tested were of new design such as the Si-BISO, the $\mathrm{Zr}$ buffer, and particles that had an additional thin layer of ZrC deposited directly on the kernel, that is, an additional. layer between the kernel and the buffer. See Tables 1 (fissile particles) and 2 (fertile particles) for a descriptive summary of particle types in the experiment.

All fertile particles contain $\mathrm{ThO}_{2}$ in the kernel (Table 2); however, the kernel may be of different diameters or may have been produced by alferent manutacturing processes. Fissile particles (Table 1) can have mixtures of $\mathrm{ThO}_{2}$ and $\mathrm{UO}_{2}$ in the kernel (mixed-oxide kernels), or they can have kernels of $\mathrm{UO}_{2}, \mathrm{UC}_{2}$, or $\mathrm{UC}_{\mathrm{x}} \mathrm{O}_{\mathrm{y}}$ with various $0 / \mathrm{U}$ ratios. Thus, the purpose of experiment $H R B-15 b$ was to provide irradiation experience with a variety of candidate HTGR soated particles. All the uranium contained in the coated particles was $20 \%$ enriched in ${ }^{235} \mathrm{U}$.

PURPOSE AND SCOPE OF REPORT

An experiment such as HRB-15b begins with the manufacture of the candidate particles. Next, the particles are encapsulated and irradiated in a nuclear reactor. Following the irradiation period, the particles 
Table 1. Experiment HRB-15b, fissile particles

\begin{tabular}{|c|c|c|c|}
\hline $\begin{array}{l}\text { Test plan } \\
\text { designation }\end{array}$ & $\begin{array}{l}\text { Parent batch } \\
\text { number }\end{array}$ & $\begin{array}{l}\text { Kernel } \\
\text { material }\end{array}$ & $\begin{array}{l}\text { Description of } \\
\text { particle coatings }\end{array}$ \\
\hline $\begin{array}{l}1 \\
1\end{array}$ & $\begin{array}{l}6155-05-010 \\
6155-05-020\end{array}$ & $\begin{array}{l}(\mathrm{Th}, \mathrm{U}) \mathrm{O}_{2} \\
(\mathrm{Th}, \mathrm{U}) \mathrm{O}_{2}\end{array}$ & $\begin{array}{l}\text { TRISOa } \\
\text { TRISO }\end{array}$ \\
\hline $\begin{array}{l}2 \\
3 \\
4 \\
5\end{array}$ & $\begin{array}{l}6157-08-020 \\
6157-08-030 \\
6157-09-010 \\
6152-01-010\end{array}$ & $\begin{array}{l}\mathrm{UCO}(0 / \mathrm{U}=0.5) \\
\mathrm{UCO}(0 / \mathrm{U}=1.0) \\
\mathrm{UCO}(0 / \mathrm{U}=1.5) \\
\mathrm{UO}_{2}\end{array}$ & $\begin{array}{l}\text { TRISO } \\
\text { TRISO } \\
\text { TRISO } \\
\text { TRISO }\end{array}$ \\
\hline $\begin{array}{l}6 a \\
6 b \\
6 c\end{array}$ & $\begin{array}{l}6152-02-010 \\
6152-03-010 \\
6152-03-020\end{array}$ & $\begin{array}{l}\mathrm{UO}_{2} \\
\mathrm{UO}_{2} \\
\mathrm{U} \mathrm{O}_{2}\end{array}$ & $\begin{array}{l}\text { TRISO, Zr buffer }{ }^{b} \\
\text { TRISO, } 5-\mu \mathrm{m} \mathrm{ZrC} \\
\text { TRISO, } 10-\mu \mathrm{m} \mathrm{ZrC} \mathrm{Zr}^{c}\end{array}$ \\
\hline $\begin{array}{r}7 \\
8 \\
9 \\
10 \\
11 \\
12\end{array}$ & $\begin{array}{l}6151-21-010 \\
6445-01-010 \\
6448-02-010 \\
6448-01-010 \\
6448-00-010 \\
6447-00-010\end{array}$ & $\begin{array}{l}\mathrm{UC}{ }_{2} \\
(\mathrm{Th}, \mathrm{U}) \mathrm{O}_{2} \\
\mathrm{UCO}(0 / \mathrm{U}=0.5) \\
\mathrm{UCO}(0 / \mathrm{U}=1.0) \\
\mathrm{UCO}(0 / \mathrm{U}=1.5) \\
\mathrm{UO}_{2}\end{array}$ & $\begin{array}{l}\text { TRISO } \\
\text { S1-BISOd } \\
\text { Si-BISO } \\
\text { Si-BISO } \\
\text { Si-BISO } \\
\text { Si-BISO }\end{array}$ \\
\hline $\begin{array}{l}13 a \\
13 b \\
13 c \\
14\end{array}$ & $\begin{array}{l}6447-01-010 \\
6447-02-010 \\
6447-02-020 \\
6449-00-010\end{array}$ & $\begin{array}{l}\mathrm{UO}_{2} \\
\mathrm{UO}_{2} \\
\mathrm{UO}_{2} \\
\mathrm{UO}_{2}\end{array}$ & 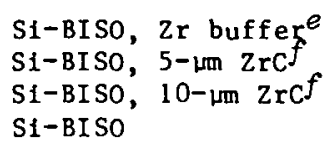 \\
\hline
\end{tabular}

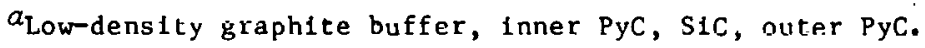

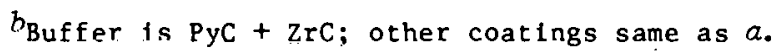

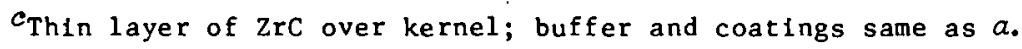

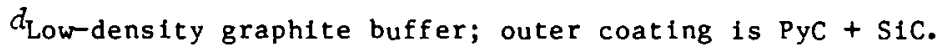

$e_{\mathrm{Buffer}}$ is PyC $+\mathrm{ZrC}$; outer coating same as $\lambda$.

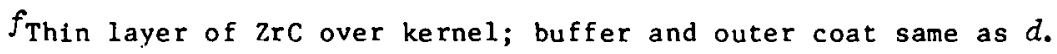

Table 2. Experiment HRB-15b, fertile particles

\begin{tabular}{cccc}
\hline $\begin{array}{c}\text { Test plan } \\
\text { designation }\end{array}$ & $\begin{array}{c}\text { Parent batch } \\
\text { number }\end{array}$ & $\begin{array}{c}\text { Kernel } \\
\text { material }\end{array}$ & $\begin{array}{c}\text { Description of } \\
\text { particle coatings }\end{array}$ \\
\hline 15 & $6252-15-010$ & $\mathrm{ThO}_{2}$ & TRISO $^{a}$ \\
16 & $6542-27-015$ & $\mathrm{ThO}_{2}$ & BISO $^{b}$ \\
$17 \mathrm{a}$ & $6542-42-010$ & $\mathrm{ThO}_{2}$ & Si-BISO $^{c}$ \\
$17 \mathrm{~b}$ & $6542-42-010$ & $\mathrm{ThO}_{2}$ & Si-BISO \\
ORNL $^{2}$ & & $\mathrm{ThO}_{2}$ & BISO \\
\hline
\end{tabular}

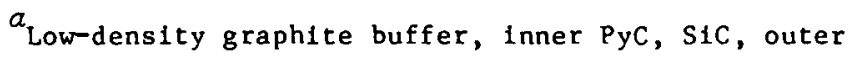
Pyc.

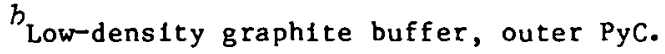

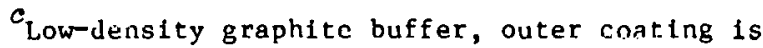
PyC + SiC.

$d_{\text {Sol-Gel process. }}$
} 
are removed from the capsule (in a hot cell) for subsequent postirradiation testing. The scope of this report is confined to the in-reactor irradiation of the candidate fissile and fertile particles. The purpose of the report is to document the models and data used to specify particle loadings and to report particle temperatures, fuel burnup, and fast neutron fluence during the irradiation period. Detalls of the theory are presented in various sections of Appendix A.

\section{DESCRIPTION OF EXPERIMENT}

The loose particles were loaded into trays that resemble flat graph1te washers, each having 116 holes drilled in one face. The trays were stacked in columns in an alternate fertile particle-fissile particle sequence. There were 46 trays per unit or subassembly. A column of four units (184 trays) was then sealed in a stainless steel primary vessel. The primary vessel was contained in a secondary stainless steel vessel to provide double-wall containment for the experiment when in the reactor. Heat is removed from the experiment by the flow of reactor coolant (water) through an annulus external to the secondary vessel.

The inside radius of the primary vessel was $12.3 \mathrm{~mm}$, and the outside radius of the secondary vessel was $16.4 \mathrm{~mm}$. The length of each unit was $105.6 \mathrm{~mm}$ (total axial length of the specimen region was $\sim 422 \mathrm{~mm}$ ).

There was a total of eight thermocouples, with the junction of each located at approximately the tray inside radius $(\sim 5.6 \mathrm{~mm})$; in the axial direction, there are two thermocouples per unit. The central region of the stack of trays provided space for testing some additional inert particles (i.e., particles that did not contain fuel in the kernels).

When the experiment was operating in-reactor, the temperature of the particles was controlled by varying the composition of the gas mixture (i.e, by varying the thermal conductivity) in a gap between the outside radius of the stacked trays and the inside radius of the primary vessel. The tray outside radius was one of the design parameters to be evaluated.

The experiment resided in the High Flux Isotope Reactor (HFIR) removable beryllium reflector facility $(R B-5)$. The cylindrical reactor control plates ("rods") are positioned between the HFIR core and the RB-5 
facility. Control rod management introduces considerable variation in the neutron flux during a reactor cycle. (Neutron fluxes are discussed in detail in Appendix A, Sect. A. 5.) The HFIR is a batch-loaded reactor, operating about 21 full power days per cycle. The experiment was inreactor for eight cycles. First cycle operation began at 4:15 PM (EDT) on July 6, 1978; 1ast cycle operation ended at 5:59 PM (EST) on January 4, 1979. Therefore, the experiment was in-reactor for 182.11 calendar days or 169.44 full power days [i.e., equivalent calendar days of operation at HFIR rated power $-100 \mathrm{MW}(t)]$. HFIR operating data during the time the experiment was in-reactor are shown in Table 3. The two midcycle shutdowns, one during cycle 1 and the other during cycle 6 , began at 0900 on $7 / 14 / 78$ and at 0815 on $11 / 13 / 78$, respectively.

\section{PARTICLE LOADINGS PER TRAY}

The types of fissile particles (Table 1) and fertile particles (Table 2) to be loaded into each of the 184 trays were prespecified and were not subject to change. The number of particles of a particular type to be loaded into each tray and the tray radius were quantities that had to be evaluated. The number of particles loaded into each tray, cross referenced to test $\mathrm{plan}$ designation numbers and the tray radius, is shown in Tables 4 through 7 for each of the four subassemblies. The units or subassemblies are numbered $15 \mathrm{~b}-1$ through $15 \mathrm{~b}-4$ (top to bottom) in the experiment. How these loadings were obtained is the subject for most of this report.

MODEL FOR COMPUTING REGIONAL TEMPERATURES

The aim is to load each tray and arrive at various gap thicknesses (between tray and primary vessel) that ideally produce a smooth and almost flat axial temperature profile in the specimen region at ail times during the history of the experiment. The alternate fertile particlefissile particle stacking pattern and the thermal contact resistance between adjacent trays suggest use of a one-dimensional cylindrical heat transfer model. The specimen region was assumed to have a uniformly 
Table 3. HFIR operating data for experiment HRE-15b

\begin{tabular}{|c|c|c|c|c|c|c|c|c|c|c|}
\hline \multirow{3}{*}{$\begin{array}{l}\text { Experiment } \\
\text { cycle } \\
\text { No. }\end{array}$} & \multicolumn{4}{|c|}{ Reactor schedule } & \multirow{3}{*}{$\begin{array}{l}\text { Reactor } \\
\text { energy } \\
\text { (MWd) }\end{array}$} & \multirow{3}{*}{$\begin{array}{l}\text { Accumulated } \\
\text { FPD }^{a}\end{array}$} & \multirow{2}{*}{\multicolumn{4}{|c|}{ Cycle time ${ }^{b}(h r)$}} \\
\hline & \multicolumn{2}{|c|}{ Startup } & \multicolumn{2}{|c|}{ Sbutdown } & & & & & & \\
\hline & Date & Time & Date & Time & & & & & & \\
\hline 1 & $7 / 6 / 78$ & 1615 & $7 / 30 /: 8$ & 2350 & $2147 . J$ & 21.47 & & $5: 8.45$ & 65.133 & 583.58 \\
\hline 2 & $7 / 31 / 78$ & 1752 & $8 / 22 / 78$ & 0030 & $2124 . l$ & 42.71 & $18.03=$ & 510.63 & & 528.67 \\
\hline 3 & $8 / 22 / 78$ & 1838 & $9 / 13 / 78$ & 0400 & 2137.7 & 64.09 & $18.15 C$ & 513.35 & & 531.50 \\
\hline 4 & $9 / 15 / 78$ & 1824 & $10 ; 6: 78$ & 2115 & 2110.10 & 85.19 & $62.40 \mathrm{C}$ & 506.85 & ' & 569.25 \\
\hline 5 & $10 / 7 / 78$ & 1650 & $10 / 28 / 78$ & 2400 & $2128.1)$ & 106.47 & $19.58 \equiv$ & 511.17 & & 530.75 \\
\hline 6 & $10 / 29 / 78$ & 1725 & $11 / 22 / 78$ & 0225 & $2091 . !$ & 127.38 & 18.58? & 50.2 .75 & 58.083 & 579.42 \\
\hline 7 & $11 / 22 / 78$ & 2147 & $12 / 14 / 78$ & 0140 & 2113.8 & 148.52 & 19.366 & 5017.89 & . & 527.26 \\
\hline \multirow[t]{2}{*}{8} & $12 / 14 / 78$ & 1945 & $1 / 4 / 79$ & 1759 & 2092.0 & 169.44 & 13.083 & $5 C \cdot 2.23$ & & 520.31 \\
\hline & & & & & & Total & $17 \div .20$ & 4073.3 & 123.22 & 4370.7 \\
\hline
\end{tabular}

$a_{\mathrm{FPD}}=$ full power tays.

$b_{R}=$ refueling; $M=$ midcycle downtime; $0=$ operating, but not necessari-y at $100 \mathrm{MW}(\mathrm{t})$. 
Table 4. Experiment HRB-15b, tray size (1n.) and particle loadings for subassembly $15 \mathrm{~b}-1$

\begin{tabular}{|c|c|c|c|c|c|c|c|}
\hline \multicolumn{2}{|c|}{ Tray } & \multicolumn{2}{|c|}{ Fertile particles } & \multicolumn{2}{|c|}{ Tray } & \multicolumn{2}{|c|}{ Fissile particles } \\
\hline No. & Radius & ID & No. & No. & Radius & ID & No. \\
\hline 1 & 0.439 & ORNL & 58 & 2 & 0.439 & 8 & 116 \\
\hline 3 & 0.439 & ORNL & 85 & 4 & 0.439 & 12 & 106 \\
\hline 5 & 0.439 & $17 b$ & 116 & 6 & 0.439 & 10 & 6.5 \\
\hline 7 & 0.439 & ORNL & 58 & 8 & 0.439 & 1 & 116 \\
\hline 9 & 0.439 & ORNL & 58 & 10 & 0.439 & 1 & 116 \\
\hline 11 & 0.448 & ORNL & 106 & 12 & 0.448 & 3 & 83 \\
\hline 13 & 0.448 & ORNL & 106 & 14 & 0.448 & 3 & 83 \\
\hline 15 & 0.448 & 15 & 116 & 16 & 0.448 & 5 & 114 \\
\hline 17 & 0.454 & ORNL & 111 & 18 & 0.454 & 2 & 65 \\
\hline 19 & 0.454 & ORNL & 111 & 20 & 0.454 & 14 & 77 \\
\hline 21 & 0.454 & $17 b$ & 116 & 22 & 0.454 & 4 & 73 \\
\hline 23 & 0.454 & 15 & 116 & 24 & 0.454 & $13 a$ & 97 \\
\hline 25 & 0.458 & ORNL & 112 & 26 & 0.458 & 4 & 69 \\
\hline 27 & 0.458 & ORNL & 112 & 28 & 0.458 & $13 b$ & 108 \\
\hline 29 & 0.458 & ORNL & 112 & 30 & 0.458 & 2 & 63 \\
\hline 31 & 0.458 & 16 & 102 & 32 & 0.458 & 5 & 116 \\
\hline 33 & 0.458 & $17 \mathrm{~b}$ & 116 & 34 & 0.458 & 7 & 68 \\
\hline 35 & 0.458 & ORNL & 103 & 36 & 0.458 & 5 & 113 \\
\hline 37 & 0.461 & ORNL & 116 & 38 & 0.461 & 7 & 76 \\
\hline 39 & 0.461 & ORNL & 105 & 40 & 0.461 & $6 \mathrm{~b}$ & 99 \\
\hline 41 & 0.461 & ORNL & 105 & 42 & 0.461 & $6 \mathrm{~b}$ & 99 \\
\hline 43 & 0.461 & 15 & 116 & 44 & 0.461 & 4 & 66 \\
\hline 45 & 0.461 & ORNL & 105 & 46 & 0.461 & 7 & 68 \\
\hline
\end{tabular}

Table 5. Exper1ment HRB-15b, tray size (in.) and particle loadings for subassembly $15 \mathrm{~b}-2$

\begin{tabular}{|c|c|c|c|c|c|c|c|}
\hline \multicolumn{2}{|c|}{ Tray } & \multicolumn{2}{|c|}{ Fertile particles } & \multicolumn{2}{|c|}{ Tray } & \multicolumn{2}{|c|}{ Fissile particles } \\
\hline No. & Radius & ID & No. & No. & Radius & ID & No. \\
\hline 47 & 0.461 & 16 & 69 & 48 & 0.461 & 1 & 116 \\
\hline 49 & 0.461 & ORNL & 72 & 50 & 0.461 & 1 & 116 \\
\hline 51 & 0.461 & $17 b$ & 104 & 52 & 0.461 & 1 & 116 \\
\hline 53 & 0.461 & ORNL & 75 & 54 & 0.461 & 1 & 116 \\
\hline 55 & 0.461 & ORNL & 75 & 56 & 0.461 & 1 & 116 \\
\hline 57 & 0.461 & 16 & 72 & 58 & 0.461 & 1 & 116 \\
\hline 59 & 0.461 & ORNL & 78 & 60 & 0.461 & 1 & 116 \\
\hline 61 & 0.461 & ORNL & 78 & 62 & 0.461 & 1 & 116 \\
\hline 63 & 0.461 & ORNL & 78 & 64 & 0.461 & 1 & 116 \\
\hline 65 & 0.461 & ORNL & 78 & 66 & 0.461 & 1 & 116 \\
\hline 67 & 0.464 & $17 b$ & 116 & 68 & 0.464 & 9 & 55 \\
\hline 69 & 0.464 & ORNL & 109 & 70 & U. 464 & 130 & 91 \\
\hline 71 & 0.464 & 15 & 116 & 72 & 0.464 & 11 & 57 \\
\hline 73 & 0.464 & ORNL & $\ln 8$ & 74 & 0.464 & 3 & 65 \\
\hline 75 & 0.464 & ORNL & 108 & 76 & 0.464 & 3 & 62 \\
\hline 77 & 0.464 & 16 & 103 & 78 & 0.464 & 3 & 62 \\
\hline 79 & 0.464 & ORNL & 107 & 80 & 0.464 & 3 & 62 \\
\hline 81 & 0.464 & $17 b$ & 116 & 82 & 0.464 & 3 & 62 \\
\hline 83 & 0.464 & ORNL & 107 & 84 & 0.464 & 4 & 54 \\
\hline 85 & 0.464 & ORNL & 107 & 86 & 0.464 & 3 & 62 \\
\hline 87 & 0.464 & 15 & 116 & 88 & 0.464 & $6 \mathrm{~b}$ & 85 \\
\hline 89 & 0.461 & ARN. & 107 & 90 & 0.464 & 7 & 59 \\
\hline 91 & 0.464 & ORNL & 86 & 92 & 0.464 & 1 & 114 \\
\hline
\end{tabular}


Table 6. Experiment HRB-15b, tray size (in.) and particle loadings for subassembly $15 b-3$

\begin{tabular}{|c|c|c|c|c|c|c|c|}
\hline \multicolumn{2}{|c|}{ Tray } & \multicolumn{2}{|c|}{ Fertile particles } & \multicolumn{2}{|c|}{ Tray } & \multicolumn{2}{|c|}{ Fissile particles } \\
\hline No. & Radius & ID & No. & No. & Radius & ID & No. \\
\hline 93 & 0.464 & 15 & 114 & 94 & 0.464 & 1 & 114 \\
\hline 95 & 0.464 & URNL & 107 & 96 & 0.464 & 7 & 59 \\
\hline 97 & 0.464 & 16 & 103 & 98 & 0.464 & $6 b$ & 85 \\
\hline 99 & 0.464 & ORNL & 107 & 100 & 0.464 & 3 & 61 \\
\hline 101 & 0.464 & ORNL & 107 & 102 & 0.464 & 5 & 98 \\
\hline 103 & 0.464 & $17 a$ & 105 & 104 & 0.464 & 3 & 62 \\
\hline 105 & 0.464 & is & 116 & 106 & 0.464 & 3 & 62 \\
\hline 107 & 0.464 & $17 a$ & 105 & 108 & 0.464 & 3 & 62 \\
\hline 109 & 0.464 & ORNL & 107 & 110 & 0.464 & 3 & 62 \\
\hline 111 & 0.464 & ORNT. & ing & 112 & 0.464 & 3 & 66 \\
\hline 113 & 0.464 & ORNL & 87 & 114 & 0.464 & 8 & 116 \\
\hline 115 & 0.464 & ORNL & 110 & 116 & 0.164 & 10 & 66 \\
\hline 117 & 0.464 & 16 & 105 & 118 & 0.464 & 12 & 105 \\
\hline 119 & 0.464 & ORNL & 114 & 120 & 0.464 & $6 a$ & 98 \\
\hline 121 & 0.464 & 16 & 109 & 122 & 0.464 & $6 a$ & 98 \\
\hline 123 & 0.464 & ORNL & 114 & 124 & 0.464 & $6 a$ & 98 \\
\hline 125 & 0.464 & ORNL & 114 & 126 & 0.464 & $6 a$ & 90 \\
\hline 127 & 0.464 & $17 a$ & 115 & 128 & 0.464 & $6 a$ & 105 \\
\hline 129 & 0.464 & ORNL & 116 & 130 & 0.464 & $6 a$ & 105 \\
\hline 131 & 0.464 & 15 & 116 & 132 & 0.464 & $6 a$ & 105 \\
\hline 133 & 0.464 & ORNL & 116 & 134 & 0.464 & $6 a$ & 105 \\
\hline 135 & 0.464 & ORNL & 116 & 136 & 0.464. & $6 a$ & 112 \\
\hline 137 & 0.464 & 16 & 116 & 138 & 0.464 & Ga & 112 \\
\hline
\end{tabular}

Table 7. Experiment $H R B-15 b$, tray size (in.) and particle loadings for subassembly $15 b-4$

\begin{tabular}{|c|c|c|c|c|c|c|c|}
\hline \multicolumn{2}{|c|}{ Tray } & \multirow{2}{*}{$\frac{\text { Fertile }}{\text { ID }}$} & \multirow{2}{*}{$\begin{array}{c}\text { particles } \\
\text { No. }\end{array}$} & \multicolumn{2}{|c|}{ Tray } & \multicolumn{2}{|c|}{ Fissile particles } \\
\hline No. & Radius & & & No. & Radius & ID & No. \\
\hline 139 & 0.458 & ORNL & 70 & 140 & 0.458 & 1 & 116 \\
\hline 141 & 0.458 & $17 \mathrm{a}$ & 90 & 142 & 0.458 & 3 & 62 \\
\hline 143 & 0.458 & ORNL & 70 & 144 & 0.458 & 1 & 116 \\
\hline 145 & 0.458 & 15 & $116^{\circ}$ & 146 & 0.458 & 3 & 62 \\
\hline 147 & 0.458 & ORNL & 99 & 148 & 0.4598 & 5 & 108 \\
\hline 149 & 0.438 & UKNL & 99 & 150 & 0.458 & 2 & 55 \\
\hline 151 & 0.458 & ORNL & 99 & 152 & 0.458 & 4 & 60 \\
\hline 153 & 0.458 & 16 & 95 & 154 & 0.4 .58 & $13 c$ & 94 \\
\hline 155 & 0.454 & ORNL & 107 & 156 & 0.454 & $13 a$ & 103 \\
\hline 1.57 & 0.454 & ORNL & $1 \cap 7$ & 158 & 0.454 & 14 & 72 \\
\hline 159 & 0.454 & ORNL & 107 & 160 & 0.454 & 4 & 66 \\
\hline 161 & 0.454 & $17 a$ & 105 & 162 & 0.454 & $6 c$ & 104 \\
\hline 163 & 0.448 & 15 & 116 & 164 & 0.448 & $6 c$ & 103 \\
\hline 165 & 0.448 & ORNL & 99 & 166 & 0.448 & 7 & 69 \\
\hline 167 & 0.448 & 16 & 95 & 168 & 0.448 & 4 & 63 \\
\hline 169 & 0.448 & ORNL & 99 & $17 n$ & 0.448 & $6 \mathrm{~b}$ & 99 \\
\hline 171 & 0.448 & ORNL & 100 & 172 & 0.448 & 7 & 75 \\
\hline 173 & 0.448 & ORNL & 93 & 174 & 0.448 & 5 & 116 \\
\hline 175 & 0.448 & $17 a$ & 91 & 176 & 0.448 & $6 b$ & 101 \\
\hline 177 & 0.448 & ORNL & 93 & 178 & 0.448 & 7 & 70 \\
\hline 179 & 0.448 & ORNL & 93 & 180 & 0.448 & 9 & 59 \\
\hline 181 & 0.448 & 15 & 116 & 182 & 0.448 & $13 b$ & 100 \\
\hline 183 & 0.448 & ORNL & 93 & 184 & 0.448 & 11 & 64 \\
\hline
\end{tabular}


dispersed heat source contributed by one tray of fertile particles and one tray of fissile particles. The graphite trays and the stainless steel vessels expand with increasing temperature; thus, thermal expansion was included in the heat transfer model. Thermal conductivities of the graphite trays, the stainless vessels, and the gas in the gaps (1.e., helium, neon, or helium-neon mixtures) are temperature dependent. Thermal conductivity of graphite is also affected by neutron damage. Temperature and neutron fluence effects on thermal conductivity were included in the thermal analysis computer program. The thermal analysis program is discussed in Appendix A, Sect. A.1, and the thermal properties of materials are 1 isted in Appendix A, Sect. A.2. The Poco graphite trays also "grow" as a function of fast neutron damage. Dimensional change of the trays attributable to graphite "growth" (discussed in Appendix A, Sect. A. 3) was also incorporated into the thermal analysis program.

The heat source in the stainless steel vessels results from nuclear (primarily gamma ray) heating in the metal. Part of the heat source in the specimen region is contributed by nuclear heating in graphite. Nuclear heating varies as a function of both axial position and time into each reactor cycle. (See Appendix A, Sect. A.4, for data on nuclear heating in both graphite and stainless steel.) Nuclear fission in the kernel of the particles in each tray contributes the remaining part of the heat source in the specimen region. Fission power (watts) per particle resulted from fuel depletion calculations, discussed in the next section.

FUEL DEPLETION

To calculate fuel depletion, fissile particles were reclassified into seven types according to initial amounts of fissile material containcd in the kernel. Data for each particle type, cross referenced to test plan designation, are shown in Table 8. The two quantities of interest are the fission power (watts) per particle and the fuel burnup in units of fissions per initial heavy metal atom (FIMA).

To calculate the above quantities, solutions for nuclide concentration (atoms per barn-cm) must first be obtained. for each nuclide of 
Table 8. Particle classification for fuel depletion study

$\begin{array}{ccc}\text { Type } \begin{array}{c}\text { Test plan } \\ \text { designation }\end{array} & \text { Kernel material Kernal loading, } \\ \mathrm{mg}(\mathrm{U} / \mathrm{Th})\end{array}$

\begin{tabular}{|c|c|c|c|}
\hline \multicolumn{4}{|c|}{ Fissile particles } \\
\hline$I$ & 1,8 & $(\mathrm{Th}, \mathrm{U}) \mathrm{O}_{2}$ & $0.111 / 0.109$ \\
\hline II & 2,9 & $\mathrm{UCO}(0 / \mathrm{U}=0.5)$ & $0.258 / 0$ \\
\hline I I I & 4,11 & $\operatorname{UCO}(0 / U=1.5)$ & $0.237 / 0$ \\
\hline IV & 3,10 & $\operatorname{UCO}(0 / \mathrm{U}=1.0)$ & $0.207 / 0$ \\
\hline V & 7,14 & $\mathrm{UC}_{2}$ & $0.216 / 0$ \\
\hline VI & 5,12 & $\mathrm{UO}_{2}$ & $0: 130 / 0$ \\
\hline VII & $6 a b c, 13 a b c$ & $\mathrm{UO}_{2}^{-}$ & $0.150 / 0$ \\
\hline \multicolumn{4}{|c|}{ Fertile particles } \\
\hline I & $17 b$ & $\mathrm{ThO}_{2}$ & $0 / 0.412$ \\
\hline II & 15 & $\mathrm{ThO}_{2}$ & $0 / 0.430$ \\
\hline III & $17 a$ & $\mathrm{ThO}_{2}$ & $0 / 0.590$ \\
\hline IV & 16 & $\mathrm{ThO}_{2}$ & $0 / 0.600$ \\
\hline V & ORNL & $\mathrm{ThO}_{2}$ & $0 / 0.575$ \\
\hline
\end{tabular}

interest shown in the chain description (Fig. 1). With the cxception of the mixed-oxide particles, the fissile particles did not contain thorium; thus, the nuclides to the left of ${ }^{235} \mathrm{U}$ in Fig. 1 would not be a part of the chain description for those type particles. Each depletion case considers a single particle at a specified axial position and obtains solutions for the nuclide concentration as a function of exposure time. A series of cases were run at several (24) axial positions for each particle classification 1 isted in Table 8. These calculations were performed with the CACA-2 codel (with some modification).

The system of ordinary differential equations of the form

$$
\frac{d N(t)}{d t}=f(t, N)
$$

are solved in $\mathrm{CACA}-2$ by using numerical integration formulas. The procedure is based on the self-starting Runge-Kutta method. 2 For a particular isotope, the rate of change in nuclide concentration ( $\partial \mathrm{N} / \partial t$ ) depends 
ORNL-DWG 79-6696 ETD

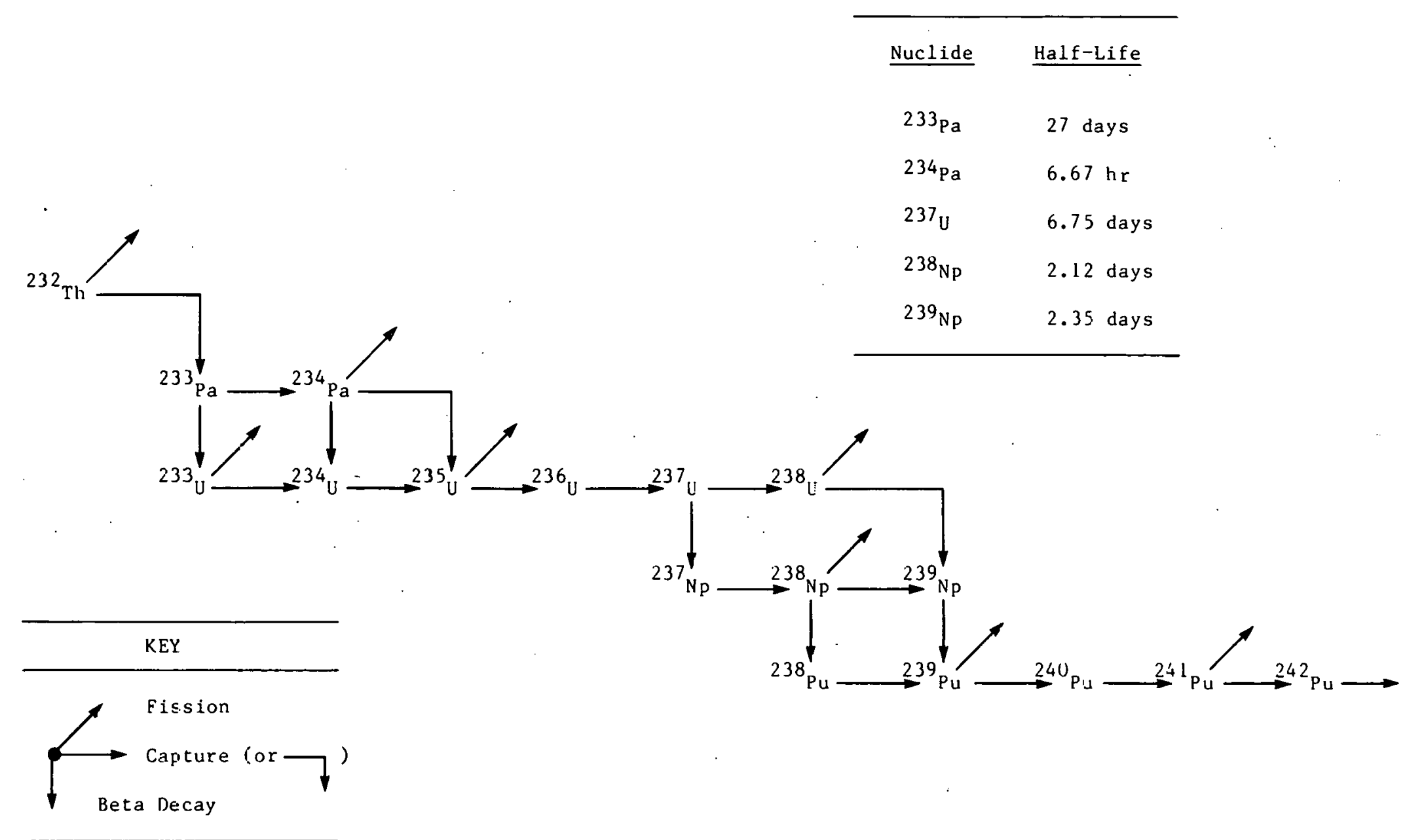

Fig. 1. Heavy nuclide chain description. 
on its rate of production by radiative capture and/or beta decay minus its loss rate attributable to fission and/or radiative capture and/or beta decay - symbolically represented above by $f(t, N)$. The principle behind the Runge-Kutta formulas ${ }^{2}$ is to develop an integration formula for the differential equation above of the form

$$
\mathrm{N}_{\mathrm{J}+1}=\mathrm{N}_{\mathrm{J}}+\mathrm{h} \sum_{i} \alpha_{i} \mathrm{f}\left(\mathrm{t}_{\mathrm{i}}, \mathrm{N}_{\mathrm{i}}\right)
$$

where the $\alpha_{1}, t_{1}$, and $N_{1}$ are chosen to make the integration formula agree with the Taylor series expansion of $N(t)$ to some order. The fourth-order integration formulas are as follows:

$$
\mathrm{N}_{\ell+1}=\mathrm{N}_{\ell}+(\mathrm{h} / 6)\left(\mathrm{K}_{1}+2 \mathrm{~K}_{2}+2 \mathrm{~K}_{3}+\mathrm{K}_{4}\right),
$$

where

$$
\begin{aligned}
& \mathrm{K}_{1}=\mathrm{f}\left(\mathrm{t}_{\ell}, \mathrm{N}_{\ell}\right), \\
& \mathrm{K}_{2}=\mathrm{f}\left[\mathrm{t}_{\ell}+(\mathrm{h} / 2), \mathrm{N}_{\ell}+\left(\mathrm{K}_{1} / 2\right)\right], \\
& \mathrm{K}_{3}=\mathrm{f}\left[\mathrm{t}_{\ell}+(\mathrm{h} / 2), \mathrm{N}_{\ell}+\left(\mathrm{K}_{2} / 2\right)\right], \\
& \mathrm{K}_{4}=\mathrm{f}\left(\mathrm{t}_{\ell}+\mathrm{h}, \mathrm{N}_{\ell}+\mathrm{K}_{3}\right) .
\end{aligned}
$$

The l's in the above equation are time indices. The lungth of each time step $h$ is $6 \mathrm{hr}$ in CACA-2.

Once the nuclide concentrations have been computed, then fuel burnup and power per particle can be evaluated. The code maintains a filp on cumulative fissions per unit volume of fuel so that fuel burnup can be evaluated from the following equation:

$$
F \operatorname{TMA}(T, z)=\sum_{J}\left[\int_{t=0}^{T} \phi(t, z) \sigma_{f}(J) N(J, t, z) d t\right] /\left[10^{24} \sum_{k} N(k, o, z)\right] .
$$

As seen from the above equation, fuel burnup (FIMA) is the timeintegrated fission rate (fission per cubic centimeter) per atom density (atoms per cubic centimeter) of preirradiation heavy nuclides in the particle kernel $\mathrm{N}(\mathrm{k}, \mathrm{o}, \mathrm{z})$. Heavy nuclides are defined as the isotopes ${ }^{232} \mathrm{Th}$, 
${ }^{235} \mathrm{U}$, and ${ }^{238} \mathrm{U}$. Fission rate for fuel at axial position $z$ is the product of the space-time-dependent total neutron flux $\phi(t, z)$, the weighted fission cross sections $\sigma_{f}(J)$, and nuclide concentration $N(J, t, z)$ for each fissionable nuclide $\mathrm{J}$. The isotopes ${ }^{232} \mathrm{Th},{ }^{234} \mathrm{~Pa},{ }^{233} \mathrm{U},{ }^{235} \mathrm{U},{ }^{238} \mathrm{U}$, ${ }^{238} \mathrm{~Np},{ }^{239} \mathrm{Pu}$, and ${ }^{241} \mathrm{Pu}$ constitute the 1 ist of fissionable nuclides. Fission power per particle $P(1, T, z)$ is the product of a constant, the kernel volume $V(i)$, and the fission rate occurring in the kernel at time T.

$$
P(1, T, z)=\left(2.884 \times 10^{-11}\right) V(1) \sum_{J} \phi(T, z) \sigma_{f}(J) N(J, T, z) \cdot
$$

The index 1 in the above equation relates to particle classification, that is, each particle type shown in Table 8. The quantity $2.884 \times 10^{-11} \mathrm{~J}$ per fission is based on the assumption that the useful energy release per fission locally within the specimen region will be $180 \mathrm{MeV}$ per fission.

At the end of the third cycle of operation, the experiment was repositioned in the facility (axially moved) so that a fuel particle, which had been irradiated at axial position $z$, thereafter would be exposed to a different flux magnitude characteristic of the new position $z+\Delta z$. The nuclide concentrations at the end of the third cycle were saved and used for restarting each case. As can be seen from the equation above for fission power per particle, if $\phi(T, z)$ were changed to $\phi(T, z+\Delta z)$, that calculation would be continued properly. The saved nuclide concentrations would begin depleting at rates characteristic of $\phi(T, z+\Delta z)$, which is also a proper continuation. Fuel burnup had to be treated as a two-part problem; that is, the numerator of the burnup equation now becomes the sum of two integrals, with the first integral reflecting fission rate (at position $z$ ) during the first three cycles of operation and the second integral reflecting the change in fission rate at the new position $(z+\Delta z)$ during subsequent cycles.

One-group microscopic cross sections ${ }^{3}$ used to calculate fuel depletion are shown in Table 9. The values in parentheses were results from sensitivity studies with previous rod-type HRB experiments. The 
Table 9. One-group microscopic cross section (barn)

\begin{tabular}{lcc}
\hline Nuclide & Capture & Fission \\
\hline $232 \mathrm{Th}$ & $3.96(2.77)$ & $0.008(0.006)$ \\
$233^{\mathrm{Pa}}$ & 32.2 & \\
$234 \mathrm{~Pa}$ & 150.0 & 1500.0 \\
$233 \mathrm{U}$ & 16.1 & 151.0 \\
$234 \mathrm{U}$ & 40.1 & 144.0 \\
$235 \mathrm{U}$ & 27.9 & \\
$236 \mathrm{U}$ & 10.2 & $0.033(0.023)$ \\
$237 \mathrm{U}$ & 110.0 & \\
$238 \mathrm{U}$ & $8.44(5.908)$ & 570.0 \\
$237 \mathrm{~Np}$ & 65.6 & \\
$238 \mathrm{~Np}$ & 13.0 & 281.0 \\
$239 \mathrm{~Np}$ & 8.3 & \\
$238 \mathrm{Pu}$ & 130.0 & 239.0 \\
$239 \mathrm{Pu}$ & 142.0 & \\
$240 \mathrm{Pu}$ & 287.0 & \\
$24 \mathrm{Pu}$ & 109.0 & \\
$242 \mathrm{Pu}$ & 36.5 & \\
\hline
\end{tabular}

cross sections not in parentheses were found to be more realistic for the very dilute $\mathrm{HRB}-15 \mathrm{~b}$ experiment.

\section{PROCEDURE FOR COMPUTING PARTICLE LOADINGS}

At this stage of the calculation, the time-dependent fission power (warts) perir single particle is known for each particle classification at 24 discrete axial positions over the length of the experiment. For example, the data in Fig. 2 11.1ustrate the fission power per particle during the irradiation history for one type of $\mathrm{UO}_{2}$ fissile particle (type VI, Table 8) and one type of fertile particle (type $v$, Table 8) if positioned near the extremity of the experiment. As stated previously, HFIR control rods are located between the experiment and the reactor core. The rods are more properly described as "plates" or as two concentric cylinders, with the smaller diameter cylinder moving toward the bottom of the core and the larger diameter cylinder moving toward the top of the core during 


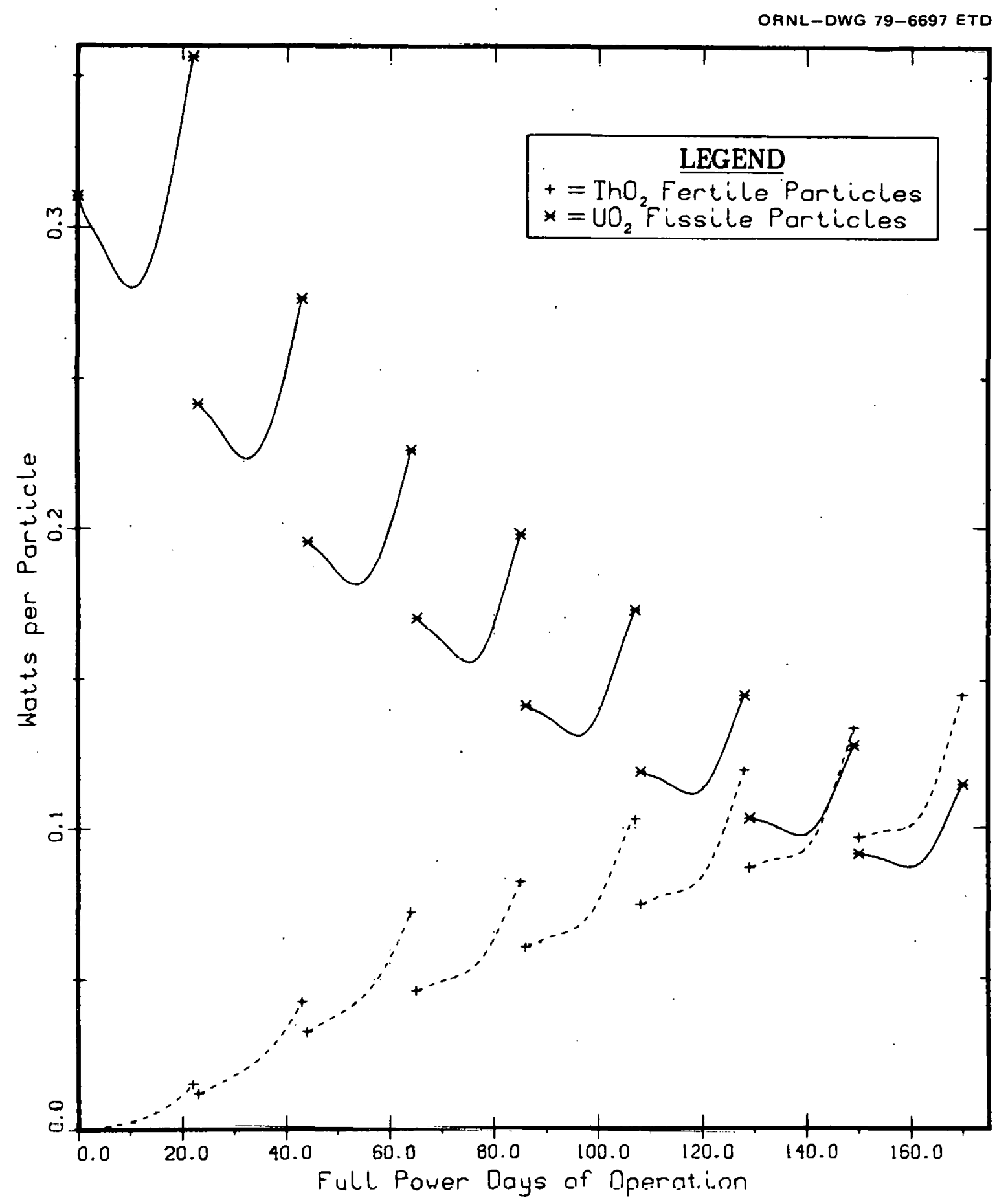

F1g. 2. Exper1ment HRB-15b, power per particle vs fuel residence t1me. 
each reactor cycle. The neutron absorbers in the control plates (cylinders) therefore are moved progressively in a direction from reactor horizontal midplane (HMP) at beginning of cycle (BOC) toward each extremity of the core during the cycle. Each plecewise discontinuous curve in Fig. 2 shows the variation in fission power per particle during each reactor cycle. There are 21 full power days per reactor cycle.

In developing the equation for computing particle loadings, the following must be considered.

1. There is a significant difference in the amount of fissile material in the kernel of the various type fissile particles. The various types of fertile particles also contain differcnt initial amounts of $\mathrm{ThO}_{2}$ in the kernel. The type of fissile particle and the type of fertile particle to be loaded into each tray is specified.

2. The power per particle is both position and time dependent; that is, the shape and magnitude of the power per particle shown in Fig: 2 is different at other axial positions for the same type particle.

3. The magnitude of nuclear heating in both graphite and stainless steel is a function of both axial position and time into a reactor cycle. (See Figs. A. 2 and A. 3 of Appendix A, Sect. A.4.)

4. The temperature of the particles can be controlled only by varying the composition of the gas in the gap between the stack of trays (all 184) and the primary vessel.

5. The gap may be the same over several trays but must become progressively wider from HMP to each extremity of the experiment. A pattern of narrow gap-wide gap-narrow gap should be avoided.

6. The maximum number of particles that can be loaded into any tray is 116. It was desirable that the minimum number of particles per tray not he less than abuul 60 .

7. The heat source in the specimen region has been modeled by contributions from tray pairs, that is, from a tray of fertile particles plus an adjacent tray of fissile particles.

Because of HFIR control rod management, a flat axial temperature profile in the specimen region cannot be maintained throughout the cycle. The trays, however, can be loaded so that at two points in time (during 
the history of the experiment) the ratio of power per tray pair can be made constant; that is, for each tray pair, the trays can be loaded to obtain a common value for the constant $c$ in the following equation:

$$
c=\frac{\left(N_{1} P_{12}\right)+\left(N_{2} P_{22}\right)}{\left(N_{1} P_{11}\right)+\left(N_{2} P_{21}\right)} .
$$

In the above equation, $\mathrm{N}_{l}$ is the number of fissile particles in a tray, and $\mathrm{N}_{2}$ is the number of fertile particles in the adjacent tray. The denominator is the power per tray pair early in the history of the experiment; we chose the beginning of fuel lifetime (BOL), that is, shortly after the initial start-up. The numerator is the power per tray pair later in the history of the experiment - the middle of cycle 7 was chosen. Therefore, $P_{11}$ is the power per fissile particle at BOL, and $P_{12}$ is the power per fissile particle at middle of cycle 7. Likewise, $P_{2 l}$ and $\mathrm{P}_{22}$ are power per fertile particle at $\mathrm{BOL}$ and midcycle 7 , respectively. Maximizing the value for $c$ in the above equation is advantageous. The highest value possible for $c$ will reduce the likelihood of using argon sweep gas and having to cope with ${ }^{41} \mathrm{~A}$ activities. Helium and mixtures of helium and neon were preferred. A value of 0.5 for $c$ was adequate.

A more useful form of the above equation is expressed in terms of the ratio of the number of fertile particles to the number of fissile particles $R$, for each tray pair, that is,

$$
R=\left(c P_{11}-P_{12}\right) /\left(P_{22}-c P_{21}\right)
$$

Let $M$ be defined as the minimum number of particles to be loaded in a tray (i.e., $M \sim 60$ from constraint No. 6 above). For any tray pair loading to be acceptable implies that $R$ must 1 ie within the following range:

$(M / 116) \leq R \leq(116 / M)$

Note that $R$ depends on the power per particle at two points in time and the choice for the constant c. The power per particle depends on the type of particle to be loaded into each tray and the axial position of that tray in the experiment. The type of particles to go into each of 
the 184 trays was specified, along with a desired minimum number of particles to be loaded into a tray. The value for the constant $c$, of course, will be the same for each of the 92 tray pairs. Thus, the largest value for $c$ must be found so that $R$ is always within acceptable range for the type of particles to be loaded in each tray pair.

If $R=1.0$, then 116 fertile particles and 116 fissile particles could be loaded in the tray pair. If $R<1.0$, then only the tray containing fissile particles could be filled; $R>1.0$ implies that only the tray containing fertile particles could be filled. The more particles loaded into a tray pair, the higher the fission power per tray pair will be. Thus, if one or the other (or hnth) of the trays arc filled, then maximum fission power per tray pair is achieved. The range on $R$ for an acceptable loading also implies that both of the trays may be only partially fllled. For example, if $R>1.0$, there can be $M$ (about 60) $\mathrm{fis}$ sile particles per tray and somewhat more (the product MR) fertile particles $(M<M R \leq 116)$ in an adjacent tray. Thus, the fission power per tray pair for acceptable loadings can range from some minimum power to some maximum power.

If one point in time is selected (e.g., BOL) and the maximum fission power per tray pair is tabulated, along with the minimum fission power per tray pair, then when the contribution from nuclear heating in each tray pair is included, the range of the heat source in the specimen region at each axial position will have been defined, at one time in the history of the experiment, for all acceptablc particle loadings. Knowing the range of heat source as a function of axial position, then the gap ch1ckness must be specified (i.e., tray outside diameters) to give the desired axial temperature profile; that is, at the axial position of each tray pair, there will he some "best compromicc" fission power per tray pair, $\mathrm{P}^{*}$, and some tray diameter that will give the desired axial temperature profile in the specimen region. The magnitude of $P *$ must lie somewhere between the maximum and the minimum fission power por tray pair. The tray diameters were selected so that there is a stepwise increasing gap from the middle of the experiment to each extremity. Once $P^{*}$ was determined, then the final particle loadings were computed. A summary of expressions applicable to particle loading is given in Table 10. 
Table 10. Summary of expressions for particle loading

Range of particles per tray

\begin{tabular}{|c|c|c|c|c|}
\hline \multirow[b]{2}{*}{ Expression } & \multicolumn{2}{|c|}{ Maximum No. } & \multicolumn{2}{|c|}{ Minimum No. } \\
\hline & Fertile & Fissile & Fertile & Fissile \\
\hline$R>1.0$ & 116 & $116 / R$ & MR & $M$ \\
\hline$R<1.0$ & $116 \mathrm{R}$ & 116 & M & $M / R$ \\
\hline
\end{tabular}

Range of fission power per tray pair

\begin{tabular}{|c|c|c|}
\hline Expression & Maximum power & Minimum power \\
\hline $\begin{array}{l}R>1.0 \\
R<1.0\end{array}$ & $\begin{array}{l}{\left[\left(P_{11} / R\right)+P_{21}\right] 116} \\
{\left[P_{11}+\left(R P_{21}\right)\right] 116}\end{array}$ & $\begin{array}{l}{\left[P_{11}+\left(R P_{21}\right)\right] M} \\
{\left[\left(P_{11} / R\right)+P_{21}\right] M}\end{array}$ \\
\hline
\end{tabular}

Number of particles loaded per tray

\begin{tabular}{llc} 
Expression & Fertile & Fissile \\
\hline$R>1.0$ & $R P * /\left[P_{11}+\left(R_{21}\right)\right]$ & $P^{*} /\left[P_{11}+\left(R P_{21}\right)\right]$ \\
$R<1.0$ & $R P * /\left[P_{11}+\left(P_{21} / R\right)\right]$ & $P^{*} /\left[P_{11}+\left(P_{21} / R\right)\right]$
\end{tabular}

Once the loadings were computed, but before the experiment was placed in-reactor, several additional thermal cases were run. The purpose of these calculations was to (1) check the computed temperature profiles at various times during a cycle and over the expected irradiation history (many cycles); (2) check the sensitivity of computed temperatures to uncertainties in basic thermal data, such as thermal conductivity, surface emissivity, and coefficient of linear expansion; and (3) include graphite growth in the model (see Appendix A, Sect. A.3) and test the effect of graphite growth on temperature control. The maximum tray diameter $(23.57 \mathrm{~mm})$ was established from consideration of anticipated graphite growth during the history of the experiment. Results of these additional 
calculations confirmed that the loadings selected would meet the various requirements.

MODELS FOR COMPUTING PARTICLE SURFACE TEMPERATURES

One of the requirements on temperatures was that the maximum particle surface temperature should not exceed $1000^{\circ} \mathrm{C}$ for any particle in the experiment. The one-dimensional (1-D) cylindrical model can be used for predicting the centerline temperature and also the surface temperatures at the inside and outside surfaces of the secondary vessel, the primary vcssel, and the tray.

Loose particles are resting in drilled holes in the trays. Therefore, a method was needed to estimate temperature differences from tray to particle surface. If we assume that the partirles "float" in the drilled holes, then an equivalent 1-D spherical model can be used to estimate particle surface temperatures. The equations for the 1-D spherical model are derived in Appendix A, Sect. A.1. An equivalent volume spherical annulus surrounding a particle does not adequately represent the actual particle resting in the tray and tends to overpredict $\Delta \mathrm{T}$ (tray to particle surface). Alternatively, multidimensional models were considered, and the HEATING code $^{4}$ was used for calculating particle surface temperatures. The results for maximum particle surface temperature from a series of such calculations could then be correlated as functions of particle power $P$, tray mean temperature $\bar{T}$, and gas composition. For example, if helium gas surrounds the $800-\mu m$ particle, maximum $\Delta T$ (tray to particle surface) can be obtained from the following equation:

$$
\Delta T(\max )=P[2915.7387-\bar{T}] / 19.1415
$$

If $\mathrm{P}=1.32 \mathrm{~W}$ per particle and $\overline{\mathrm{T}}=800^{\circ} \mathrm{C}, \Delta \mathrm{T}$ from the above expression is $146^{\circ} \mathrm{C}$. For the same problem, the equivalent $1-D$ spherical. model predicts average $\Delta T=183^{\circ} \mathrm{C}$. The series of cases from the HEATING code had not been completed by the time the experiment began in-reactor operation. Therefore, during the first cycle, results from the 1-D spherical model were used to estimate particle surface temperature. Once all the results were in for the multidimensional models, an equation of 
the form

$$
\Delta T=P_{(J, z, \theta)}\left[g_{1}-\vec{T}_{(z)}\right] / g_{2}
$$

could be included in the thermal program to compute fissile particle and fertile particle maximum surface temperatures. Of course, power per particle $P(J, z, \theta)$ will depend on the type or classification of the particle $J$, its axial position in the experiment $z$, and the time $\theta$ that the experiment was in-reactor. The constants $g_{1}$ and $g_{2}$ depend on the gas composition that surrounds the particles; values for $g_{1}$ and $g_{2}$ are 1 isted in Table 11. To be conservative, we assumed that tray "mean" temperature $\overline{\mathrm{T}}_{(\mathrm{z})}$ at axial position $\mathrm{z}$ and the tray inside surface temperature (at the same axial location) were identical.

Table 11. Constants for the equation used to compute tray to particle surface temperatures

\begin{tabular}{lll}
\hline $\begin{array}{c}\text { Mole fraction } \\
\text { of helium in } \\
\text { helium-neon } \\
\text { gas mixture }\end{array}$ & \multicolumn{1}{c}{$\mathrm{g}_{1}$} & $\mathrm{~g}_{2}$ \\
\hline 1.0 & & \\
\hline 0.9 & 2915.74 & 19.14 \\
0.8 & 2648.5 & 16.1 \\
0.7 & 2605.0 & 14.8 \\
0.6 & 2625.0 & 14.0 \\
0.5 & 2666.92 & 13.49 \\
0.45 & 2773.0 & 13.3 \\
0.4 & 2839.6 & 13.3 \\
0.35 & 2928.0 & 13.4 \\
0.30 & 3010.5 & 13.5 \\
0.25 & 3087.0 & 13.6 \\
0.20 & 3194.7 & 13.8 \\
0.15 & 3311.2 & 14.02 \\
0.10 & 3448.8 & 14.4 \\
0.05 & 3584.3 & 14.75 \\
0.0 & 3759.0 & 15.25 \\
\hline
\end{tabular}


TEMPERATURES, FUEL BURNUP, AND FAST NEUTRON FLUENCE

Particle loadings and tray diameters (Tables 4 through 7) were specified so that, with helium gas in the tray to primary vessel gap, the thermocouples near HMP indicated about $800^{\circ} \mathrm{C}$ early in the first cycle; that is, the junction of each thermocouple is located at approximately the tray inside radius, and the computed temperatures at these radial positions (and near HMP) were approximately $800^{\circ} \mathrm{C}$. After about one day of power operation, the thermocouple in the bottom of unit $15 \mathrm{~b}-2$ and those in the top and bottom of unit $15 \mathrm{~b}-3$ peaked at $775,79.5$, and $81 n^{\circ} \mathrm{r}$, respectively. Agreement between computed temperatures and measured temperatures appeared to be very good in that part of the experiment. All thermocouple readings are listed in tables of Appendix A, Sect. A.6, with one table of data for each of the eight cycles that the experiment was in the reactor. Figure 3 shows the axlal temperature profile at the end of one full power day of operation. Calculated temperatures shown in the figures result from separate 1-D heat transfer calculations. The temperatures are connected by straight lines to form the axial profiles. In each figure, one of the curves will illustrate particle surface temperatures, which are the maximum particle surface temperatures as computed by the mechod described in the previous section. Another curve in each figure, the one labeled tray maximum, is for computed temperatures at tray inside radius. The tray maximum temperatures can be compared with the measured (thermocouple) temperatures to demonstrate agreement between computed and measured temperatures at the various axial positions over the length of the experiment. Each symbol is drawn at the axial location either of each of the 92 tray pairs or of each thermocouple. A1 1 measurements are referenced to the top of the HFTR active core. Total length of the active core is $508 \mathrm{~mm}$ ( $20 \mathrm{in.}$ ); thus, HMP will be at $254 \mathrm{~mm}$ in each of the figures.

The axial temperature profile shown in Fig. 3 was expected to be more symmetrical about HMP than the early results indicated. It was discovered that the middle of the experiment was positioned about $0.02 \mathrm{~m}$ above HMP, which is probably the primary reason for the asymmetric axial temperature distribution. Helium sweep gas was used throughout cycle 1. 


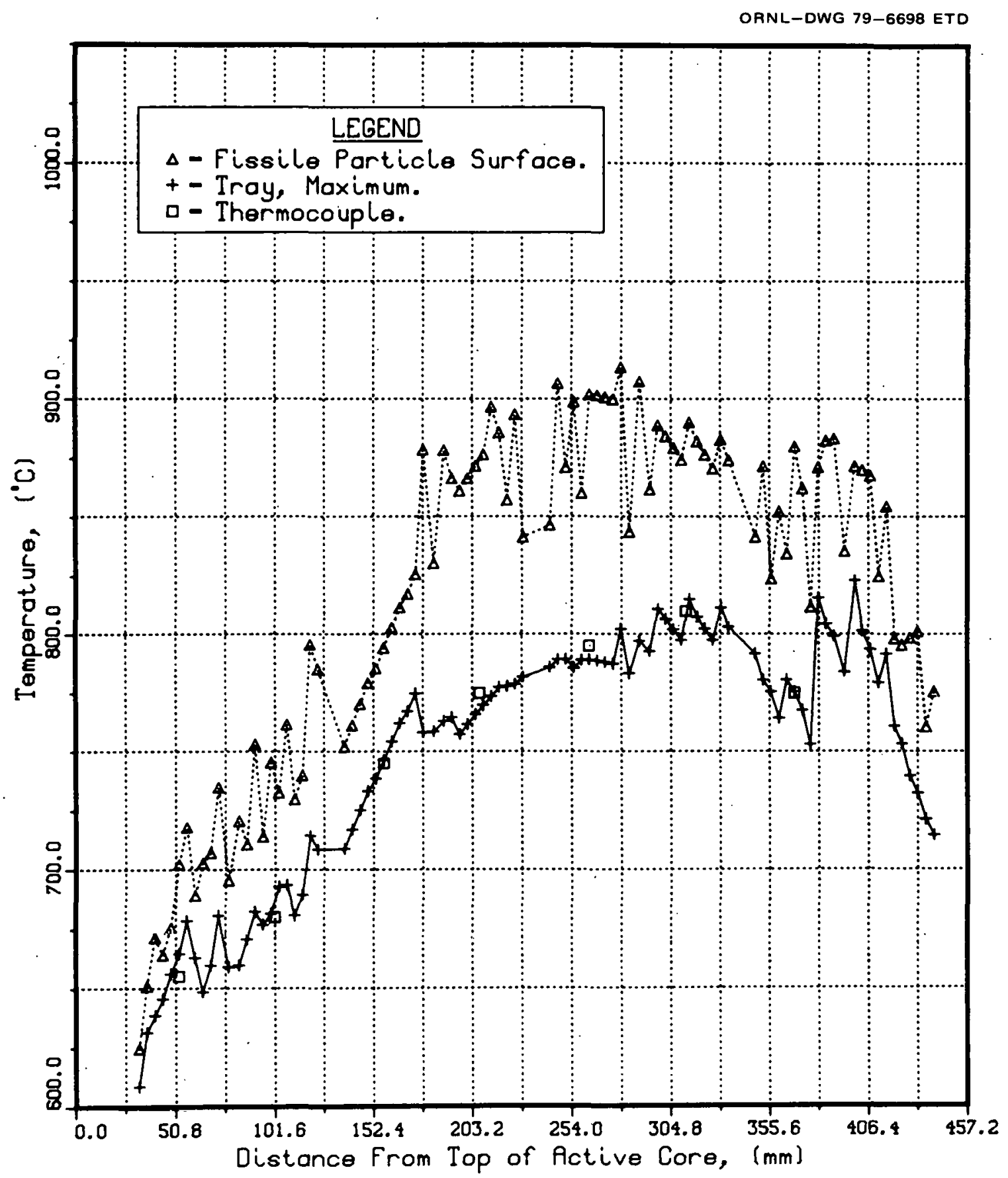

Fig. 3. Experiment $H R B-15 b$, temperature vs axial position at one day into cycle 1 . 
At that time, the results from the 1-D spherical model were also used for estimating the maximum particle surface temperatures. The particle surface temperatures shown in Figs: 3 and 4 are results from recalculations and are based on the multidimensional models described in the previous section. The change in the shape of the curves (Fig. 3 vs Fig. 4) shows how HFIR control rod management affects temperatures in the experiment during a reactor cycle.

Beginning with cycle 2, mixtures of helium and neon were used to control particle surface temperatures. The temperatures shown in Figs. 5 and 6 are characteristic of early cycle 2 and late cycle 2 operation, respectively. By the cnd of cyele $3(9 / 13 / 78)$, a prucedure and the necessary parts were avallable for centering the experiment with respect to reactor HMP. As illustrated by Fig. 7, axial temperature distribution was more symmetrical about reactor HMP thereafter.

Thermal calculations were made frequently throughout the irradiation history of the experiment. The results from those calculations were then used to specify the controlling thermocouple temperature, that is, to establish the maximum thermocouple temperature so that the maximum particle surface temperature would not exceed the $1000^{\circ} \mathrm{C}$ limit. The data in Fig. 6 indicate that particles in trays near the extremity of the experiment have highest temperatures during the last few days of a cycle. At other times during the cycle (Figs. 3, 5, 7, and 8), particles in trays at other axial positions may be at highest operating temperatures. During the fifth cycle of operation (Fig. 8), the surface temperatures of some of the fertile particles equaled or exceeded the surface temperatures of the fissile particles. Therefore, during the last few cycles of operation, the surface temperature of fertile particles was of primary concern.

Fuel burnups in units of fission per initial heavy metal atom (FIMA) are shown in Figs. 9 and 10 for the fissile and the fertile particles, respectively ( $1 \%$ of fuel fissioned is $\sim 9500 \mathrm{MWd} /$ metric ton). Fuel burnups are results from the depletion calculation as described in a previous section of this report. The burnups shown in these figures are spacially averaged over the specimen region (radial and azimuthal), and 


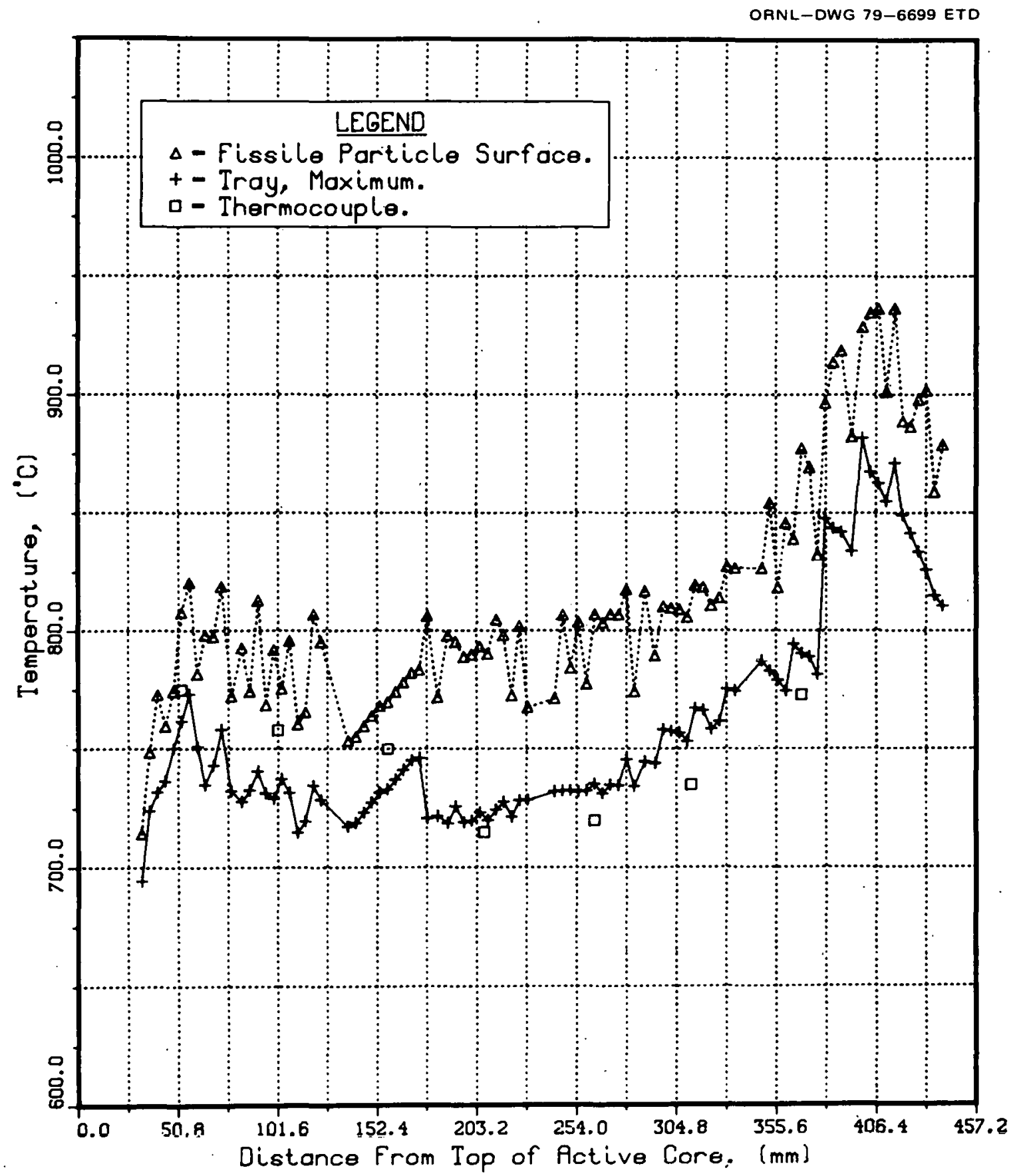

Fig. 4. Experiment $H R B-15 b$, temperature vs axial position at 21 days into cycle 1 . 


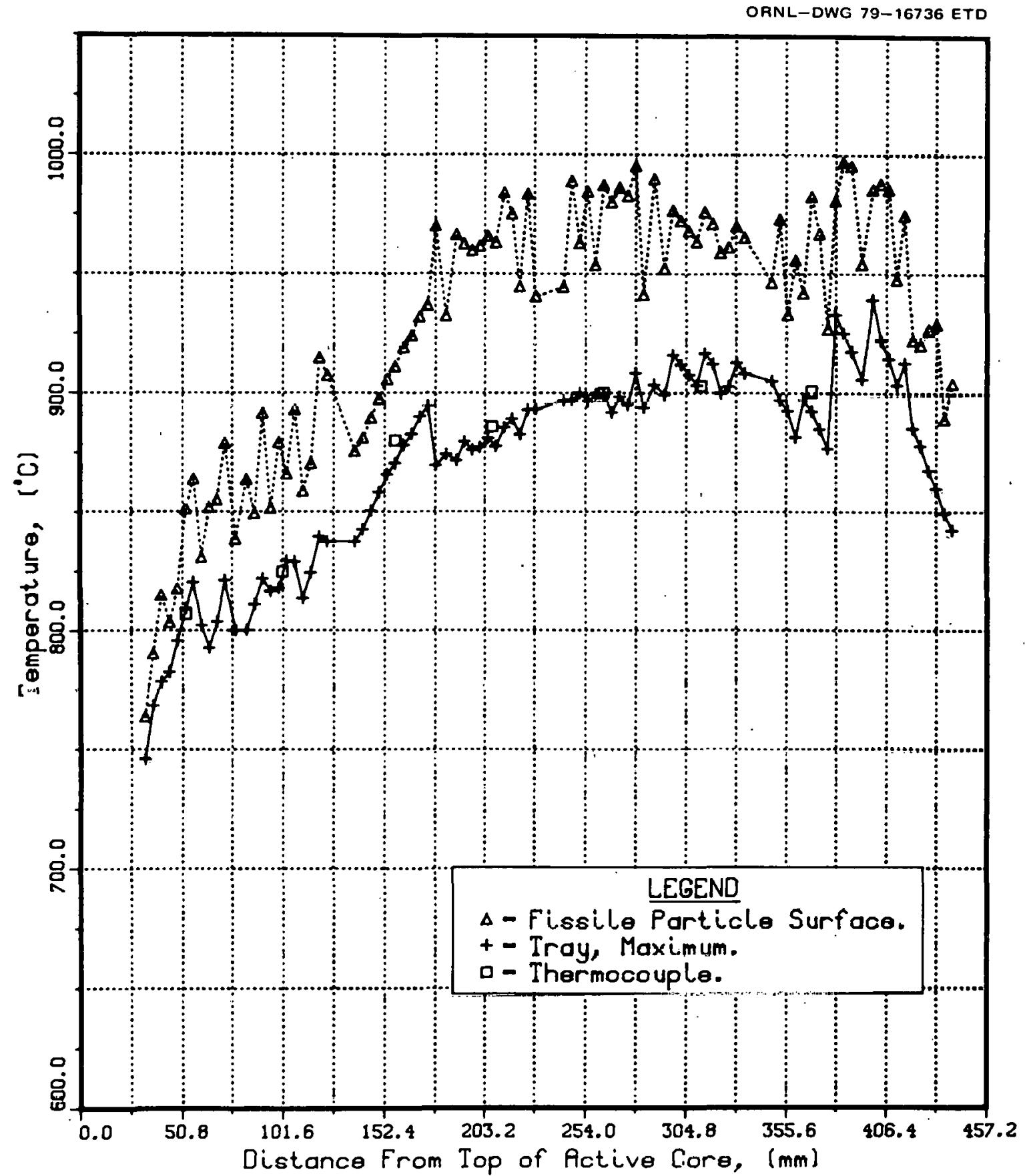

Fig. 5. Experiment $H R B-15 b$, temperature vs axial position at two days Into cycle 2 . 


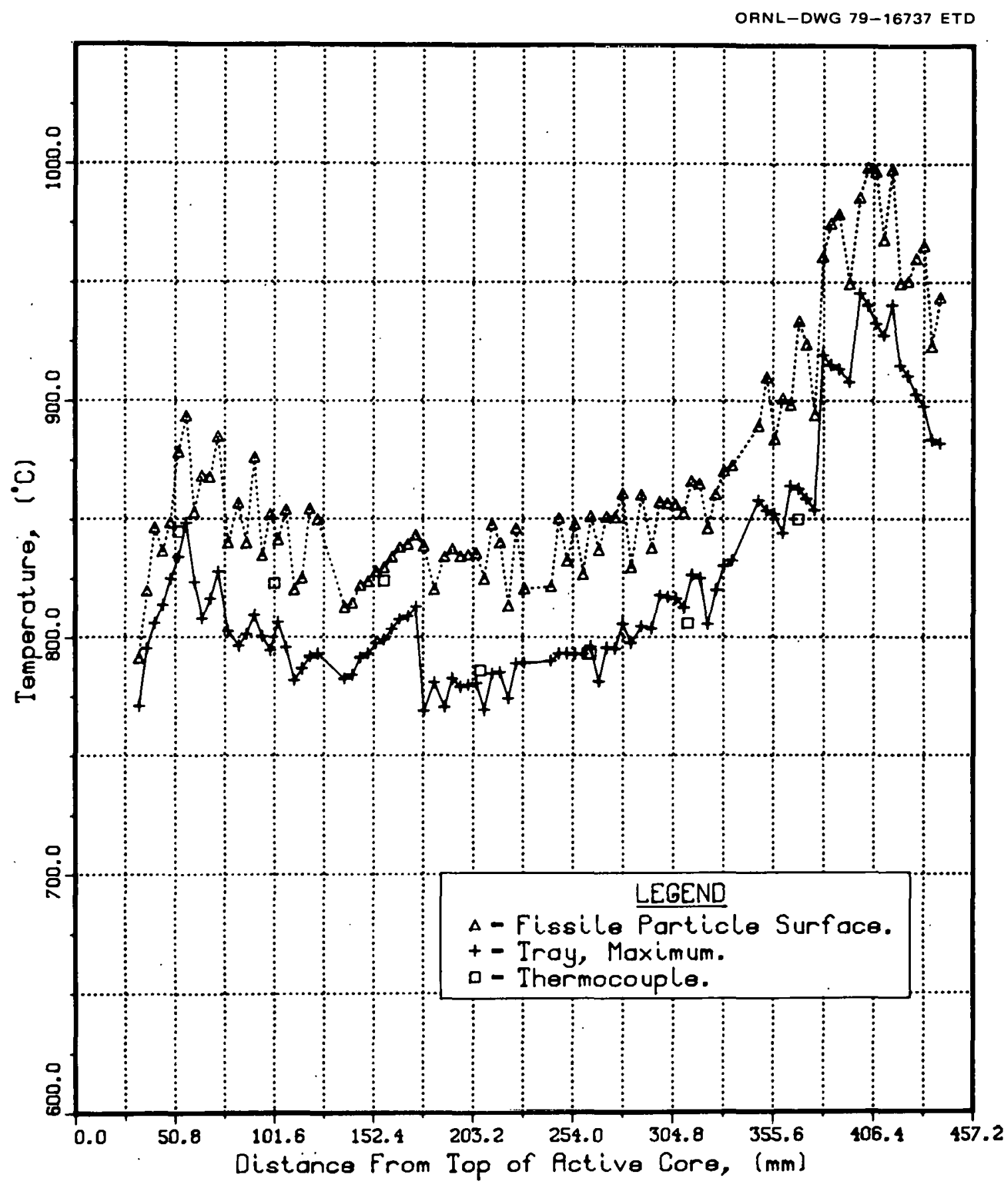

Fig. 6. Experiment $\mathrm{HRB}-15 \mathrm{~b}$, temperature vs axial position at 21 days into cycle 2 . 


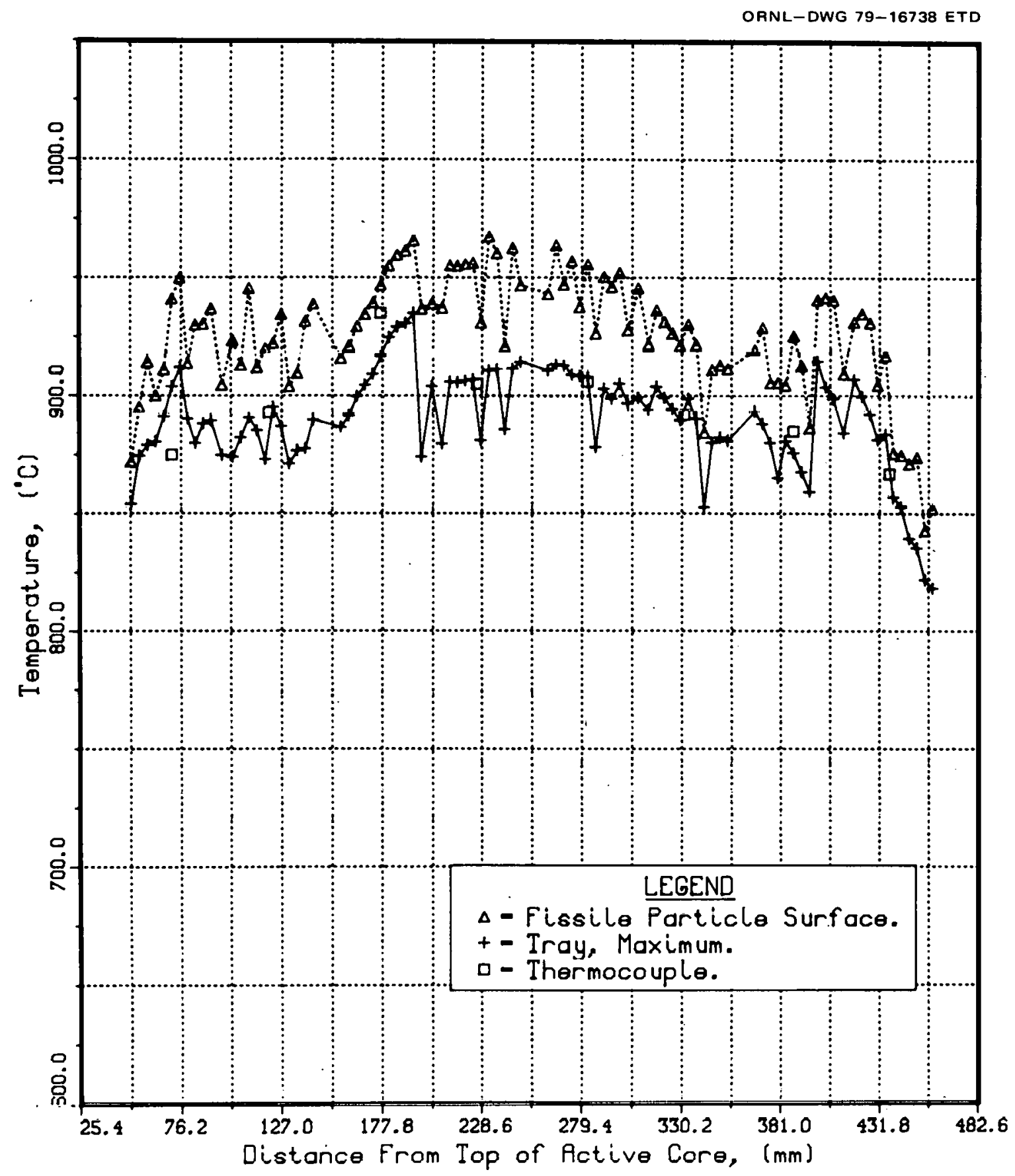

Fig. 7. Experiment HRB-15b, temperature vs axial position at five days into cycle 4. 


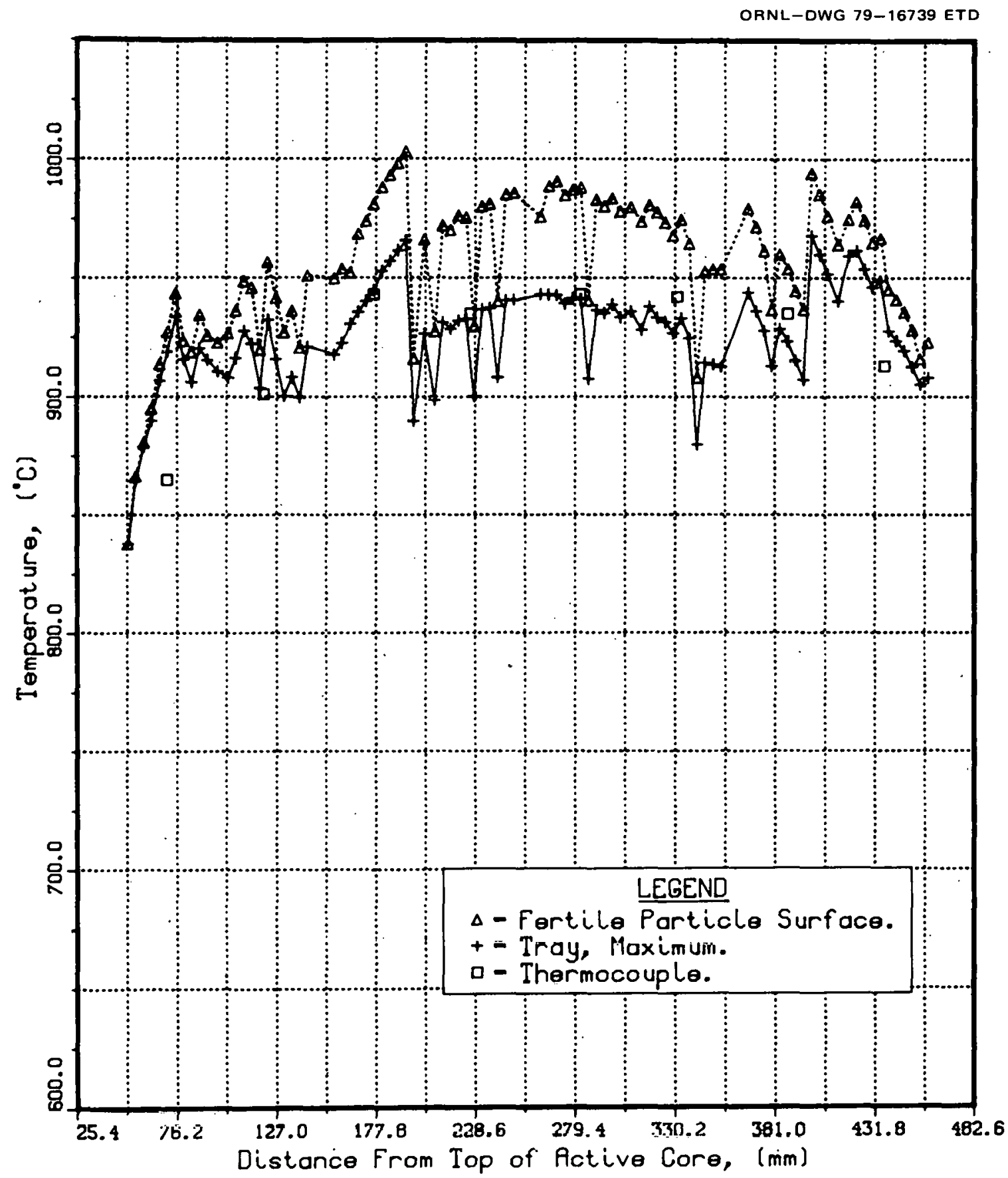

Fig. 8. Experiment $\mathrm{HRB}-15 \mathrm{~b}$, temperature vs axial position at 13 days into cycle 5 . 


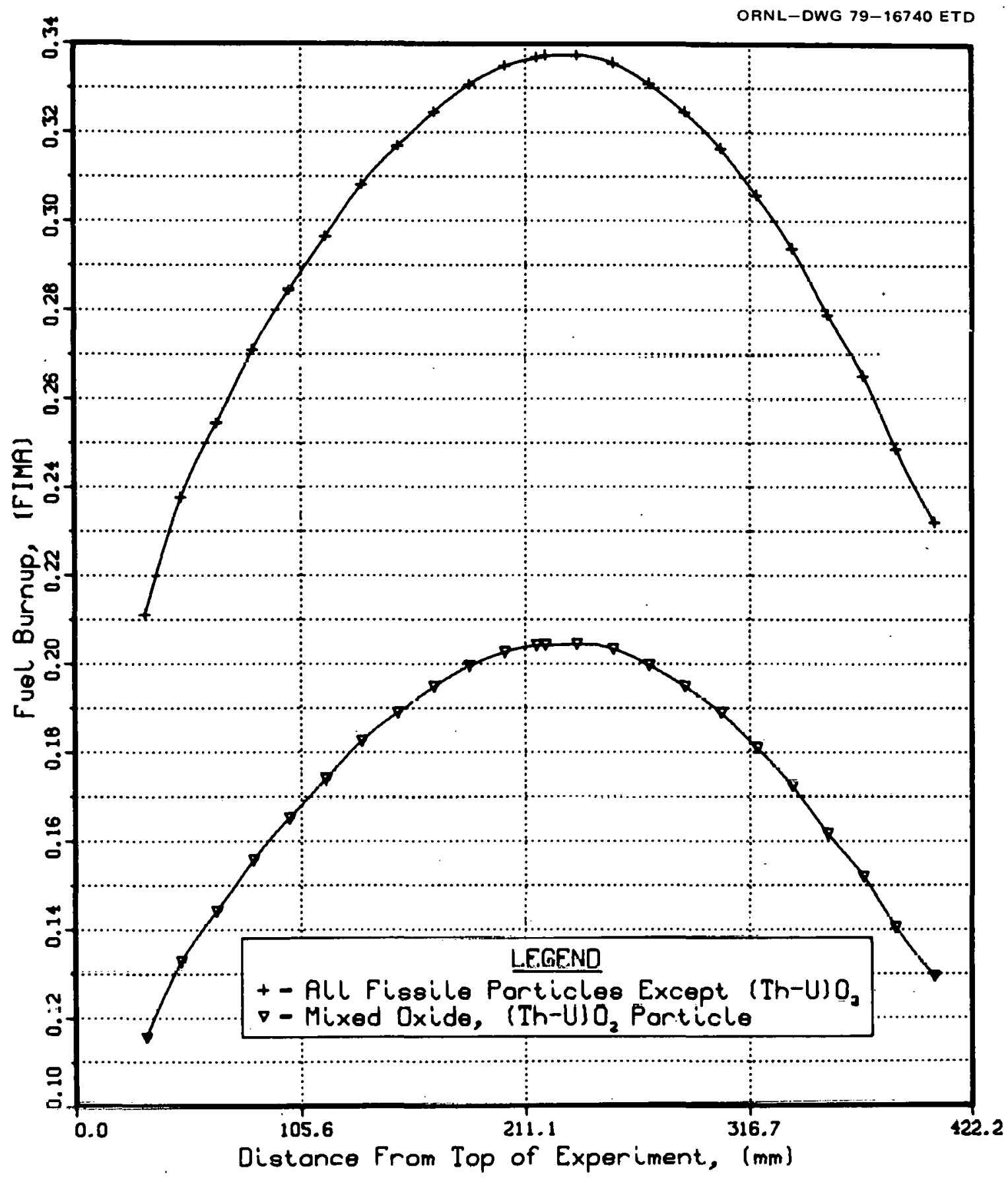

F1g. 9. Experiment HRB-15b, particle average burnup for fissile particles at end of test. 


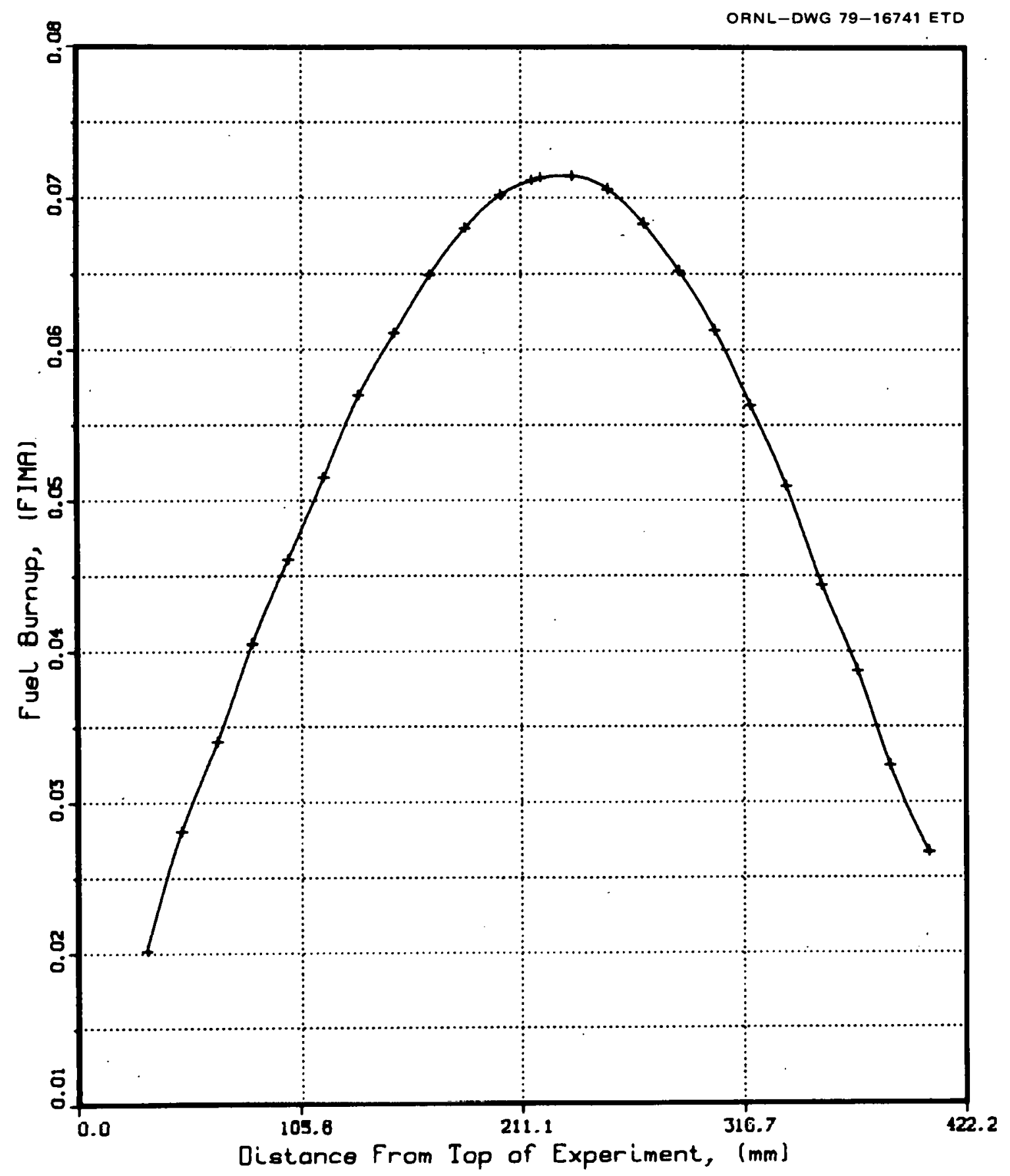

Fig. 10. Experiment $\mathrm{HRB}-15 \mathrm{~b}$, particle average burnup for fertile particles at end of test. 
the magnitudes reflect the total time that the experiment was in the reactor. The abscissas of the graphs are graduated in units of length equal to the length of each unit in the experiment. For example, 0.0 to $105.6 \mathrm{~mm}$ corresponds to unit 15b-1. The symbols on the burnup curves correspond to the 24 discrete axial positions of the depletion calculations and should not be interpreted to mean that trays of particles will indeed exist at those locations. The data shown in Figs. 9 and 10 must be used with the information on Tables 4 through 7 for extracting fuel burnup.

Fast neutron fluence ( $\mathrm{E}>183 \mathrm{keV}$ ) is shown in Fig. 11 as a function of axial position in the experiment. Fast neutron flux used to produce the fluence curve is discussed in Appendix A, Sect. A.5. It is a spacially averaged flux in the specimen region (radial and azimuthal) at discrete axial positions over the length of the experiment. Another parameter, the "equivalent HTGR fluence for damage in graphite," 5 can be obtained by multiplying the magnitude of the axial position-dependent fluence in Fig. 11 by the factor 0.940 .

\section{CONCLUSIONS}

The methods for computing particle loadings, the models for computing temperatures, and the basic data given in this report resulted in a design for this experiment which was very predictable; that is, the preirradiation computed temperatures and the observed thermocouple temperatures (once operation began) were in very good agreement. The flux gradients in the HFIR removable beryllium reflector facilities are very steep at the extremities of the experiment, but they are predictable. A consistent set of data for neutron fluxes, cross sections, and thermal properties of materials must be used. All of the necessary data that would be required for designing another experiment of similar design to $\mathrm{HRB}-15 \mathrm{~b}$ have been included in this report. 


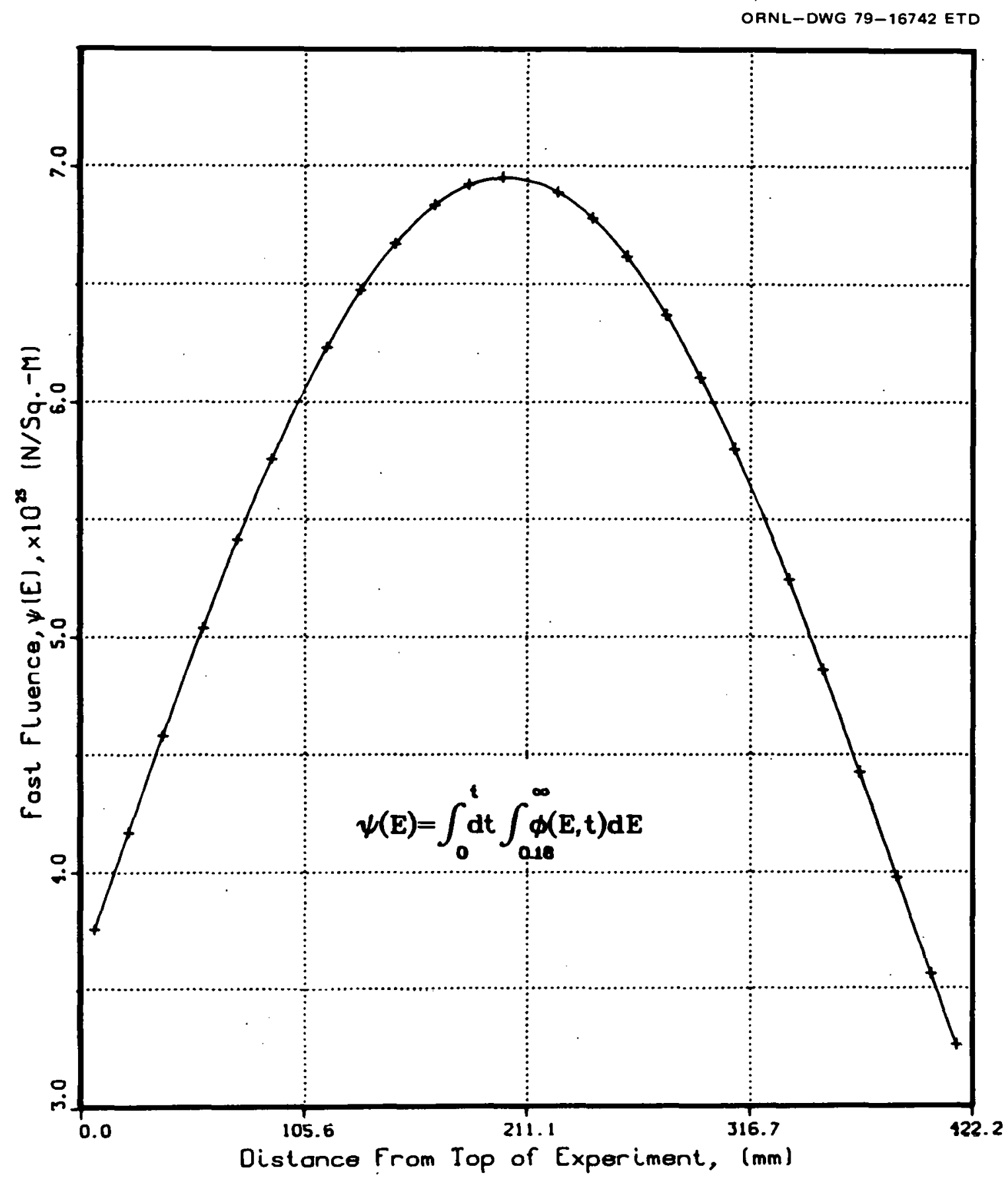

Fig. 11. Experiment HRB-15b, fast neutron fluence at end of test. 


\section{ACKNOWLEDGMENTS}

We are grateful to J. W. Ketterer (General Atomic Corporation) for reviewing our work on particle loadings and to J. C. Cleveland and E. J. Allen for reviewing this report. We express appreciation to W. P. Eatherly and M. J. Kania for advice and data on graphite growth. A special thanks to H. T. Kerr and J. F. Mincey for sharing their knowledge of and experimental data on neutron fluxes and microscopic cross sections. We also appreciate the advice and data on the time behavior of neutron fluxes supplied by B. H. Montgomery and K. R. Thoms. Without the good work of J M Robbins, B. R. Chilcoat, and C. A. Wallace, the experiment would not have been assembled. Many thanks to E. D. Clemmer who operated the experiment and maintained an excellent set of notes during the operating period. Last, but definitely not least, we sincerely appreciate the effort of those responsible for the preparation of this report. The report was typed by members of Mrs. Judy Kibbe's Word Processing group; Mrs. Georgia Bower proofread the draft report; and members of the ETD Publications Office were responsible for the figures and publication of the report. 
Appendix A

DATA AND CALCULATIONAL PROCEDURES

The appendix is subdivided into seven sections according to subject matter. Two computer programs (the thermal program and the utility program) were written specifically for experiment HRB-15b. Neither of these programs will be published in a separate report. The fundamental theory in each of the programs is discussed in Sects. A.1 and A.7 of this appendix.

\section{A. 1 Thermal Analysis Program}

The purpose of this section is to describe the heat transfer equations used in the thermal analysis computer program and to indicate the necessary assumptions required for reducing the general equations to simpler forms. Numerical techniques were also used in the overall program and are described in this section. Units for the various terms appearing in the equations have generally been omitted; a consistent set of units, of course, is implied. The various regions of the experiment can be modeled with concentric cylinders; however, as a separate problem, there was interest in surface temperatures of the spherical particles resting in the drilled holes of each tray. The heat transfer equations that follow are developed in both the cylindrical coordinate system and the spherical coordinate system.

The gelleid lieat conduction equation 13 as followes

$$
k \nabla^{2} T+G=\rho c \partial T / \partial \theta
$$

where

$$
\begin{aligned}
\rho & =\text { density of material, } \\
c & =\text { speciflc lieat, } \\
k & =\text { thermal conductivity, } \\
\mathrm{T} & =\text { temperature, } \\
\theta & =\text { time, } \\
\mathrm{C} & =\text { heat generated by internal, snurces, } \\
\nabla^{2} \mathrm{~T} & =\text { Laplacian operator. }
\end{aligned}
$$


Assume steady state $(\partial \mathrm{T} / \partial \theta=0.0)$ and uniform heat generation rate ( $G=q$, the volumetric heat rate). These assumptions reduce the general equation to the Poisson ${ }^{6}$ equation:

$$
\nabla^{2} \mathrm{~T}=-\mathrm{q} / \mathrm{k}
$$

For a cylinder of radius $r$, neglecting the axial gradient $(\partial \mathrm{T} / \partial z=$ $0.0)$ and the azimuthal gradient $(\partial T / \partial \psi=0.0)$ simplifies the Laplacian to the following expression:

$$
\nabla^{2} T=\frac{1}{r} \frac{\partial}{\partial r}\left(r \frac{\partial T}{\partial r}\right)
$$

For a sphere of radius $r$, neglecting the polar and the azimuthal gradients gives

$$
\nabla^{2} \mathrm{~T}=\frac{1}{\mathrm{r}^{2}} \frac{\partial}{\partial \mathrm{r}}\left(\mathrm{r}^{2} \frac{\partial \mathrm{T}}{\partial \mathrm{r}}\right)
$$

The solution for temperature rise $\Delta T$ across a solid cylinder of radius $r_{1}$ is

$$
\Delta \mathrm{T}=\mathrm{q}_{1} \mathrm{r}_{1}^{2} / 4 \mathrm{k}_{1},
$$

where $q_{l}$ is the volumetric heat rate in the cylinder and $k_{1}$ is the thermal conductivity evaluated at mean temperature. If there are $n$ concentric cylindrical annul $(n>1)$ then the temperature rise across the $n^{i}$ th region is

$$
\begin{aligned}
\Delta T_{(n)}=\frac{q_{(n)}}{4 k(n)}\left[r_{(n)}^{2}-r_{(n-1)}^{2}\right]+\frac{1}{k(n)} \ln \left[\frac{r_{(n)}}{r(n-1)}\right] \\
\times\left\{\left[\sum_{m=1}^{n-1} \frac{Q(m)^{r}(m)}{A_{(m)}}\right]-\frac{q_{(n)^{2}(n-1)}}{2}\right\} .
\end{aligned}
$$


The above equation is strictly applicable for conduction in the $n$ 'th region having an outside radius of $r_{(n)}$ and inside radius of $r_{(n-1)}$. The heat transfer rate is $Q$, and $A$ is the surface area through wh1ch heat must flow.

The solution for $\Delta T$ across a solid sphere of radius $r_{1}$ is

$$
\Delta \mathrm{T}=\mathrm{q}_{1} \mathrm{r}_{1}^{2} / 6 \mathrm{k}_{1},
$$

and for $n$ concentric spherical annuli $(n>1), \Delta T$ for the $n^{\prime}$ th region is as follows:

$$
\begin{aligned}
& \Delta T_{(n)}=\frac{q(n)}{6 k(n)}\left[r_{(n)}^{2}-r_{(n-1)}^{2}\right]+\frac{1}{k(n)}\left[\frac{r_{(n)}-r(n-1)}{r_{(n)}(n-1)}\right] \\
& \times\left\{\left[\sum_{m=1}^{n-1} \frac{Q(m) r^{r^{2}(m)}}{A_{(m)}}\right]-\frac{q(n)^{r^{3}(n-1)}}{3}\right\} .
\end{aligned}
$$

The above equations illustrate the difference in conductive heat transfer for spheres and 1-D cylinders.

Some of the transparent regions, such as the gas gaps, will transport part of the heat by conduction Qc and the remainder by radiation Qr. Convection should be negligible and was ignored. If the $n$ 'th region was transparent $(n>1)$, the heat balance equation would be

$$
Q \mathrm{r}+Q c=\sum_{m=1}^{\mathrm{n}-1} Q_{(m)}
$$

The rate of heat transfer by conduction across a cylindrical annulus, with no internal heat generation, is

$$
Q c=\left[k_{(n)} \Delta T(n){ }_{(n-1)}^{A}\right] /\left\{r_{(n-1)} \ln \left[r_{(n)} / r_{(n-1)}\right]\right\} .
$$


The rate of heat transfer by conduction across a spherical annulus, also with no internal heat generation, is

$$
Q c=\left[k_{(n)} \Delta T_{(n)} A_{(n-1)} r_{(n)}\right] /\left\{r_{(n-1)}\left[r_{(n)}-r_{(n-1)}\right]\right\} .
$$

The radiative heat transfer rate for both concentric cylinders and concentric spheres is

$$
Q r=0.1714 F_{(n-1)}\left\{\left[T_{(n-1)} / 100\right]^{4}-\left[T_{(n)} / 100\right]^{4}\right\} .
$$

We call the factor $F$ a "shape" factor. In the literature, $F$ has also been called the geometric, view, or angle factor. For concentric cylinders and concentric spheres, ${ }^{7} \mathrm{~F}$ is a function of emissivity $\varepsilon$ and surface area.

$$
F=1 /\left[1 / \varepsilon_{(n-1)}+n\left(1 / \varepsilon_{(n)}-1\right)\right]
$$

For cylinders,

$$
n=r_{(n-1)} / r_{(n)}
$$

For epheree,

$$
n=\left[r_{(n-1)} / r_{(n)}\right]^{2}
$$

Temperature-dependent thermal conductivity appearing in the conduction equations has been expressed in polynomial form:

$$
k_{(n)}=\sum_{i=0}^{N} c_{(i)}(\bar{r})^{1} .
$$

Coefficients $c_{(1)}$ for polynomials of degree $N$ are generated from basic thermal conductivity data by the utility program (see Sect. A.7). Values for $k_{(n)}$ in the above equation are based on the arithmetic mean temperature $(\bar{T})$ of the annulus. Temperature rise $\Delta T$ across any region depends on $k$, and $k$ depends on the inside and outside surface temperatures of that region; thus, an iterative procedure was required. First 
estimate for $k$ was based on a known outside surface temperature for the region, then $\Delta \mathrm{T}$ across the region was computed using that estimate for $\mathrm{k}$. Thermal conductivity was reevaluated based on the first estimate for mean temperature of the annulus before repeating the process. Five iterations were considered adequate to obtain converged temperatures. These are defined as the "inner" iterations.

Once the temperatures have been computed for each regional surface of the model, the radil are then corrected for thermal expansion. Surface temperatures are then recomputed based on new estimates for the radii. These are the "outer" iterations.

Thermal expansion coefficlent, $\alpha$, for the material in each region was calculated from the following equation:

$$
\alpha=\beta_{1}+\beta_{2} \bar{T}
$$

The expansion coefficients are the average from $70^{\circ} \mathrm{F}$ to $\overline{\mathrm{T}}$, where $\overline{\mathrm{T}}$ is the region mean temperature. Values for the constants $\beta_{1}$ and $\beta_{2}$ must be supplied to the code as input data.

The estimate for radil for the $(J+1)$ outer iteration is based on radil from the previous iteration $(\mathrm{J})$ as indicated by the following expression:

$$
r_{(J+1)}=r_{(J)}+\gamma\left\{r_{0}[1+\alpha(\bar{T}-70)]-r_{(J)}\right\}
$$

The radius $r_{0}$ is the "cold" $\left(70^{\circ} \mathrm{F}\right)$ radius, and $\gamma$ is a relaxation factor. A value of one-third was satisfactory for $\gamma$. Eight outer iterations were maximum.

The thermal code treats temperature dependence of thermal conductivity (inner iterations) and thermal expansion of solid materials (outer iterations). The procedures are the same as used in the GENGTC 8 code. The thermal program was, in fact, an outgrowth from GENGTC and, as in GENGTC heat transfer from the secondary vessel to reactor coolant, is evaluated by the following expression:

$$
T_{s}=T_{\infty}+(Q / h A) \text {. }
$$


Ts is the outside surface temperature of the secondary vessel; To is the bulk temperature of the reactor coolant (water) flowing in the annulus external to the secondary vessel (assumed to be $130^{\circ} \mathrm{F}$ ). The convective heat transfer coefficient $\mathrm{h}$ was assumed to be $3490 \mathrm{Btu} / \mathrm{hr} \cdot \mathrm{ft}^{2} \cdot{ }^{\circ} \mathrm{F}$ for the experiment in the RB-5 facility. Total heat load $Q$ and external surface area $A$ are each per unit length of experiment. See Sect. A.2 for discussion of thermal properties of the materials in the experiment. Graphite growth was also included in the thermal model. See Sect. A.3 for detalls.

\section{A. 2 Properties - Emissivity, Thermal Conductivity, Coefflcienc of Expansinn, and lensity for Materials in Experiment $\mathrm{HRB}-15 \mathrm{~b}$}

The purpose of this section is to document the density and thermal properties of the materials in the experiment, that is, to 1 ist the values that were used in the thermal program.

Surface emissivity was required for both graphite and stainless steel in computing radiative heat transport. Values of 0.9 for graphite and 0.7 for stainless steel were assumed.

Coefficient of 1 inear expansion was required to compute hot dimensions for the center spine (graphite), graphite trays, and the stainless steel primary and secondary vessels. Consistent with the equation for the expansion coefficient described in Sect. A. 1 , the constants are as follows :

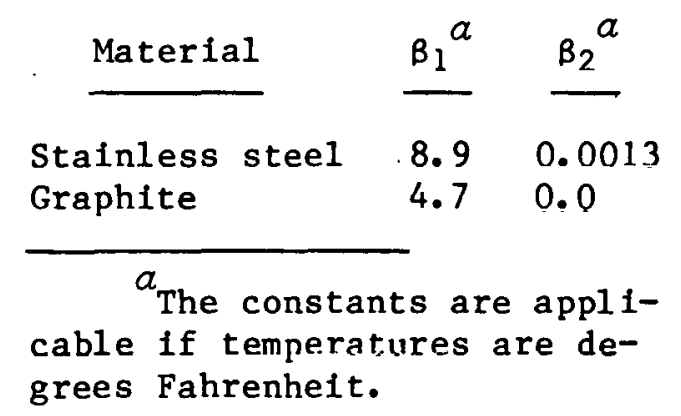

Density of materials was used in computing heat sources from nuclear heating; see Sect. A.4 for a discussion of nuclear heating in graphite and stainless steel. Allowing for the penetrations in the graphite parts, 
the effective room temperature density for graphite was $1.555 \mathrm{~g} / \mathrm{cm}^{3}$. A value of $7.98 \mathrm{~g} / \mathrm{cm}^{3}$ was used for stainless steel (at room temperature). The true temperature-dependent thermal conductivity ${ }^{9}$ for the graphite trays must be adjusted to account for the holes or penetrations in the trays and for radiation damage. Accounting for the drilled holes in the trays yields an effective $k$ that is about $60 \%$ of the true graphite thermal conductivity. Effective $k$ was determined from a separate 3-D mock-up of a single graphite tray. Fortunately, the effective conductivity was relatively insensitive to temperature change over the range of expected tray operating temperatures $\left(700\right.$ to $950^{\circ} \mathrm{C}$ ) and could be assumed temperature independent.

Effective tray (graphite) thermal conductivity used in the thermal analysis program is as follows:

\begin{tabular}{lc}
$\begin{array}{l}\text { Time } \\
\text { BOC-1 } a\end{array}$ & $k\left(\mathrm{Btu} / \mathrm{hr} \cdot \mathrm{ft} \cdot{ }^{\circ} \mathrm{F}\right)$ \\
$\begin{array}{l}\text { BOC-2 } \\
\text { Midcycle 2 }\end{array}$ & 17.14 \\
Cycles 3t & 14.0 \\
\hline & 10.28 \\
$a_{\mathrm{BOC}-1}=$ beginning of \\
cycle No. 1.
\end{tabular}

Thermal conductivity for the stainless steel vessels ${ }^{9}$ was assumed to have a linear temperature dependence; $k$ was computed from the following cquation for the 300 series stainless:

$$
k_{(t)}=8.5+0.00417 \bar{t} \text {, }
$$

where $\bar{t}$ is the arithmetic mean temperature of the vessel in degrees Fahrenheit, and $\mathrm{k}$ is in units of $\mathrm{Btu} / \mathrm{hr} \cdot \mathrm{ft} \cdot{ }^{\circ} \mathrm{F}$.

Helium, neon, and mixtures of hellum and neon were used as sweep gas and for particle temperature control. Temperature-dependent thermal conductivity for the binary gas mixture was computed by the method described in Sect. A.7 on the utility program. For a specific gas mixture, thermal conductivity as a function of temperature (degrees Fahrenheit) could be represented by second-degree polynomials, that is, computed from equations 
of the form

$$
k_{(t)}=A_{0}+A_{1} \bar{t}+A_{2}(\bar{t})^{2}
$$

The coefficients $A_{0}, A_{1}$, and $A_{2}$ are 1 isted in Table $A_{1} 1$. Each set of coefficients is applicable to a specific helium-neon gas mixture as indicated in the table.

Table A. 1. Data for equation used to compute temperature-dependent thermal conductivity for mixtures of hellum and neon

\begin{tabular}{|c|c|c|c|}
\hline $\begin{array}{l}\text { MOLE-FRAE TION } \\
\text { OF HE IN MIX. }\end{array}$ & 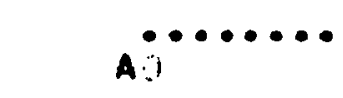 & $\begin{array}{c}\text { COEFFICIENTS } \\
\text { AI }\end{array}$ & $\cdots \cdots \dot{A 2}$ \\
\hline $\begin{array}{l}1.01 \\
0.93 \\
0.83 \\
0.70 \\
0.63 \\
0.53 \\
0.45 \\
0.43 \\
0.35 \\
0.39 \\
0.25 \\
0.21 \\
0.15 \\
0.19 \\
0.05 \\
0.0\end{array}$ & $\begin{array}{l}0.81361 E-01 \\
0.73746 E-01 \\
0.67026 E-01 \\
0.60950 E-01 \\
0.54301 E-01 \\
0.49621 E-01 \\
0.46953 E-01 \\
0.44979 E-01 \\
0.42040 E-01 \\
0.40256 E-01 \\
0.37496 E-01 \\
0.36196 E-01 \\
0.33281 E-01 \\
0.32381 E-01 \\
0.29360 E-01 \\
0.28211 E-01\end{array}$ & $\begin{array}{l}0.8822 U E-04 \\
0.7936 U E-04 \\
0.71230 E-04 \\
0.63369 E-04 \\
0.59440 E-04 \\
0.50930 E-04 \\
0.48036 E-04 \\
0.45100 E-04 \\
0.43065 E-04 \\
0.40320 E-04 \\
J .38445 E-04 \\
0.35250 E-04 \\
0.34143 E-04 \\
0.30670 E-04 \\
0.30127 E-04 \\
0.27050 E-04\end{array}$ & $\begin{array}{l}-0.16000 E-08 \\
-0.18000 E-08 \\
-0.18000 E-08 \\
-0.17296 E-08 \\
-0.24000 E-08 \\
-0.17000 E-08 \\
-0.16945 E-08 \\
-0.16000 E-08 \\
-0.17120 E-08 \\
-0.16000 E-08 \\
-0.16992 E-08 \\
-0.15000 E-08 \\
-0.16630 E-08 \\
-0.13000 E-08 \\
-0.16088 E-08 \\
-0.13000 E-08\end{array}$ \\
\hline
\end{tabular}

\section{A. 3 Graphite Growth}

The Poco graphite (AFX-9Q) trays will "grow" as a function of fast neutron fluence and perhaps also as a function of temperature. Neglecting temperature effects and normalizing the axial position-dependent fast neutron fluence $(\psi)$ to $1.0 \times 10^{21}$ neutrons $/ \mathrm{cm}^{2}$, that is,

$$
\psi(z) \equiv\left[\int_{\text {time }} \mathrm{dt} \int_{\mathrm{E}=0.18 \mathrm{MeV}}^{\infty} \phi(E, z) \mathrm{dE}\right] /\left(1.0 \times 10^{21}\right),
$$


allowed us to compute the ratio of tray radius $r *$ after exposure relative to the intial (unirradiated) tray radius $r_{0}$ from the following expression:

$$
r^{* / r_{0}}=1.0+\left[a_{1} \psi(z)+a_{2} \psi_{(z)}^{2}+a_{3} \psi_{(z)}^{3}+a_{4} \psi_{(z)}^{4}\right] f
$$

The coefficients 10 are as follows:

$$
\begin{aligned}
& a_{1}=6.69103 \mathrm{E}-03, \\
& a_{2}=9.14204 \mathrm{E}-04, \\
& a_{3}=-4.06037 \mathrm{E}-04, \\
& a_{4}=2.58982 \mathrm{E}-05
\end{aligned}
$$

Neutron flux $\phi(E, z)$ is discussed in Sect. A. 5 .

Graphite growth was assumed to be isotropic, that is, not preferential in any particular direction. Growth can be properly accounted for in the 1-D cylindrical heat transfer model by correcting both the radius of the graphite components, $r=r_{0}\left(r * / r_{0}\right)$, and the graphite density, $\rho=\rho_{o} /\left(r * / r_{o}\right)^{3}$. Thermal expansion was treated as an additional effect on tray physical dimensions.

The factor $f$ was included in the growth equation as a means for normalizing the expression to the "true" growth. There will be some unique value for the gross correction (f) which minimizes the deviation between the eight measured (thermocouple) temperatures and the corresponding computed temperatures. The thermocouple temperatures are listed in sect. A.6. The justification for including $f$ in the equation is: (1) graphite growth may be a function of temperature as well as a function of fast neutron fluence, and, if true, the equation (when $f=1$ ) could be representative of graphite growth at specimen temperatures other than the actual graphite operating temperatures in the experiment; and (2) the growth equation also may be somewhat sensitive to the type or grade of graphite subjected to irradiation. The value for $f$ was determined only from thermocouple readings taken during the time the experiment was operated with $100 \%$ helium sweep gas. The reason for this is that temperature-dependent thermal conductivty for hellum gas appears to be well known, whereas there may be some uncertainty in thermal conductivity for mixtures of helium and neon. 
During the operating history of the experiment, a control plot similar to that shown in Fig. A.l was maintained for graphite growth. The data shown in Fig. A.l are applicable to the trays in the vicinity of reactor horizontal midplane (HMP). Radius ratios predicted by the equation (with $f=1.0$ ) are compared with radius ratios (labeled, "best fit to Exp.") which would be required to obtain agreement between calculated temperatures and measured temperatures. During first cycle operation (fluence $<1.0 \times 10^{21}$ neutrons $/ \mathrm{cm}^{2}$ ), we could obtain agreement between calculated and measured temperatures only if graphite growth were assumed to be essentially zero. Tray average temperatures during the first cycle were, at most, about $775^{\circ} \mathrm{C}$. Starting with the second cycle, tray average temperatures were increased about $75^{\circ} \mathrm{C}$ in the trays around HMP. As can be seen by the data in Fig. A. 1, a sudden and significant increase in radius ratio was required to produce agreement between calculated and measured temperatures.

Finally, although computed temperatures for experiment $H R B-15 b$ were very sensitive to gap thickness, we cannot guarantee that the "best fit" trend in radius ratio shown in $\mathrm{Fig}$. A. 1 is necessarily correct. The following assumptions were made: (1) the coefficient of expansion for graphite (Sect. A.2) is unaffected by irradiation; however, it may not be; (2) the specimen trays are always perfectly centered with respect to the primary vessel inner wall; this also may not be true; (3) the shape of the trays remained perfect circles throughout the irradiation history; neutron gradients across the experiment may create a nonctrcular geometry with increased exposure which might affect calculated temperatures; and (4) the thermocouple readings were always correct, that is, that the eight type $k$ Chromel-Alumel thermocouples are stable and did not decalibrate during the time the experiment resided in-reactor.

On the positive side, there 1 at least a bit of evidencell,12 that, at moderate temperatures, high-density graphite can be dimensionally quite stable (see the curve labeled "Pitner" in Fig. A.1). 


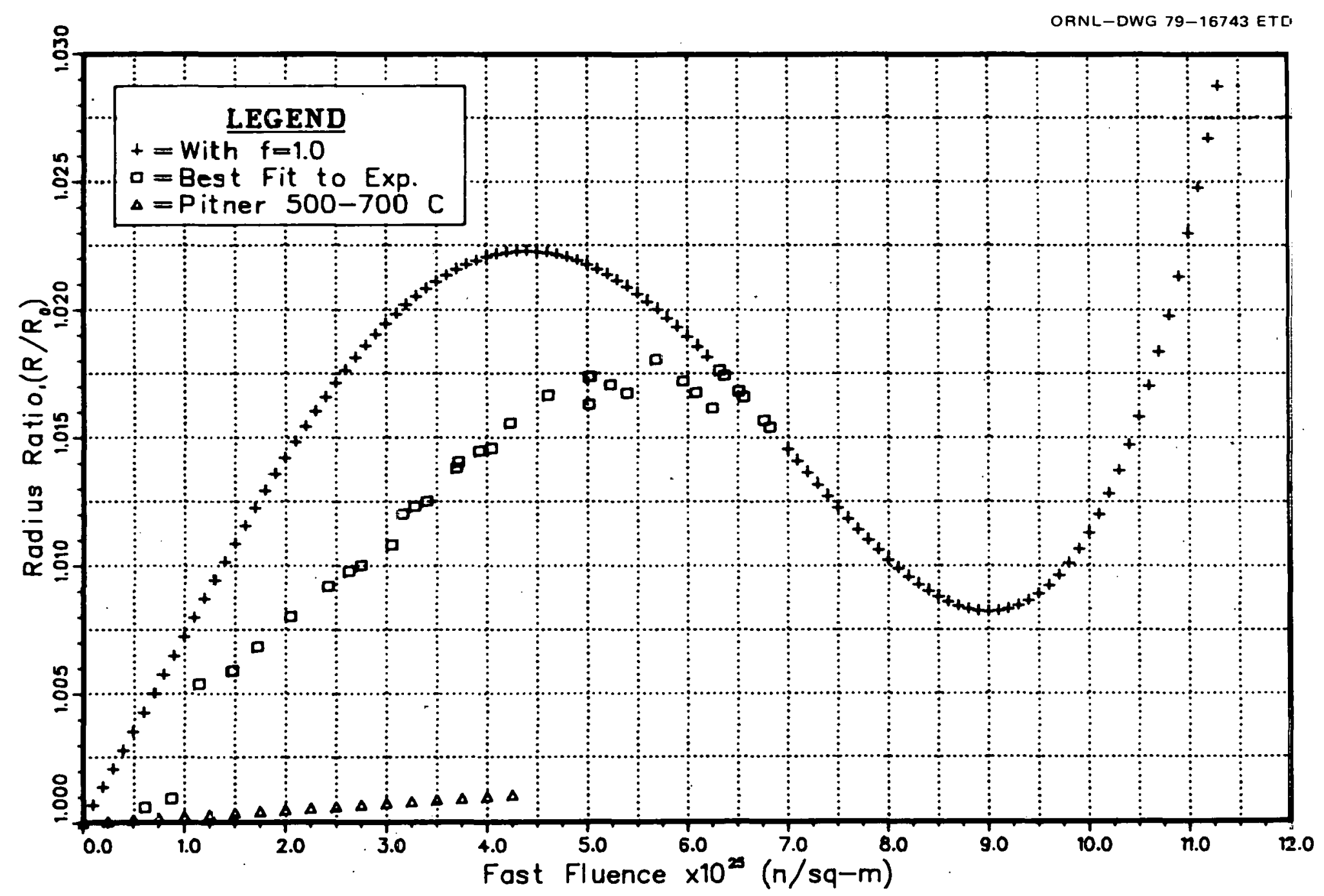

Fig. A. 1. Dimensional stability of Poco graphite. 


\section{A. 4 Nuclear Heating in Graphlte and Stainless Steel}

Basic data for nuclear heating in both graphite and stainless steel were obtained from the 1iterature. 13 It was our understanding that the data were experimentally determined from calorimeters placed in the HFIR-RB facilities. A reasonable assumption is that the integral measurements would include neutron scattering, as well as beta-gamma interactions with matter, and, thus, the quantity is defined as nuclear heating. The product of three torms - nuclear heating in a particular material (watts per gram), the effective density of that material in a particular region of the experiment (grams per cubic centimeter), and the regional volume (cubic centimeter) - yields a regional heat source that is independent of the fissions occurring in the particle kernels. The above heat source would be present even if the trays were empty.

The magnitude of nuclear heating in both graphite and stainless steel from the literature comprises the data base. For use in the thermal program, it was necessary to compute watts per gram of graphite (or watts per gram of stainless steel) as a function of both axial position and time into each cycle. We chose to subdivide cycle time into increments of one full power day. Using the method of least squares (Sect. A.7), magnitude of nuclear heating vs axial position at some discrete time Into the cycle could be expresed by analytical functions. Good fits to the basic data were obtained with polynomials of fourth degree. At a particular time $t$ full power days into each cycle, nuclear heating in graphite (or stainless steel) at some axial position $z$ can be expressed by equations of the following form:

$$
P(t, z)=\sum_{\ell=0}^{4} a(t, \ell) z^{\ell},
$$

where $a(t, l)$ is the $\ell^{\prime}$ th coefficient for the polynomial and $P(t, z)$ is watts per gram of graphite (or watts per gram of stainless steel) at times $t$ and $z$ inches from the top of the active core. The coefficients (i.e., the a's in the above equation) for graphite and stainless steel are given 
In Tables A. 2 and A. 3, respectively. The coefficients, of course, resulted from statistical analysis of the basic data.

The above equation was programmed in our thermal code for use in computing nuclear heating in both the graphite trays and the stainless steel vessels. We found that the method (and the coefficients) described in this section gave good results for nuclear heating in both the graphite trays and the stainless steel vessels at all times during the irradiation history of the experiment.

Results for nuclear heating in graphite as a function of distance from the top of the active reactor. core are shown in Fig. A.2.

The curves in Fig. A. 2 also 111 ustrate the change in magnitude (watts per gram of graphite) during a typical reactor cycle, that is, from beginning of cycle (BOC) to end of cycle (EOC) ( $21 \mathrm{full}$ power days). Similar results for nuclear heating in stainless steel are shown in Fig. A. 3. Note that the peak nuclear heating tends to occur slightly above the reactor HMP (HMP $=254 \mathrm{~mm})$.

\section{A. 5 Neutron Fluxes}

Fast neutron flux (E $>183 \mathrm{KeV}$ ) in units of neutrons per square centimeter per second at $Z$ inches from the top of HFIR active core can be evaluated from the following equation:

$$
\underset{\substack{\phi(Z) \\ E>0.18 \mathrm{MeV}}}{\infty} \int_{0.18 \mathrm{MeV}}^{\infty} \phi(E, Z) \mathrm{dE}=\sum_{\ell=0}^{4} c(\ell) \mathrm{z}^{\ell} .
$$

The coefficients are as follows:

$$
\begin{aligned}
& c(0)=1.83215 \times 10^{14}, \\
& c(1)=3.84547 \times 10^{14}, \\
& c(2)=3.04433 \times 10^{12}, \\
& c(3)=-5.43494 \times 10^{11}, \\
& c(4)=1.44914 \times 10^{10}
\end{aligned}
$$

Coefficients for the above equation were generated by the utility program (Sect. A.7). Data for magnttude of axial position-dependent fast 
Table A.2. Time-dependent axlal nuclear heating for graphite in HFIR RB-5 facility

\begin{tabular}{|c|c|c|c|c|c|c|c|}
\hline $\begin{array}{l}\text { IIME } \\
\text { IFULL }\end{array}$ & $\begin{array}{l}\text { INIO CYCLE } \\
\text { PUWER DAYSI }\end{array}$ & A? & & -COCFFIC & $\begin{array}{c}\text { IS FUR THE } \\
\text { \& } 2\end{array}$ & $\begin{array}{c}\text { JUATIONS. } \\
\text { A3 }\end{array}$ & $A_{4}$ \\
\hline & $\begin{array}{l}3 . \\
1 . \\
2 . \\
3 . \\
4 . \\
5 . \\
0 . \\
7 . \\
0 . \\
9 . \\
13 . \\
11 . \\
12 . \\
13 . \\
14 . \\
15 . \\
10 . \\
17 . \\
18 . \\
19 . \\
20 . \\
21 . \\
22 . \\
23 .\end{array}$ & 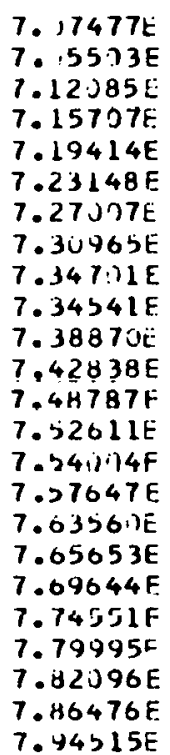 & $\begin{array}{l}00 \\
00 \\
0 j \\
00 \\
0.1 \\
00 \\
00 \\
05 \\
03 \\
00 \\
00 \\
03 \\
00 \\
00 \\
01 \\
05 \\
00 \\
00 \\
03 \\
00 \\
00 \\
011 \\
03 \\
00\end{array}$ & 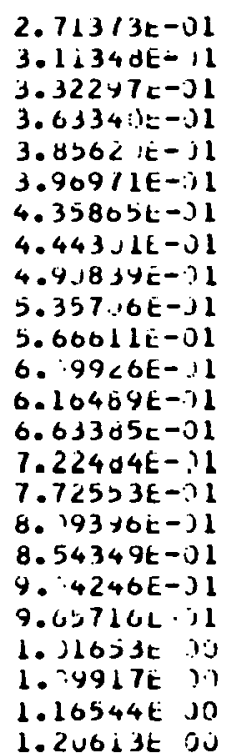 & 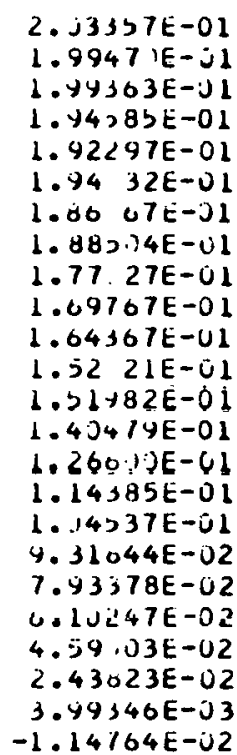 & 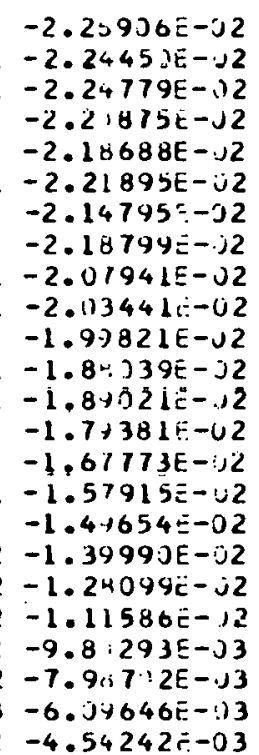 & $\begin{array}{l}5.91907 E-04 \\
5.84365 E-04 \\
5.82976 E-04 \\
5.71366 E-04 \\
5.02584 E-04 \\
5.75338 E-04 \\
5.53455 E-04 \\
5.08580 E-J 4 \\
5.35544 E-04 \\
5.26911 E-14 \\
5.19171 E-04 \\
4.8449 J E-04 \\
4.93395 E-04 \\
4.04892 E-04 \\
4.33387 E-34 \\
4.08827 E-04 \\
3.87245 E-04 \\
3.61495 E-04 \\
3.314436 E-04 \\
2.81542 E-04 \\
2.47083 E-04 \\
1.78559 E-04 \\
1.44331 E-04 \\
9.77415 E-03\end{array}$ \\
\hline
\end{tabular}

Table A.3. Time-dependent axial nuclear heating for stainless steel in HFIR RB-5 factility

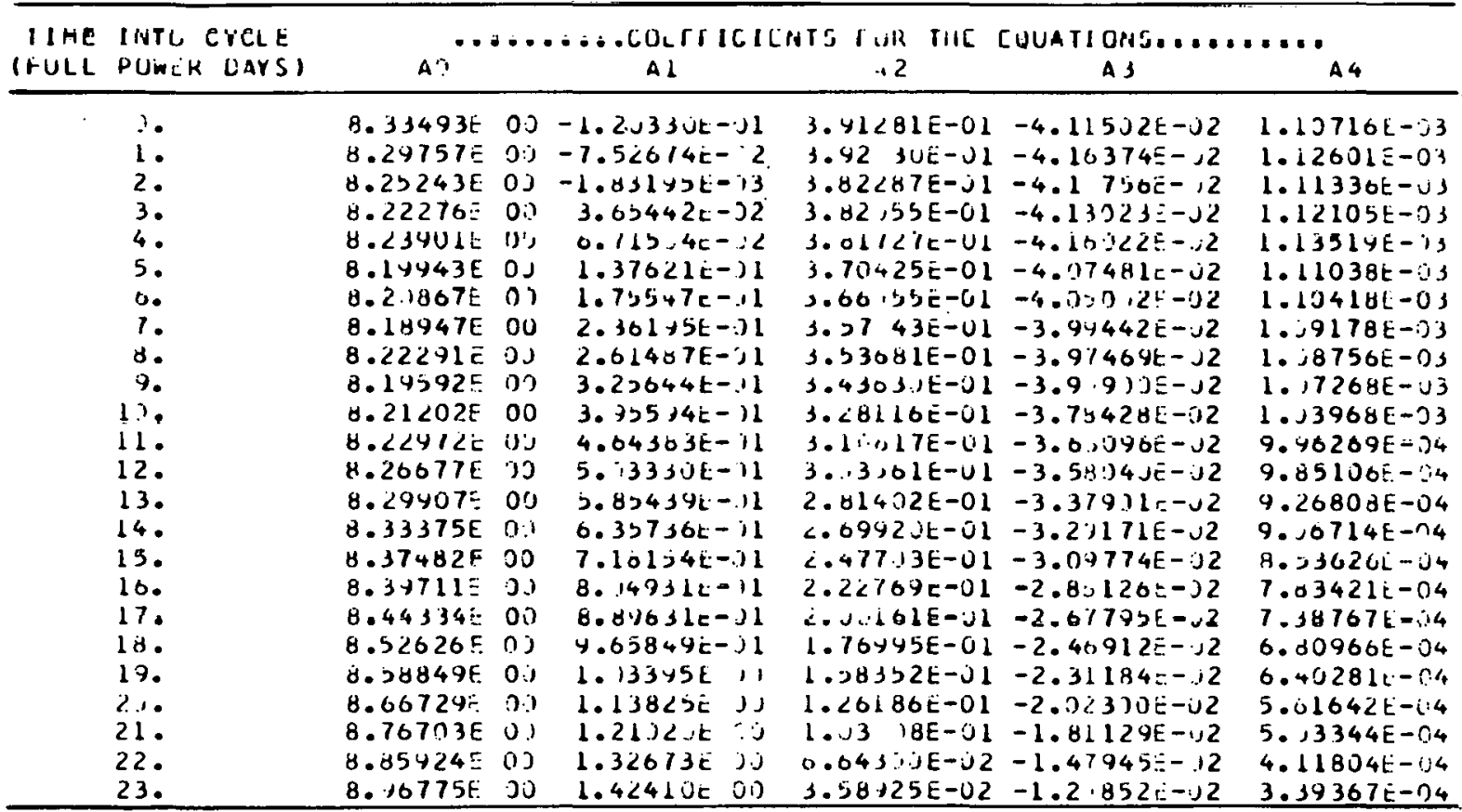




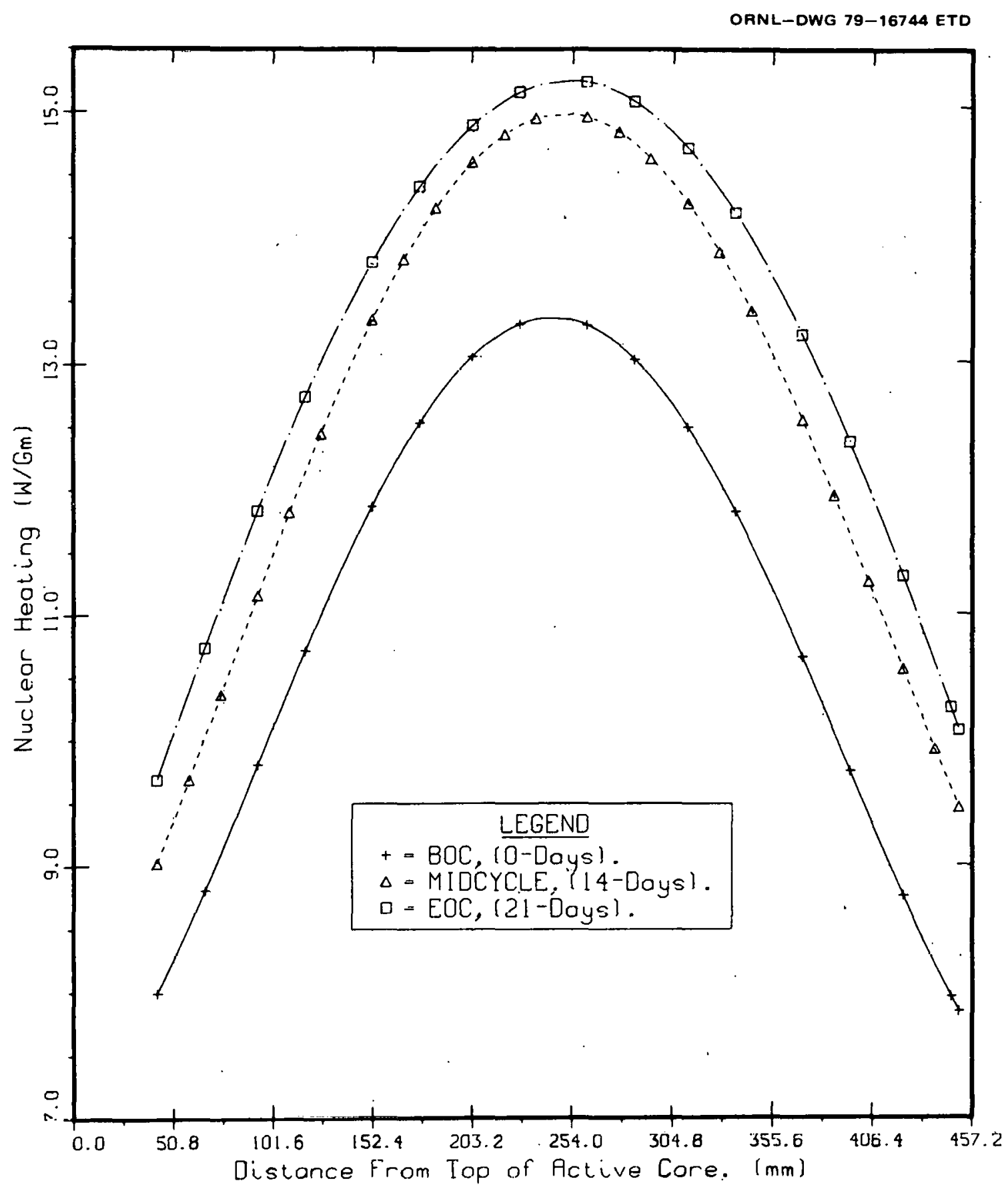

Fig. A.2. Nuclear heating in graphite for experiment $H R B-15 b$ in HFIR Facility RB-5. 


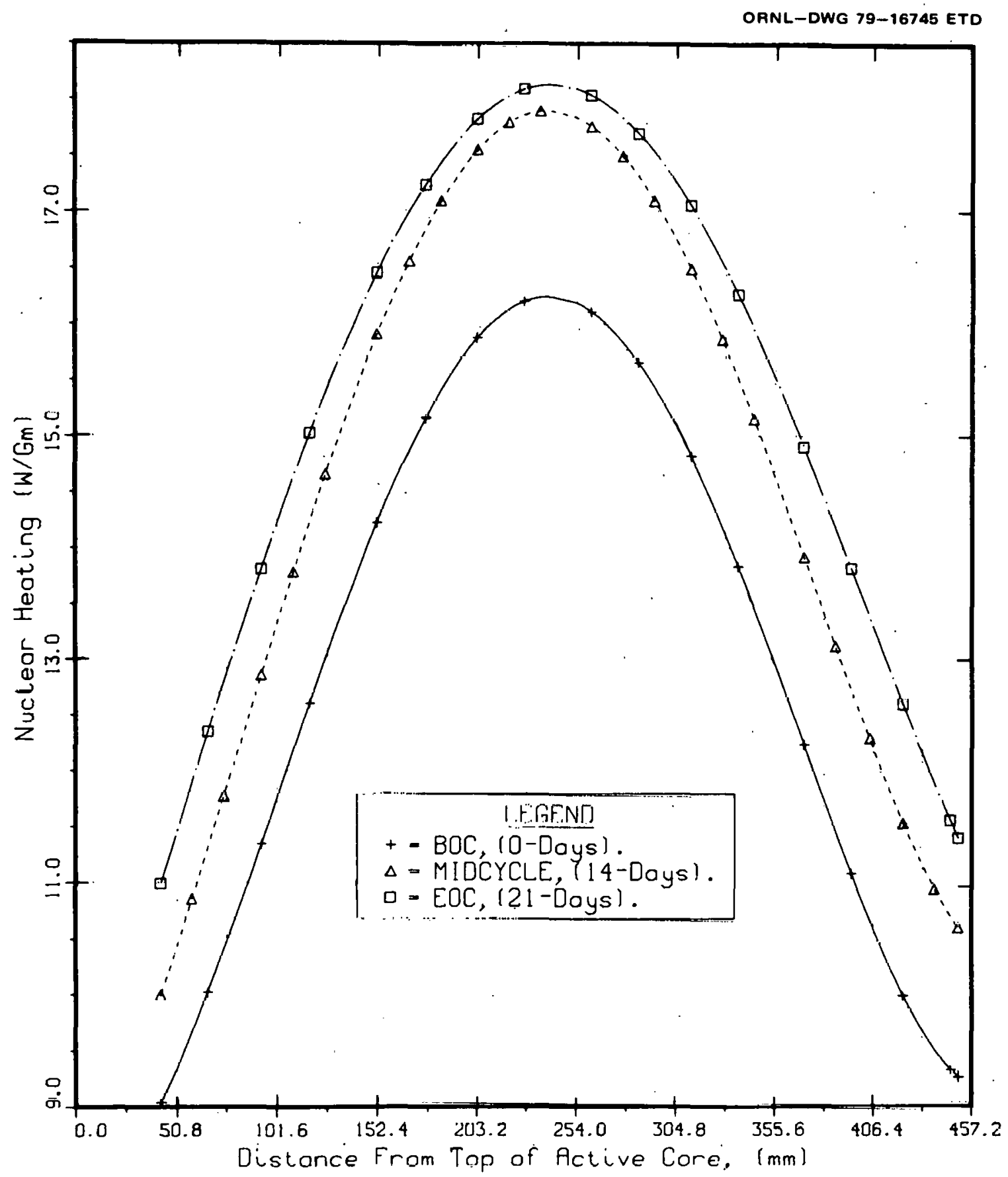

Fig. A.3.' Nuclear heating in stainless steel for experiment HRB-15b in HFIR Facility $\mathrm{RB}-5$. 
neutron flux were obtained from dosimeter experiments ${ }^{3}$ irradiated in HFIR facility $R B-3$. Experiment $H R B-15 b$ resided in the $R B-5$ facility. The two facilites are each in the removable beryllium reflector, and each are at the same radius from core center. Azimuthal flux symmetry is generally assumed for the HFIR; therefore, flux data obtained in RB-3 should also be applicable to RB-5. Fast neutron fluxes in the RB-5 facility are not symmetrical about reactor HMP in the axial (top to bottom) direction. ${ }^{14}$ Fast neutron fluxes peak $\sim 1 \mathrm{~cm}$ above HMP. Axial flux asymmetry is reflected in the above equation for the fast neutron flux.

Reasons for asymmetric axial flux distribution in the RB-5 facility can be explained with the aid of a schematic diagram for the reactor (Fig. A.4). HFIR is a flux trap reactor, cylindrical in shape. In the innermost (target) region are facilities for irradiation testing which require the maximum flux magnitude. Surrounding the target region is the cylindrical reactor core. The actual core consists of two concentric cylindrical sections, which, to avoid confusion, have not been shown in Fig. A.4. External to the core are the cylindrical reactor control "plates." The innermost cylindrical reactor control plate moves toward the bottom of the core as fuel depletes during the cycle. The outermost cylindrical reactor control "plate" consists of four quadrants which can be moved independently (but usually are moved as a group) toward the top of the core with fuel burnout. We therefore can best describe HFIR control plates (or control rods) as being two concentric cylinders, one smaller than the other, with the innermost moving toward the bottom of the core and the outermost moving toward the top of the core as fuel depletes during the cycle. External to the reactor control region is the beryllium reflector. The beryllium reflector is also fabricated in two parts; the innermost region is called the removable beryllium reflector and the outermost region is called the permanent beryllium reflector. Facility $\mathrm{RB}-5$ is in the innermost (removable) beryllium reflector region. The reactor is cooled (and neutrons moderated) by 1 ight water. Water is present in the target and core and surrounds the control plates and flows through an annulus external to the experiment in the RB-5 facility. The control plates have a section containing tantalum (cross-hatched in Fig. A.4), a section containing europium oxide (shaded region in Fig. A.4), and 


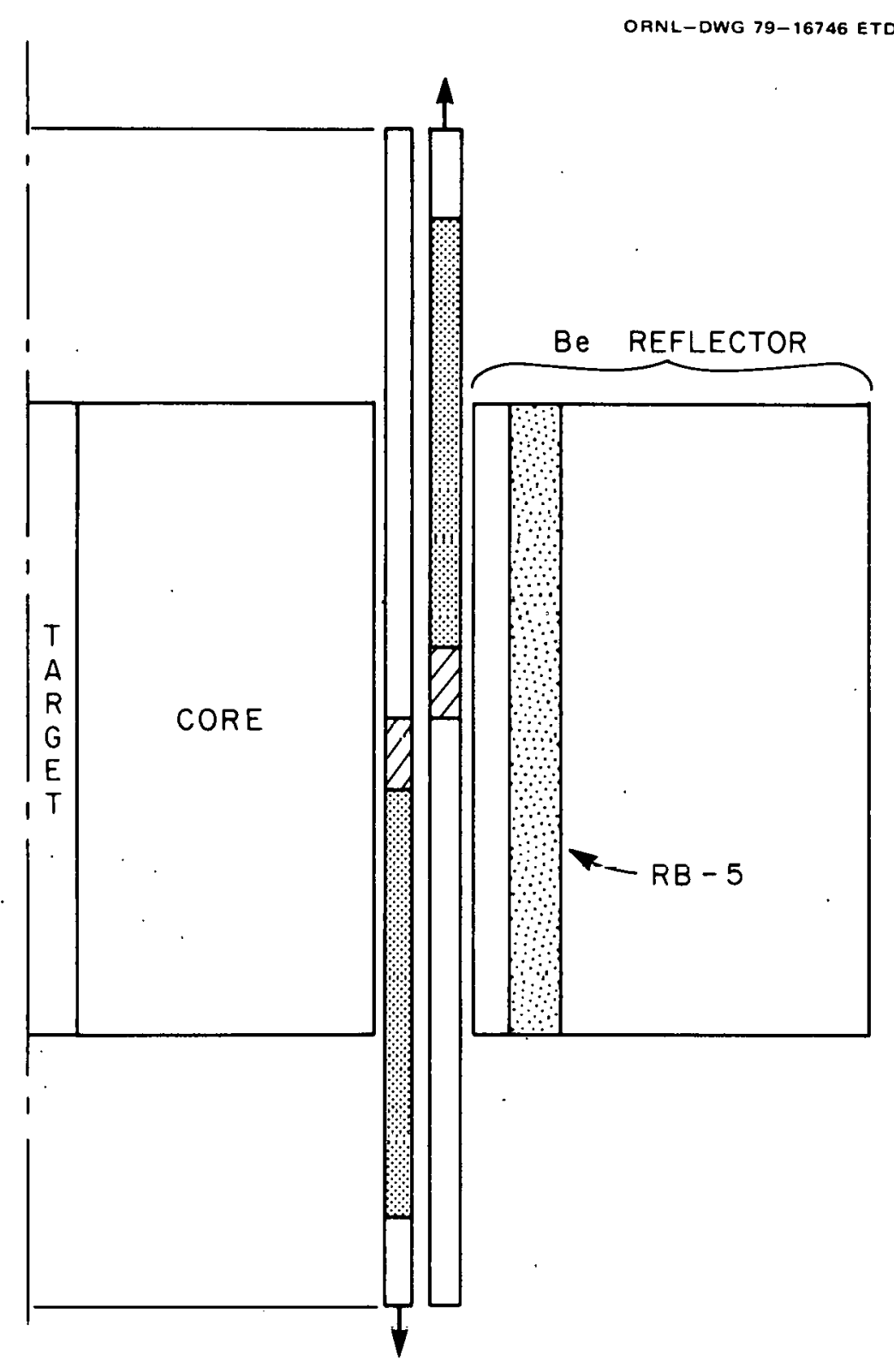

Fig. A.4. Schematic diagram of HFIR to illustrate location and management of control "rods."

aluminum followers (unshaded region in Fig. A.4). The control poisons (tantalum and $\mathrm{Eu}_{2} \mathrm{O}_{3}$ ) are positioned approximately as shown in Fig. A.4 at the beginning of cycle. In the upper half of the reactor, fast neutrons born in the core, escaping and heading toward the experiment (in $\mathrm{RB}-5$ ) first encounter the aluminum-water region of the inner control plates and then the absorber region of the outer control plates before 
entering the beryllium reflectors. Many escaping neutrons will suffer scattering collisions in traversing the aluminum-water section, and part of the scattered neutrons will be returned to the core. Any neutrons returned to the core can cause fission with fuel nuclei and thus increase the source of next generation fast neutrons in that part (upper half) of the core. Neutrons escaping the bottom half of the reactor first encounter the control absorbers. Most low-energy neutrons will be absorbed and not reflected back to the core from that region. Many very highenergy neutrons will pass through the tantalum and $\mathrm{Eu}_{2} \mathrm{O}_{3}$ absorbers and may suffer scattering collisions with the aluminum-water section and/or the beryllium reflector. Some scattering events will send the neutrons back toward the core. However, the energy-degraded neutrons must then return through the control absorbers with a much higher probability for absorption with the absorber atoms. Neutrons escaping the core thus have a lower probability of being returned to the core in the bottom half of the reactor than in the top half of the reactor. Therefore, the fission rate (and source of next generation fast neutrons) will be somewhat greater in the top half of the reactor, which helps to explain fast neutron peaking above HMP in the RB-5 facility.

Low energy ( $E<0.414 \mathrm{eV}$ ) neutrons peak slightly below HMP in the RB-5 facility. 14 With reactor control plates positioned as shown in Fig. A.4, a large fraction of these thermal neutrons escaping the core are absorbed in the control region and do not arrive at the RB-5 facility. It is the slowing down source which probably accounts for the asymmetric thermal neutron distribution in the facility. Neutrons with higher energies escaping the lower half of the core have a greater probability than thermal neutrons for penetrating the control region (inner control plates) and may subsequently suffer scattering collisions in the aluminum-water region of the outer control plates and in the beryllium reflector on the way toward the RB-5 facility, thus augmenting the slow neutron flux in the lower half of the RB-5 facllity. Some of the epithermal neutrons escaping the top half of the core are first slowed down in the aluminum-water region of the inner control plates before arriving at the strong absorber region (outer control plates). Thus, a larger fraction of escaping epithermal neutrois are subsequently absorbed in the reactor control plates 
In the top half of the reactor compared with the epithermal neutrons that escape the bottom half of the core. Toward the end of the cycle, axtal distribution of slow neutrons will approach symmetry about HMP in the RB-5 facllity.

Most of the fissions occurring in fuel contained in the experiment result from slow neutron fission (1.e., with neutrons whose energles are less than a few electron volts). In a one-group model, fission rate is the product of total neutron flux and effective (or weighted) microscopic fission cross section for the fissile nuclides. To account for axial flux asymmetry, the time-averaged total neutron flux was assumed to peak about $1 \mathrm{~cm}$ below HMP in the RB-5 facility.

Because of HFIR control rod management, time-averaged total neutron flux is not adequate for computing fission rate (and fission heat source) at all times during a cycle, especially at the extremities of the exper 1ment. To approximate the real flux-time behavior, the experimentally determined time-averaged total neutron $f 1 \mathrm{ux}^{3}$ ( $\phi_{\text {total }}$ ) was multiplied by normalized time distribution functions $\Psi(Z, \theta)$ (Ref. 9). The product is an effoctive $f 11 x h(Z, \theta)$ at a specified axial position $Z$ and time $\theta$ which, when multiplied by the welghted cruss sections, yields a true reaction rate. Effective total flux is defined as follows:

$$
\phi(z, \theta)=\phi_{\text {total }}(z) \Psi(z, \theta)=\phi_{\text {total }}(z) \sum_{l=0}^{7} e(l) \theta^{\ell},
$$

where

$$
\begin{aligned}
& \int_{\text {Cyclc t1me }} \Psi(z, \theta) \partial \theta=\sum_{\ell=1}^{8} \frac{e(\ell-1) \theta^{\ell}}{\ell}=1.0, \\
& \theta \equiv \text { full power days into a reactor cycle }(0<\theta \leq 21) .
\end{aligned}
$$

The coefficients $[e(\ell), \ell=0,1,2, \ldots, 7]$ and time-averaged total neutron flux at discrete axial positions $Z$ are given in Table A.4. 
Table A.4. Data for the position-dependent, time-dependent total neutron flux

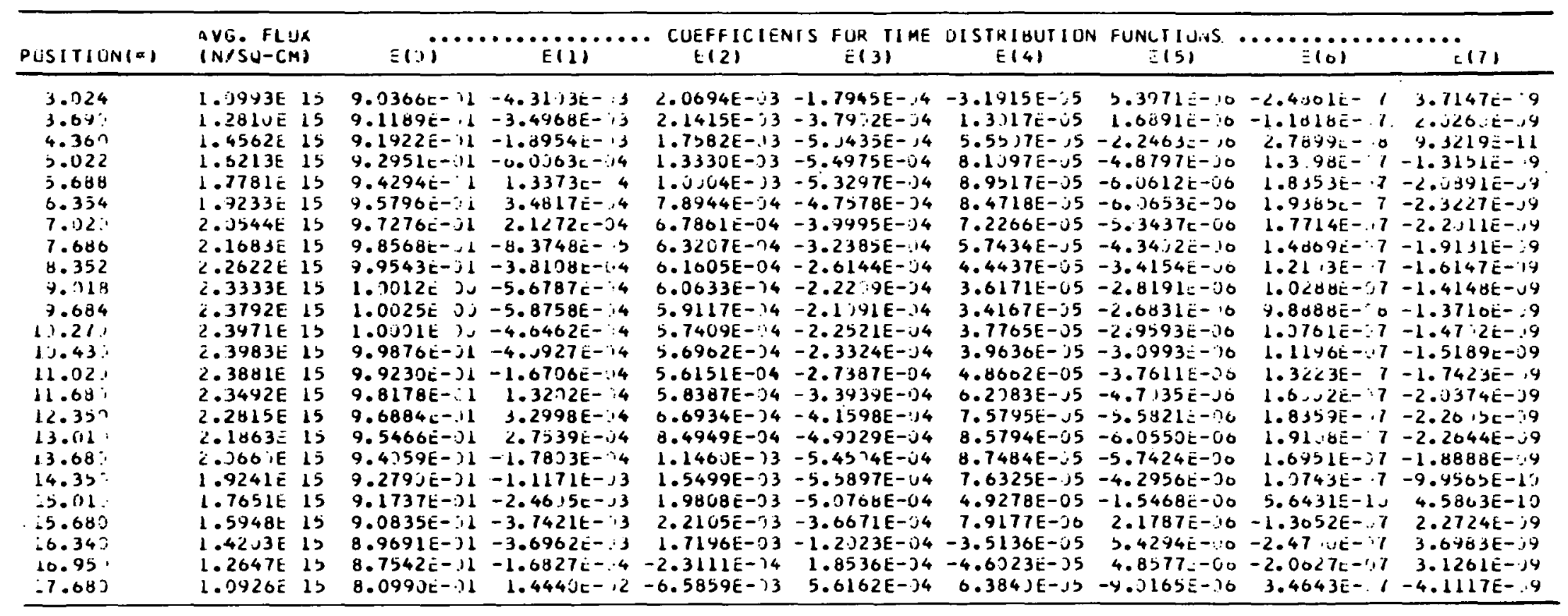

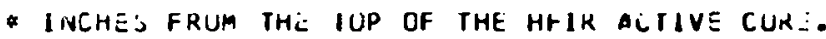


Because HFIR is a batch-loaded reactor, the implication is that the flux magnitude at each discrete axial position will be identical at corresponding times in each reactor cycle. Caution: the polynomial time distribution functions are not applicable from reactor start-up until approximately the end of first day operation; that is, the shape of the curves does not reflect the initial approach to equilibrium xenon.

\section{A. 6 Thermocouple Temperaturec}

A continuous record of thermocouple temperatures was recorded on strip charts. In addition to the chart records, thermocouple temperatures were also read and recorded on data sheets. The readings were taken at random times during each cycle throughout the irradiation history of the experiment. The records of these temperatures are shown in Tables A. 5 through A. 12 for each cycle that the experiment was inreactor. The date and time corresponding to beginning of cycle (BOC) and end of cycle (EOC) are listed at the top of each table. The date and time that the readings were taken, the mole fraction of helium in the sweep gas mixture (helium and neon), and the thermocouple temperatures are also given in each table. There were two thermocouples in each of the four subassemblies (eight total). The junction of one of the pair of thermocouples was positioned about midlength of the stack of trays in the upper half of each subassembly, and the junction of the other thermocouple was located about midlength of the stack of trays in the lower half of each subassembly. The top thermocouple in the experiment is labeled TC-1 in each table (TCs 1 and 2 are in unit 15b-1, TCs 3 and 4 are in unit $15 b-2$, etc.).

Note that some of the temperatures listed for TC-8 (the bottom thermocouple) and, on occasion, TC-6 are zero. The zeros are not true temperatures. There was a poor contact in one of the thermocouple lead wire connectors that caused some erroneous readings for both TC-8 and TC- 6 . The connector was eventually replaced and thereafter the trouble disappeared. Al1 nonzero temperatures in the attached tables are "good" readings. 
Table A.5. Data for cycle 1

$B O C=7 / U 6 / 78$ AT 1615 HRS. EOC $=7 / 31 / 78$ AT 235J HRS.

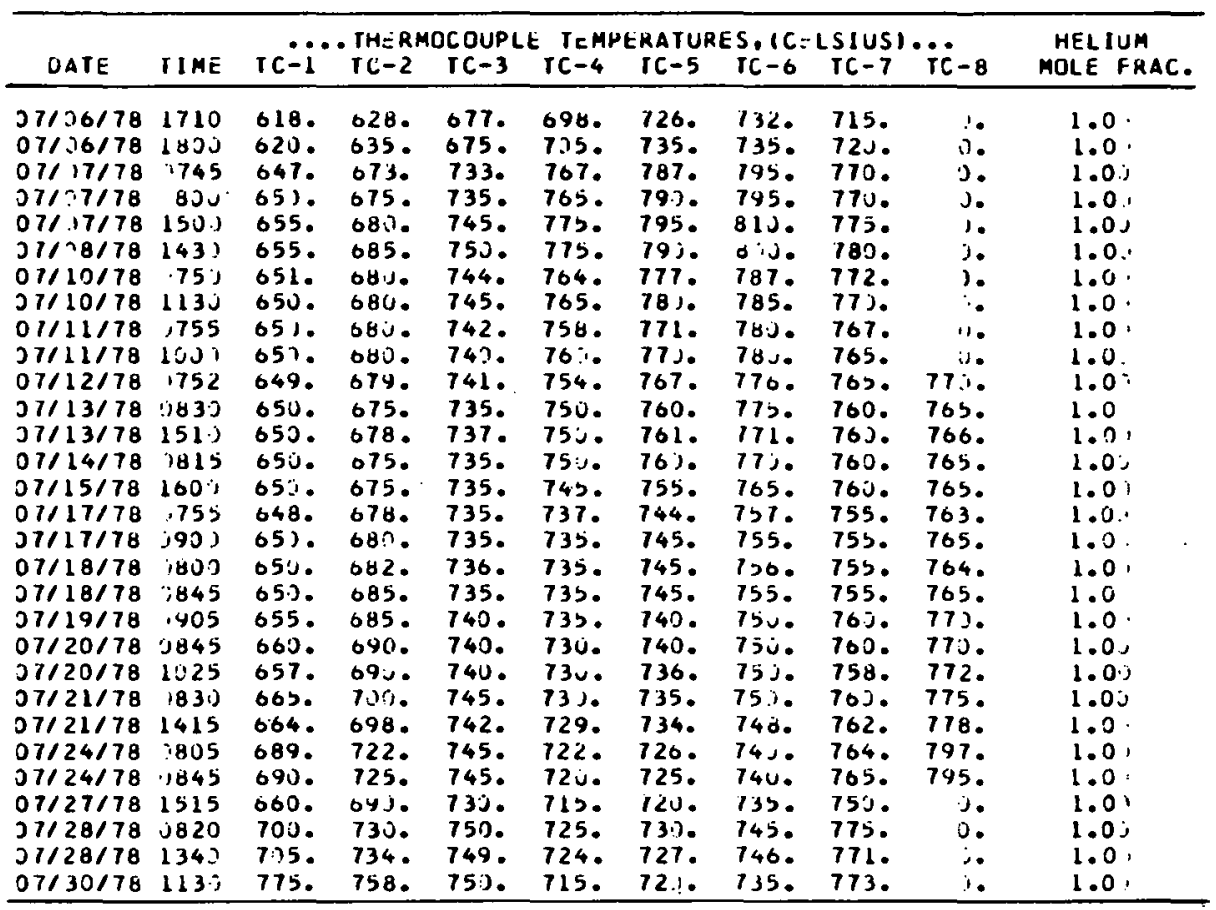

Table A.6. Data for cycle 2

$B O C=7 / 31 / 78$ AT 1752 HRS. EOC $=8 / 22 / 70$ AT 0337 HRS.

\begin{tabular}{|c|c|c|c|c|c|c|c|c|c|c|}
\hline DATE & TIME & $r c-i$ & $\begin{array}{l}\text { IHERM } \\
\text { IC-2 }\end{array}$ & $\begin{array}{l}\text { COUPLE } \\
\text { TC }=3\end{array}$ & $\begin{array}{c}\text { TEMP } \\
\text { TC-4 }\end{array}$ & $\begin{array}{l}\text { ERATUI } \\
\text { IC-5 }\end{array}$ & $\begin{array}{l}S, 1 C E \\
\text { IC }-6\end{array}$ & $\begin{array}{l}\text { SIUSI } \\
\text { IC }-7\end{array}$ & $\ddot{i c}-8$ & $\begin{array}{l}\text { HELIUM } \\
\text { MULE FRAC. }\end{array}$ \\
\hline $\begin{array}{l}0 / 1 / 1 / 78 \\
00 / 11 / 78 \\
08 / 12 / 78 \\
08 / 72 / 78 \\
0 d / 12 / 78 \\
08 / 03 / 78 \\
08 / 14 / 78 \\
00 / 17 / 78 \\
08 / 77 / 78 \\
08 / 07 / 78 \\
00 / 07 / 78 \\
08 / 18 / 78 \\
08 / 10 / 78 \\
08 / 11 / 78 \\
08 / 11 / 78 \\
00 / 14 / 78 \\
08 / 14 / 78 \\
08 / 15 / 78 \\
00 / 15 / 78 \\
08 / 15 / 78 \\
00 / 15 / 78 \\
08 / 15 / 78 \\
08 / 16 / 78 \\
08 / 17 / 78 \\
08 / 17 / 78 \\
08 / 17178 \\
08 / 17 / 78 \\
08 / 18 / 78 \\
08 / 18 / 78 \\
08 / 18 / 78 \\
08 / 21 / 78 \\
00 / 21 / 78 \\
08 / 21 / 78\end{array}$ & 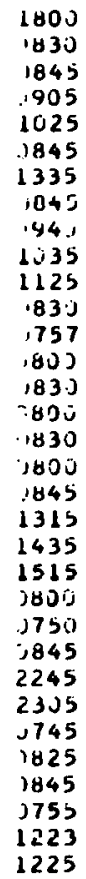 & $\begin{array}{l}590 . \\
615 . \\
620 . \\
617 . \\
807 . \\
810 . \\
810 . \\
810 . \\
809 . \\
613 . \\
810 . \\
820 . \\
82 . \\
821 . \\
815 . \\
829 . \\
815 . \\
824 . \\
820 . \\
821 . \\
637 . \\
826 . \\
834 . \\
829 . \\
825 . \\
835 . \\
818 . \\
822 . \\
797 . \\
800 . \\
845 . \\
715 . \\
715 .\end{array}$ & $\begin{array}{l}595 . \\
623 . \\
635 . \\
633 . \\
825 . \\
830 . \\
828 . \\
425 . \\
827 . \\
626 . \\
83 . \\
835 . \\
845 . \\
840 . \\
835 . \\
843 . \\
840 . \\
850 . \\
845 . \\
847 . \\
658 . \\
856 . \\
864 . \\
358 . \\
855 . \\
862 . \\
843 . \\
847 . \\
82 . \\
820 . \\
823 . \\
751 . \\
691 .\end{array}$ & $\begin{array}{l}620 . \\
670 . \\
680 . \\
682 . \\
880 . \\
885 . \\
883 . \\
875 . \\
878 . \\
671 . \\
889 . \\
885 . \\
887 . \\
89 . \\
685 . \\
895 . \\
885 . \\
885 . \\
885 . \\
881 . \\
691 . \\
888 . \\
892 . \\
878 . \\
875 . \\
877 . \\
867 . \\
860 . \\
832 . \\
835 . \\
824 . \\
694 . \\
683 .\end{array}$ & 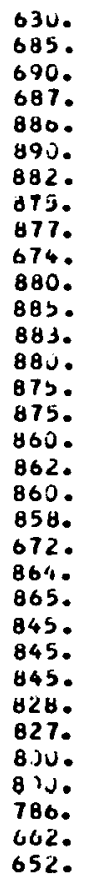 & $\begin{array}{l}655 . \\
70 . \\
731 . \\
730 . \\
901 \\
900 . \\
894 . \\
685 . \\
886 . \\
679 . \\
891 . \\
895 . \\
891 . \\
889 . \\
885 . \\
884 . \\
670 . \\
870 . \\
865 . \\
866 . \\
679 . \\
871 . \\
871 . \\
855 . \\
855 . \\
852 . \\
835 . \\
835 . \\
808 . \\
815 . \\
793 . \\
664 . \\
666 .\end{array}$ & 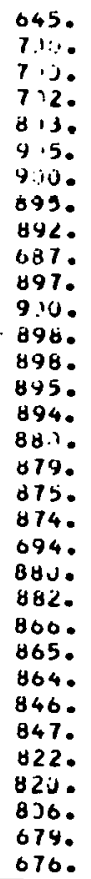 & $\begin{array}{l}640 . \\
691 . \\
701 . \\
698 . \\
901 . \\
905 . \\
900 . \\
855 . \\
896 . \\
692 . \\
901 . \\
905 . \\
907 . \\
909 . \\
905 . \\
915 . \\
901 \\
905 . \\
900 . \\
900 . \\
710 . \\
908 . \\
912 . \\
901 . \\
895 . \\
899 . \\
882 . \\
887 . \\
858 . \\
861 . \\
850 . \\
720 . \\
709 .\end{array}$ & 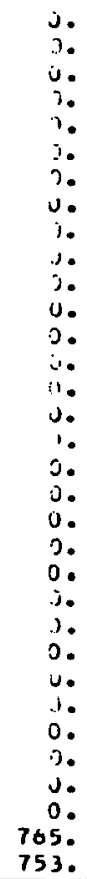 & 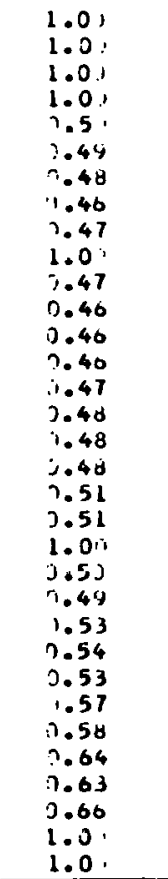 \\
\hline
\end{tabular}


Table A.7. Data for cycle 3

$B O C=8 / 22 / 18$ AT 1838 MRS. EUC $=9 / 13 / 70$ AT 440 . HRS.

\begin{tabular}{|c|c|c|c|c|c|c|c|c|c|c|}
\hline JATE & IIM $=$ & $r c-i$ & $\begin{array}{l}\text { IHERM } \\
\text { IC-2 }\end{array}$ & $\begin{array}{l}\text { COUPL } \\
\text { IC-3 }\end{array}$ & $\begin{array}{l}T=M r \\
T C-4\end{array}$ & $\begin{array}{l}\text { RATUF } \\
\text { TC-b }\end{array}$ & $\begin{array}{l}E S, 1 C \\
T C-6\end{array}$ & $\begin{array}{l}\text { SIUS) } \\
\text { TC-7 }\end{array}$ & $\ddot{i c-y}$ & $\begin{array}{l}\text { HELIUJM } \\
\text { MULE FKAC. }\end{array}$ \\
\hline 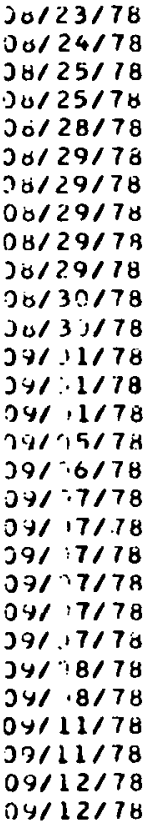 & 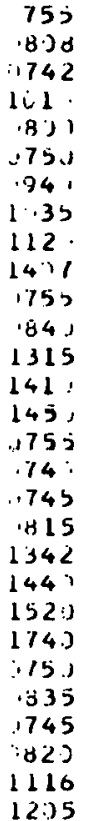 & $\begin{array}{l}585 . \\
593 . \\
595 . \\
894 . \\
831 . \\
899 . \\
816 . \\
292 . \\
820 . \\
814 . \\
813 . \\
837 . \\
832 . \\
596 . \\
826 . \\
838 . \\
839 . \\
848 . \\
824 . \\
825 . \\
619 . \\
818 . \\
825 . \\
829 . \\
879 . \\
857 . \\
837 . \\
862 . \\
684 .\end{array}$ & 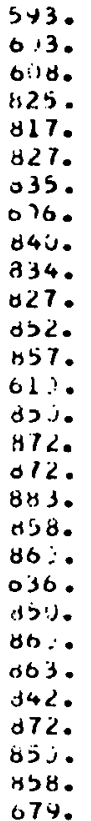 & $\begin{array}{l}631 . \\
648 . \\
650 . \\
875 . \\
865 . \\
877 . \\
883 . \\
647 . \\
886 . \\
883 . \\
883 . \\
902 . \\
905 . \\
655 . \\
911 . \\
915 . \\
912 . \\
418 . \\
692 . \\
891 . \\
675 . \\
884 . \\
890 . \\
888 . \\
871 . \\
877 . \\
858 . \\
856 . \\
681 .\end{array}$ & $\begin{array}{l}637 . \\
648 . \\
654 . \\
872 . \\
858 . \\
861 . \\
875 . \\
644 . \\
874 . \\
874 . \\
872 . \\
892 . \\
890 . \\
643 . \\
885 . \\
886 . \\
885 . \\
834 . \\
834 . \\
850 . \\
644 . \\
847 . \\
855 . \\
853 . \\
833 . \\
833 . \\
814 . \\
812 . \\
643 .\end{array}$ & 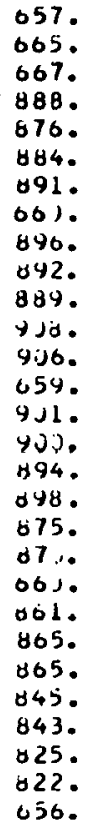 & 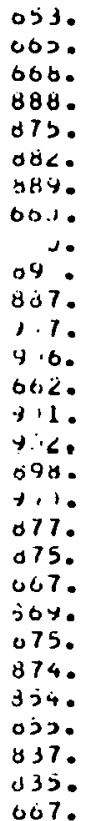 & $\begin{array}{l}65 j . \\
600 . \\
668 . \\
892 . \\
882 . \\
692 . \\
899 . \\
666 . \\
944 . \\
901 . \\
894 . \\
918 . \\
922 . \\
675 . \\
910 . \\
937 . \\
928 . \\
935 . \\
913 . \\
911 . \\
695 . \\
903 . \\
913 . \\
711 . \\
892 . \\
903 . \\
883 . \\
883 . \\
708 .\end{array}$ & 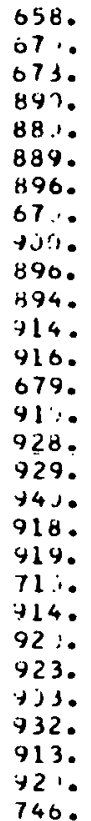 & 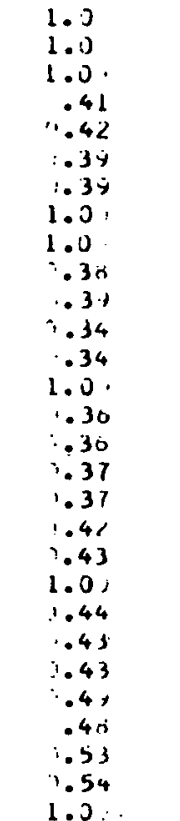 \\
\hline
\end{tabular}

Table A.8. Data for cycle 4

$\triangle O C=9 / 13 / 18$ AI 1824 HRS. EUC=1J/ O/7O AT 2115 HRS.

\begin{tabular}{|c|c|c|c|c|c|c|c|c|c|c|}
\hline DAT E & I IME & $r c-i$ & $\begin{array}{l}\mathrm{IH}=\mathrm{R} \\
\mathrm{TC}-2\end{array}$ & $\begin{array}{l}\text { COUPLE } \\
\text { TC-3 }\end{array}$ & $=I_{I C-4 R}$ & $\begin{array}{l}\text { RATUR } \\
\text { IC-5 }\end{array}$ & $\begin{array}{l}3,16: \\
1 C-0\end{array}$ & $\begin{array}{l}\text { SIUS } \\
\text { TC-7 }\end{array}$ & $\ddot{i c}-y$ & $\begin{array}{l}\text { H'L IUM } \\
\text { MULE FRAC. }\end{array}$ \\
\hline 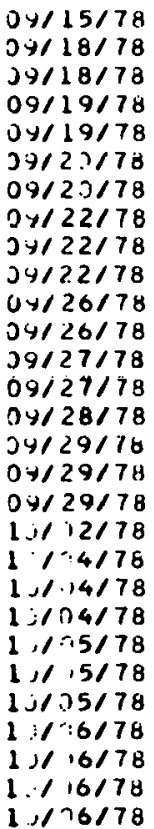 & 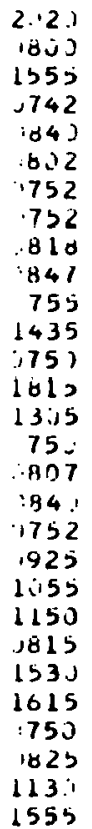 & $\begin{array}{l}598 . \\
624 . \\
624 . \\
624 . \\
864 . \\
875 . \\
875 . \\
868 . \\
617 . \\
86 . \\
865 . \\
872 . \\
872 . \\
875 . \\
870^{\circ} \\
870 . \\
029 . \\
881 . \\
910^{\circ} \\
913 . \\
683 . \\
914 . \\
425 . \\
928 . \\
408 . \\
916 . \\
710 . \\
708 . \\
713 .\end{array}$ & 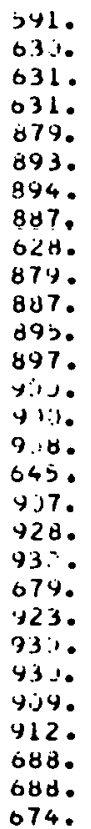 & $\begin{array}{l}614 . \\
675 . \\
675 . \\
676 . \\
923 . \\
935 . \\
937 . \\
932 . \\
667 . \\
922 . \\
424 . \\
932 . \\
932 . \\
431 . \\
932 . \\
933 . \\
667 . \\
932 . \\
935 . \\
925 . \\
672 . \\
923 . \\
925 . \\
923 . \\
900 . \\
903 . \\
677 . \\
677 . \\
662 .\end{array}$ & $\begin{array}{l}610 . \\
657 . \\
651 . \\
052 . \\
894 . \\
95 . \\
905 . \\
93.1 \\
642 . \\
891 . \\
887 . \\
894 . \\
893 . \\
895 . \\
891 . \\
894 . \\
64 . \\
892 . \\
890 . \\
878 . \\
630 . \\
875 . \\
875 . \\
875 . \\
852 . \\
850 . \\
638 . \\
636 . \\
637 .\end{array}$ & $\begin{array}{l}612 . \\
657 . \\
657 . \\
657 . \\
890 . \\
400 . \\
417 . \\
431 . \\
648 . \\
893 . \\
887 . \\
895 . \\
894 . \\
845 . \\
892 . \\
892 . \\
042 . \\
891 . \\
891 . \\
681 . \\
041 . \\
877 . \\
875 . \\
876 . \\
855 . \\
851 . \\
641 . \\
643 . \\
644 .\end{array}$ & 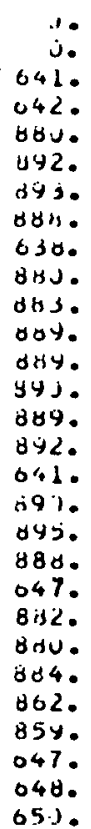 & $\begin{array}{l}568 . \\
613 . \\
629 . \\
631 . \\
870 . \\
885 . \\
885 . \\
882 . \\
632 . \\
875 . \\
883 . \\
891 . \\
892 . \\
845 . \\
890 . \\
901 . \\
644 . \\
901 . \\
913 . \\
921 . \\
672 . \\
924 . \\
925 . \\
425 . \\
903 . \\
902 . \\
681 . \\
68 \% \\
663 .\end{array}$ & $\begin{aligned} & 1 \\
& j \\
& 619 . \\
& 621 . \\
& 85 j \\
& 867 . \\
& 870 . \\
& 864 . \\
& 625 . \\
& 853 \\
& 865 . \\
& 873 . \\
& 475 . \\
& 875 . \\
& 878 . \\
& 884 . \\
& 638 . \\
& 884 . \\
& 938 . \\
& 925 . \\
& 683 . \\
& 927 . \\
& 935 . \\
& 937 . \\
& 921 . \\
& 920 . \\
& 733 . \\
& 712 . \\
& 683 .\end{aligned}$ & 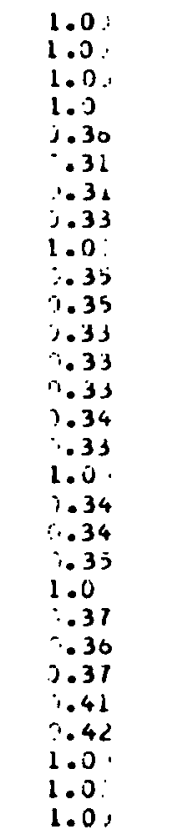 \\
\hline
\end{tabular}


Table A.9. Data for cycle 5

$B O C=10 / 07 / 78$ AT 1653 HRS. EOC $=1 U / 28 / 70$ AT 240J MRS.

\begin{tabular}{|c|c|c|c|c|c|c|c|c|c|c|}
\hline OAT & I IME & $r c-\ddot{1}$ & $\begin{array}{l}\text { THERM } \\
\text { IC }-2\end{array}$ & $\begin{array}{l}\text { COUPL } \\
\mathrm{TC}-3\end{array}$ & $\begin{array}{l}\text { TEMA } \\
\text { TC }-4\end{array}$ & $\begin{array}{l}\text { ERATU } \\
\text { TC }-5\end{array}$ & $\begin{array}{l}5,1 C \\
1 C-6\end{array}$ & $\begin{array}{l}\text { SIUS I } \\
\text { TC-7 }\end{array}$ & $\ddot{T C}-8$ & $\begin{array}{l}\text { HEL I UH } \\
\text { MOLE FRAC. }\end{array}$ \\
\hline 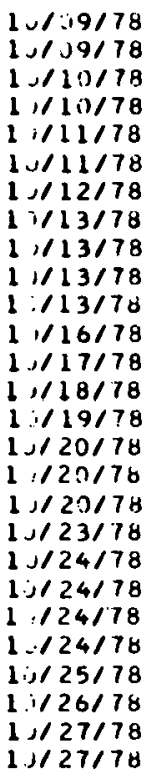 & $\begin{array}{l}1805 \\
1927 \\
.830 \\
183 . \\
1225 \\
1350 \\
.755 \\
.745 \\
1325 \\
1345 \\
1415 \\
.175 \\
.745 \\
.753 \\
1753 \\
.803 \\
.825 \\
.415 \\
1445 \\
.852 \\
1335 \\
1415 \\
1506 \\
3755 \\
1750 \\
.755 \\
1132\end{array}$ & $\begin{array}{l}590 . \\
850 . \\
848 . \\
864 . \\
856 . \\
870 . \\
872 . \\
869 . \\
869 . \\
583 . \\
873 . \\
864 . \\
862 . \\
862 . \\
862 . \\
864 . \\
591 . \\
863 . \\
875 . \\
880 . \\
878 . \\
622 . \\
880 . \\
867 . \\
874 . \\
877 . \\
658 .\end{array}$ & $\begin{array}{l}587 . \\
872 . \\
868 . \\
884 . \\
879 . \\
895 . \\
898 . \\
897 . \\
895 . \\
582 . \\
895 . \\
895 . \\
895 . \\
897 . \\
899 . \\
900 . \\
596 . \\
401 . \\
910 . \\
915 . \\
911 . \\
62 \% \\
911 . \\
890 . \\
889 . \\
87.0 \\
627 .\end{array}$ & $\begin{array}{l}634 . \\
923 . \\
917 . \\
935 . \\
930^{\circ} \\
948 . \\
950 . \\
950^{\circ} \\
948 . \\
622 . \\
948 . \\
949 . \\
948 . \\
947 . \\
945 . \\
942 . \\
623 . \\
943 . \\
935 . \\
932 . \\
926 . \\
627 . \\
926 . \\
900 . \\
884 . \\
872 . \\
623 .\end{array}$ & $\begin{array}{l}628 . \\
938 . \\
45 \% . \\
922 . \\
914 . \\
934 . \\
937 . \\
935 . \\
933 . \\
613 . \\
936 . \\
937 . \\
935 . \\
936 . \\
935 . \\
934 . \\
012 . \\
933 . \\
925 . \\
922 . \\
917 . \\
615 . \\
918 . \\
880 . \\
873 . \\
467 . \\
613 .\end{array}$ & $\begin{array}{l}639 . \\
917 . \\
910^{\circ} \\
932 . \\
924 . \\
942 . \\
945 . \\
945 . \\
444 . \\
625 . \\
945 . \\
945 . \\
943 . \\
945 . \\
943 . \\
943 . \\
622 . \\
943 . \\
945 . \\
442 . \\
437 . \\
627 . \\
937 . \\
408 . \\
894 . \\
88.1 . \\
023 .\end{array}$ & 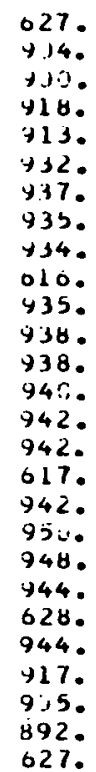 & $\begin{array}{l}603 . \\
481 . \\
877 . \\
892 . \\
887 . \\
903 . \\
907 . \\
907 . \\
907 . \\
598 . \\
91 . \\
919 . \\
921 . \\
922 . \\
928 . \\
933 . \\
612 . \\
933 . \\
953 . \\
958 . \\
952 . \\
635 . \\
953 . \\
932 . \\
923 . \\
913 . \\
638 .\end{array}$ & $\begin{array}{l}592 . \\
865 . \\
862 . \\
877 . \\
872 . \\
887 . \\
890 . \\
892 . \\
890 . \\
592 . \\
891 . \\
897 . \\
898 . \\
903 . \\
908 . \\
913 . \\
691 . \\
913 . \\
935 . \\
948 . \\
945 . \\
635 . \\
947 . \\
932 . \\
930 . \\
931 . \\
657 .\end{array}$ & 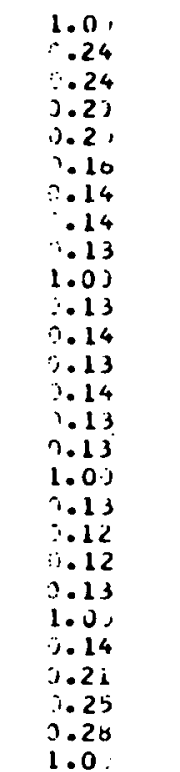 \\
\hline
\end{tabular}

Table A.10. Data for cycle 6

$B U C=10 / 29 / 78$ AT 1725 HRS. $E U C=11 / 22 / 70^{\circ}$ AT 0225 HRS.

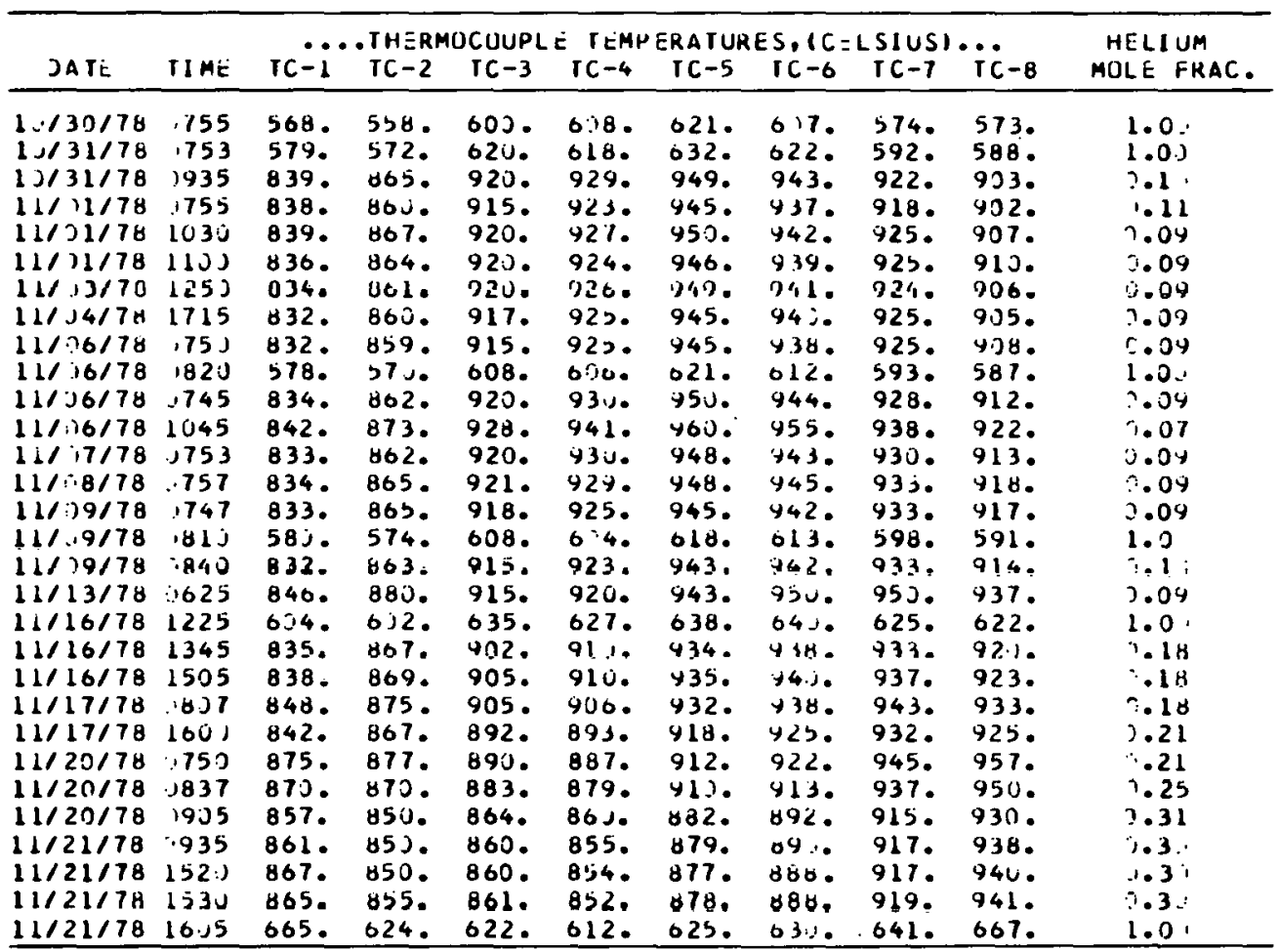


Table A.11. Data for cycle 7

$B O C=11 / 22 / 78$ AT 2147 HRS. EUC $=12 / 14 / 70$ AT 014? HRS.

\begin{tabular}{|c|c|c|c|c|c|c|c|c|c|c|}
\hline DAT & TIME & $r c-i$ & $\begin{array}{l}\text { HERM } \\
C-2\end{array}$ & $\begin{array}{l}\text { OUPLE } \\
\mathrm{C}-3\end{array}$ & $=T_{T C-4}^{T}$ & $\begin{array}{l}\text { RATU } \\
\text { IC-5 }\end{array}$ & $\begin{array}{l}S, 1 C: \\
1 C-6\end{array}$ & $\begin{array}{l}105 \\
c-7\end{array}$ & $\ddot{i c}-\theta$ & $\begin{array}{l}\text { HLLIUM } \\
\text { MULE FRAC. }\end{array}$ \\
\hline 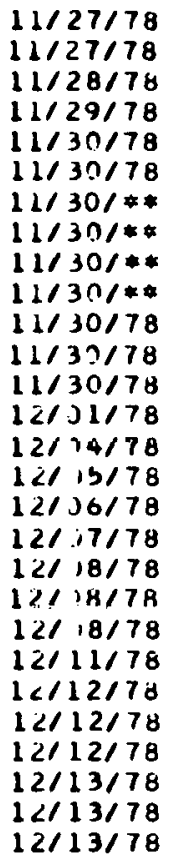 & 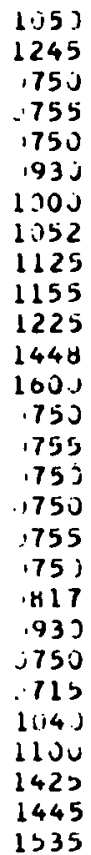 & $\begin{array}{l}574 . \\
812 . \\
813 . \\
813 . \\
818 . \\
820 . \\
781 . \\
810 . \\
801 . \\
536 . \\
571 . \\
568 . \\
817 . \\
822 . \\
823 . \\
820 . \\
831 . \\
831 . \\
838 . \\
598 . \\
82 . \\
848 . \\
846 . \\
858 . \\
850 . \\
858 . \\
856 . \\
659 .\end{array}$ & $\begin{array}{l}565 . \\
841 . \\
831 . \\
842 . \\
842 . \\
445 . \\
81.1 \\
826 . \\
827 . \\
327 . \\
554 . \\
358 . \\
841 . \\
840 . \\
654 . \\
858 . \\
865 . \\
868 . \\
872 . \\
343 . \\
847 . \\
862 . \\
853 . \\
861 . \\
848 . \\
446 . \\
848 . \\
617 .\end{array}$ & $\begin{array}{l}613 . \\
890 . \\
890 . \\
900 . \\
902 . \\
903 . \\
858 . \\
883 . \\
883 . \\
566 . \\
602 . \\
600 . \\
900 . \\
902 . \\
906 . \\
908 . \\
910 . \\
903 . \\
905 . \\
612 . \\
88 . \\
878 . \\
875 . \\
874 . \\
862 . \\
855 . \\
850 . \\
621 .\end{array}$ & 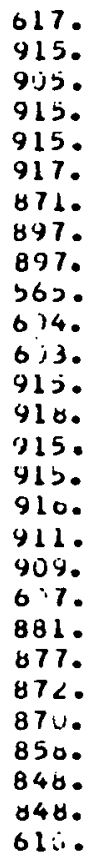 & $\begin{array}{l}632 . \\
445 . \\
435 . \\
947 . \\
947 . \\
947 . \\
901 . \\
927 . \\
927 . \\
681 . \\
618 . \\
618 . \\
947 . \\
948 . \\
943 . \\
941 . \\
943 . \\
938 . \\
937 . \\
622 . \\
917 . \\
903 . \\
899 . \\
898 . \\
834 . \\
875 . \\
672 . \\
624 .\end{array}$ & 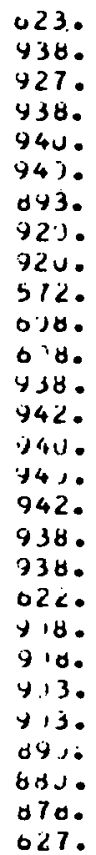 & $\begin{array}{l}992 . \\
918 . \\
912 . \\
923 . \\
927 . \\
928 . \\
883 . \\
913 . \\
913 . \\
553 . \\
585 . \\
587 . \\
926 . \\
932 . \\
938 . \\
94 j . \\
947 . \\
948 . \\
953 . \\
615 . \\
922 . \\
932 . \\
928 . \\
432 . \\
917 . \\
938 . \\
908 . \\
635 .\end{array}$ & $\begin{array}{l}578 . \\
933 . \\
498 . \\
938 . \\
978 . \\
913 . \\
867 . \\
893 . \\
893 . \\
547 . \\
578 . \\
578 . \\
938 . \\
912 . \\
918 . \\
422 . \\
928 . \\
930 . \\
937 . \\
613 . \\
998 . \\
936 . \\
432 . \\
944 . \\
931 . \\
928 . \\
927 . \\
654 .\end{array}$ & 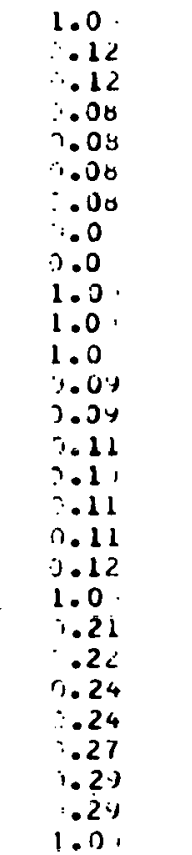 \\
\hline
\end{tabular}

Table A.12. Data for cycle 8

$B O C=12 / 14 / 78$ AT 1945 HRS. EOC $=1 / 14 / 74$ AT 1759 HRS.

\begin{tabular}{|c|c|c|c|c|c|c|c|c|c|c|}
\hline DAT: & IIME & $I c-i$ & $\begin{array}{l}H=K H \\
C-2\end{array}$ & $\begin{array}{l}\text { UUPLL } \\
\text { SC-3 }\end{array}$ & $\begin{array}{l}\text { TEMH } \\
\text { IC }-4\end{array}$ & $\begin{array}{l}\text { KATUR } \\
\text { IC-5 }\end{array}$ & $\begin{array}{l}\text { S. } 1 C: \\
\text { IC }-6\end{array}$ & $\begin{array}{l}\text { SIUS I } \\
\text { IC-7 }\end{array}$ & $i \bar{c}-8$ & $\begin{array}{l}\text { HELIUM } \\
\text { MULE FRAC. }\end{array}$ \\
\hline $\begin{array}{l}12115 / 78 \\
12118 / 78 \\
12118 / 78 \\
12119 / 78 \\
12119 / 78 \\
12119 / 78 \\
12120 / 18 \\
12121 / 78 \\
12121 / 78 \\
12122178 \\
12122178 \\
12122178 \\
11128 / 78 \\
12128 / 78 \\
01112 / 79 \\
01112 / 79 \\
01 / 12179 \\
01 / 14179 \\
011.4 / 79 \\
01 / 14 / 79\end{array}$ & $\begin{array}{l}1755 \\
.752 \\
1915 \\
.753 \\
1850 \\
: 915 \\
1000 \\
.75 \% \\
1357 \\
1425 \\
144.1 \\
1225 \\
1221 \\
1420 \\
1255 \\
1345 \\
1415 \\
803 \\
905 \\
1053\end{array}$ & $\begin{array}{l}533 . \\
565 . \\
802 . \\
8120 \\
569 . \\
815 . \\
805 . \\
801 . \\
80 \% . \\
803 . \\
562 . \\
797 . \\
815 . \\
583 . \\
841 . \\
631 . \\
831 . \\
857 . \\
853 . \\
658 .\end{array}$ & $\begin{array}{l}338 . \\
358 . \\
622 . \\
822 . \\
561 . \\
824 . \\
824 . \\
424 . \\
821 . \\
827 . \\
556 . \\
618 . \\
448 . \\
383 . \\
845 . \\
61 . \\
832 . \\
042 . \\
437 . \\
619 .\end{array}$ & $\begin{array}{l}588 . \\
608 . \\
880 . \\
885 . \\
607 . \\
887 . \\
890 . \\
885 . \\
883 . \\
887 . \\
601 . \\
878 . \\
89.5 \\
614 . \\
867 . \\
621 . \\
854 . \\
857 . \\
849 . \\
625 .\end{array}$ & 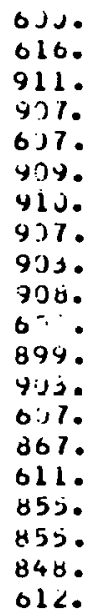 & $\begin{array}{l}616 . \\
029 . \\
442 . \\
938 . \\
624 . \\
942 . \\
443 . \\
y 4.0 \\
437 . \\
942 . \\
615 . \\
432 . \\
938 . \\
623 . \\
401 . \\
627 . \\
887 . \\
487 . \\
878 . \\
026 .\end{array}$ & $\begin{array}{l}61 \% . \\
02 \% \\
+31 . \\
427 . \\
613 . \\
420 . \\
91.0 \\
927 . \\
923 . \\
920 . \\
6 \% 3 . \\
918 . \\
932 . \\
618 . \\
912 . \\
626 . \\
889 . \\
028 . \\
081 . \\
027 .\end{array}$ & $\begin{array}{l}568 . \\
508 . \\
908 . \\
908 . \\
600 . \\
911 . \\
914 . \\
913 . \\
906 . \\
913 . \\
583 . \\
903 . \\
928 . \\
608 . \\
918 . \\
632 . \\
904 . \\
908 . \\
898 . \\
633 .\end{array}$ & $\begin{array}{l}563 . \\
579 . \\
492 . \\
892 . \\
597 . \\
894 . \\
491 . \\
493 . \\
893 . \\
895 . \\
578 . \\
885 . \\
919 . \\
654 . \\
925 . \\
045 . \\
912 . \\
925 . \\
917 . \\
053 .\end{array}$ & 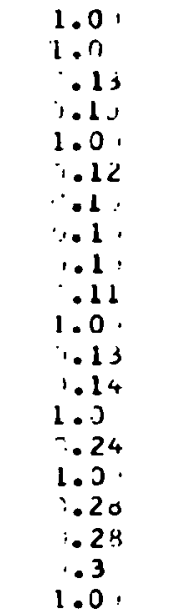 \\
\hline
\end{tabular}


During cycle 1, pure hellum was used as the sweep gas. Starting with the second cycle, mixtures of hellum and neon were used for temperature control. Helium sweep gas was always used at the start of each cycle. The higher thermal conductivity for helium keeps the particle surface temperatures well below the $1000^{\circ} \mathrm{C}$ maximum during the time the magnitude of the neutron flux is increasing most rapidly, that is, during the time required for the high cross-section fission products (primarily $135 \mathrm{Xe}$ ) to reach equilibrium in the reactor core. The sweep gas mixture was controlled by manually operated control valves (also, the experiment was not manned on a 24-hr basis); therefore, pure helium was generally used during the initial two or three days of the cycle.

We believe that the temperature-dependent thermal conductivity for helium gas is somewhat better known than the temperature-dependent thermal conductivity for helium-neon mixtures; therefore, at intervals during a reactor cycle, the experiment was flushed out with helium and thermocouple readings were taken. These data were used to renormalize the calculations for graphite growth (see Sect. A.3). As can be seen by the data in Tables A. 5 through A. 12, the times required to obtain the helium data were very short, and the experiment was not operated for a long time at reduced temperatures.

The assumption was made that the thermocouple readings were always correct and that neither irradiation nor extended operation at temperature affected the junction or any part of the lead wire in the reactor. At intervals during the test period, temperatures were also read using a calibrated potentiometer. The potentiometer readings served as a standard for maintaining the accuracy of the temperature recorders. The most disagreement between the temperatures read from the potentiometer and those read from the recorders occurred at the end of cycle 4. The last entry in Table A.8 is temperatures from the calibrated potentiometer and is to be compared with the next-to-last entry in that table - about $20^{\circ} \mathrm{C}$ maximum difference was noted. The calibrated potentiometer was used to check temperatures at the following times during the test period, as tabulated on the following page. 


\begin{tabular}{cllll} 
Cycle No. & Date & Time & Table \\
\cline { 1 - 1 } & & & & \\
4 & & $8 / 21 / 78$ & 1225 & A. 6 \\
6 & $10 / 06 / 78$ & 1555 & A. 8 \\
6 & $11 / 01 / 78$ & 1100 & A. 10 \\
7 & $11 / 21 / 78$ & 1530 & A. 10 \\
& $12 / 13 / 78$ & 1445 & A.11
\end{tabular}

All readings were taken with the HFIR at full power [100 MW(t)], with the exception of the four entries in Table A.11 which have a double asterisk symbol in the date column. Those four sets of data were taken with the reactor at $90 \mathrm{MW}(t)$. During part of that 2-hr period, we operated the experiment with neon sweep gas. The data were helpful in determining uncertainties in computed temperature-dependent thermal conductivity for neon gas and were included in Table A.11, principally for documentation.

The mole fraction of helium $F(H e)$ in the sweep gas mixture (helium plus neon) was computed from the following equation:

$$
F(\text { He })=1 /[1+(\mathrm{V} 2 / \mathrm{V} 1)] \text {, }
$$

where $V 1$ is the flow rate $\left(\mathrm{cm}^{3} / \mathrm{min}\right)$ for helium and $V 2$ is the flow rate $\left(\mathrm{cm}^{3} / \mathrm{min}\right)$ for neon. Flow rates were obtalned by multiplying flow meter scale readings by the appropriate manufacturer-suggested scale factor. For helium, V1 = S1 $\times 1.43$. For neon, V2 $=\mathrm{S} 2 \times 1.38 . \mathrm{S} 1$ and $\mathrm{S} 2$ are scale readings from the helium and neon flow meters, respectively. The tlow meters were Hastings (model ALL-50). No addicional pressure or temperature corrections were required for the sweep gas system.

\section{A. I Utility Program}

The utility program is a companion to the $1-D$ heat transfer program (see Sect. A.1). It receives various raw data and, by the method of least squares, generates coefficients for a power series. For the HRB-15b experiment, the program has been used to perform the following tasks. 
1. In the general mode of operation, any data $[(X 1, Y 1), 1=1, \ldots$, n] are used to calculate coefficients (the a's) for the power series:

$$
y=\sum_{\ell=0}^{n} a(\ell)[x]^{\ell}
$$

The coefficlents $\left(a_{0}, a_{1}, \ldots, a_{n}\right)$ can then be automatically punched on cards for later use.

2. Specifically, the program has been used to process the following data: (a) Nuclear heating, watts per gram of material (Yi), as a function of axial position (Xi). The axial distance is referenced to the top of the HFIR active core. A series of such calculations will generate arrays of coefficients which are applicable at discrete times into a cycle. (b) Thermal conductivity (Yi) as a function of temperature (Xi). Thermal conductivity may be reported in various units in the literature. For convenience, the program can automatically perform the necessary units conversion so that temperatures will be converted to Fahrenheit and $k$ converted to $B t u / h r \cdot f t \cdot F$ for processing. (c) Power per particle, watts per particle ( $Y i)$, as a function of axial position (Xi), is another example of data processed by the program. Data for watts per particle are obtained from the depletion code, CACA-2. 1 (d) The program has also been used to process axial position-dependent neutron fluxes. (e) The program may be used to compute temperature-dependent thermal conductivity for binary mixtures of gases. The method is discussed separately in this section. Once the thermal conductivities have beell cumputed, then the data are processed as described in (b) above.

\section{Least-Squares Formulas}

It is not our intent to present a detailed treatment for data reduction $^{15}$ or matrix theory. 16 only the basic formalism will be considered. We want to find solutions for the coefficients $a_{0}, a_{l}, \ldots, a_{m}$, to a curve of the form $y=a_{0}+a_{1} x+\ldots 1+a_{m} x^{m}$, which best represent the data (Xi, Yi), $\mathbf{i}=1,2, \ldots, \mathrm{n}(\mathrm{n}>\mathrm{m})$. There will be $\mathrm{m}+1$ normal equations ${ }^{17}$ 
as

follows :

$$
\begin{aligned}
& a_{0 n}+a_{1} \Sigma X 1+\ldots+a_{m} \sum X 1^{m}=\Sigma Y i,
\end{aligned}
$$

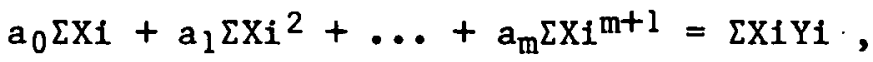

$$
\begin{aligned}
& \text { - } \\
& \text { - } \\
& a_{0} \Sigma X i^{m}+a_{1} \sum X i^{m+1}+\ldots+a_{m} \Sigma X i^{2 m}=\Sigma X i^{m} Y i
\end{aligned}
$$

The deviation $\mathrm{Di}$ of the data about the curve is

$$
\mathrm{Di}=\mathrm{Yi}-\left(\mathrm{a}_{0}+\mathrm{a}_{1} \mathrm{Xi}+\ldots+\mathrm{a}_{\mathrm{m}} \mathrm{Xi}{ }^{\mathrm{m}}\right) .
$$

The root-mean-square of $y$ deviations about the curve, sometimes called the standard error of estimate ${ }^{17}$ sy, is defined as follows:

$$
S y=\sqrt{\Sigma D i^{2} /(n-1-m)} \text {. }
$$

Finally, there are $\ddot{m}+1$ equatiuns lu be sulved simultaneously to obtain the coefficients. One method for the solution of simultaneous equations is by use of determinants. The method is illustrated by the following example. For the purpose of demonsitralluy the iuetliud, we arbitrarily chooco the second-degree polynomial. Let $\Delta$ be defined as follows:

$$
\Delta=\left|\begin{array}{lll}
n & \Sigma X i & \Sigma X i^{2} \\
\Sigma X i & \Sigma X i^{2} & \Sigma X i^{3} \\
\Sigma X i^{2} & \Sigma X i^{3} & \Sigma X^{4}
\end{array}\right|, \Delta \neq 0.0
$$

The solution for the coefficients $a_{0}, a_{1}$, and $a_{2}$ are as follows:

$$
a_{0}=\frac{1}{\Delta}\left|\begin{array}{lll}
\Sigma Y i & \Sigma X i & \Sigma X i^{2} \\
\Sigma X i Y i & \Sigma X i^{2} & \Sigma X i^{3} \\
\Sigma X i^{2} Y i & \Sigma X i^{3} & \Sigma X i^{4}
\end{array}\right|
$$




$$
\begin{aligned}
& a_{1}=\frac{1}{\Delta}\left|\begin{array}{lll}
n & \Sigma Y i & \Sigma X i^{2} \\
\Sigma X i & \Sigma X i Y i & \Sigma X i^{3} \\
\Sigma X i^{2} & \Sigma X i^{2} Y i & \Sigma X i^{4}
\end{array}\right|, \\
& a_{2}=\frac{1}{\Delta}\left|\begin{array}{lll}
n & \Sigma X i & \Sigma Y i \\
\Sigma X i & \Sigma X i^{2} & \Sigma X i Y i \\
\Sigma X i^{2} & \Sigma X i^{3} & \Sigma X i^{2} Y i
\end{array}\right| .
\end{aligned}
$$

Theoretically, the method could be applied to polynomials of any degree. We found that fifth degree (or less) was adequate for any data processing required for experiment $\mathrm{HRB}-15 \mathrm{~b}$. To avoid loss of significant digits, it was necessary to program in double precision when using the IBM- 360 series machines.

Thermal conductivity for binary mixtures of gases

The method formulated by Lindsay and Bromleyl 8 was used to evaluate temperature-dependent thermal conductivity for mixtures of helium and neon and mixtures of helium and argon. Each of the above binary mixtures were candidates for use as sweep gas. Only the applicable equations will be presented in this section of the report. The reader should refer to Lindsay and Bromely's report 18 for a detalled discussion of the theory.

Definition of the terms in each equation are given in the nomenclature at the end of the discussion. For a binary mixture of gases, the following equation defines the thermal conductivity:

$$
\mathrm{K}_{\mathrm{m}}=\frac{\mathrm{K}_{1}}{1+\left(\mathrm{A}_{12} \mathrm{x}_{2} / \mathrm{x}_{1}\right)}+\frac{\mathrm{K}_{2}}{1+\left(\mathrm{A}_{21} \mathrm{x}_{1} / \mathrm{x}_{2}\right)}
$$

The dimensionless constant $A_{1 j}$ (either $i=1$ and $j=2$ or $i=2$ and $j=1$ ) is defined as follows:

$$
A_{i j}=1 / 4\left\{1+\left[\frac{\mu_{i}}{\mu_{j}}\left(\frac{M_{j}}{M_{i}}\right)^{0.75} \frac{\left(1+S_{i} / T\right)}{\left(1+S_{j} / T\right)}\right]^{0.5}\right\}^{2} \frac{\left(1+S_{12} / T\right)}{\left(1+S_{i} / T\right)}
$$


In the absence of viscosity data, the viscosity ratio $\left(\mu_{i} / \mu_{j}\right)$ may be computed from the following equation:

$$
\frac{\mu_{i}}{\mu_{j}}=\frac{K_{i}\left(C_{p j}+1.25 R / M_{j}\right)}{K_{j}\left(C_{p i}+1.25 R / M_{i}\right)} .
$$

Values for the Sutherland constants $\left(S_{i}, s_{j}\right.$, or $\left.S_{12}\right)$ are:

$S=142$ degrees Rankine for helium,

$\mathrm{S}=1.5 \mathrm{~T}_{\mathrm{b}}$ degrees Rankine for neon or argon,

$s_{12}=\sqrt{S_{i} S_{j}}$. called the geometric mean.

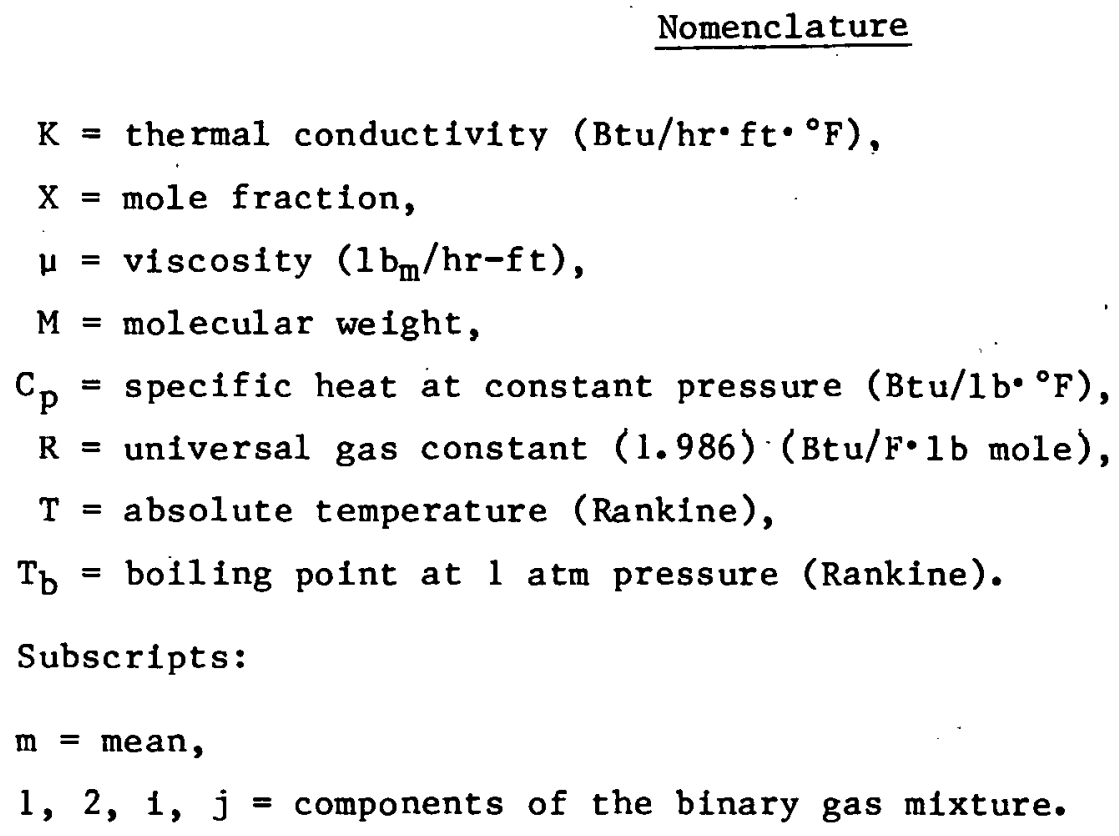




\section{REFERENCES}

1. E. J. Allen, CACA-2: Revised Version of CACA - A Heavy Isotope and Fission-Product Concentration Code for Experimental Irradiation Capsules, ORNL/TM-5266 (February 1976).

2. Melville Clark, Jr., and K. F. Hansen, Numerical Methods of Reactor Analysis, p. 93, Academic Press, New York, 1.964.

3. J. F. Mincey, Oak Ridge National Laboratory, personal communication to W. E. Thomas, February 1978.

4. W. D. Turner, D. C. Elrod, and I. I. Siman-Tov, HEATING5 - An IBM360 Heat Conduction Program, ORNL/CSD/TM-15 (October 1977).

5. H. T. Kerr, E. J. Allen, and D. L. Reed, Lattice Dispacement Calculations and Comparisons for Different Irradiation Facilities, ORNL/ TM-5269 (March 1976).

6. Frank Kreith, Principles of Heat Transfer, p. 72, International Textbook Company, Scranton, Pa., 1958.

7. W. L. McCabe and J. C. Smith, Unit Operations of Chemical Engineering, p. 521, McGraw Hill, New York, 1956.

8. H. C. Roland, GENGTC, A One-Dimensional CEIR Computer Program for Capsule Temperature Calculations in Cylindmical Geometry, ORNL/TM1942 (December 1967).

9. B. H. Montgomery, Oak Ridge National Laboratory, personal communication to W. E. Thomas, April 1978.

10. M. J. Kania, Oak Ridge National Laboratory, personal communication to W. E. Thomas, June 1978.

11. G. B. Engle and W. P. Eatherly, "Irradiation Behavior of High Temperature Graphite," High Pressure 4: 119-158, Fig. 6 (1972).

12. A. L. Pitner, "Irradiation Behavior of Poco Graphite," Carbon 9: 637-644 (1971).

13. R. L. Senn and W. R. Mixon, "Experimental Measurement of Gamma Heat in the High Flux Isotope Reactor," Nucl. Technol. 12 (October 1971).

14. R. D. Cheverton and T. M. Sims, HFIR Core Nuclear Design, ORNL-4621, p. 30 (July 1971).

15. P. R. Bevington, Data Reduction and Error Analysis for the Physical Sciences, McGraw-Hi11, New York, 1969. 
16. J. N. Franklin, Matrix Theory, Prentice-Hall, Englewood Cliffs, N.J., 1968.

17. C. D. Hodgmon, ed., CRC Standard Mathematical Tables, p. 392, Chemical Rubber Publishing Company, Cleveland, Ohio (1960).

18. A. L. Lindsay and L. A. Bromley, "Thermal Conductivity of Gas Mixtures," Ind. Eng. Chem. 42(8): 1508-1511 (August 1950). 
ORNL/TM-6892

Dist. Category UC-77

INTERNAL DISTRIBUTION

$\begin{aligned} \text { 1. } & \text { E. J. ALlen } \\ \text { 2. } & \text { A. J. Caputo } \\ 3 . & \text { B. R. Chilcoat } \\ \text { 4. } & \text { E. D. Clemmer } \\ \text { 5. } & \text { J. C. Cleveland } \\ 6 \text {-7. } & \text { J. A. Conlin } \\ 8 . & \text { D. A. Costanzo } \\ 9 . & \text { W. P. Eather1y } \\ \text { 10. } & \text { M. R. H1l1 } \\ 11 . & \text { F. J. Homan } \\ 12 . & \text { J. A. Horak } \\ 13 . & \text { M. J. Kania } \\ \text { 14-23. } & \text { P. R. Kasten } \\ 24 . & \text { H. T. Kerr } \\ 25 . & \text { W. J. Lackey } \\ 26 . & \text { T. B. Lindemer } \\ 27-28 . & \text { E. L. Long, Jr. } \\ 29 . & \text { J. E. Mack } \\ 30 . & \text { R. E. MacPherson } \\ 31 . & \text { W. R. McCauley } \\ 32 . & \text { J. F. Mincey } \\ 33 . & \text { B. H. Montgomery }\end{aligned}$

34. R. L. Pearson

35. H. Postma

36. J. L. Rich

37. J M Robbins

38. R. L. Senn

39. I. Splewak

40. D. P. Stinton

41. Jerry Swanks

42. V. J. Tenne ry

43-46. W. E. Thomas

47. K. R. Thoms

48. T. N. Tiegs

49. H. E. Tr amme11

50. D. B. Trauger

51. D. R. Vondy

52. C. A. Wallace

53. ORNL Patent Office

54-55. Central Research Library

56. Y-12 Document Reference Section

57-59. Laboratory Records Department

60. Laboratory Records (RC)

Subcontractor

61. J. W. Ketterer, General Atomic Company, P.0. Box 81608, San Diego, CA 92138

EXTERNAL DISTRIBUTION

62-63. Director, Nuclear Power Development Division, DOE, Washington, DC 20545

64-65. Director, Nuclear Research and Development Division, DOE, ORO

66. Office of Assistant Manager, Energy Research and Development, DOE, ORO

67-232. For distribution as shown in DOE/TIC -4500 under category UC -77 